\title{
DIVISION OF THE HUMANITIES AND SOCIAL SCIENCES
}

\section{CALIFORNIA INSTITUTE OF TECHNOLOGY}

PASADENA, CALIFORNIA 91125

IMPERFECT INFORMATION IN MARKETS FOR CONTRACT TERMS:

THE EXAMPLES OF WARRANTIES AND SECURITY INTERESTS

Alan Schwartz and Louis L. Wilde

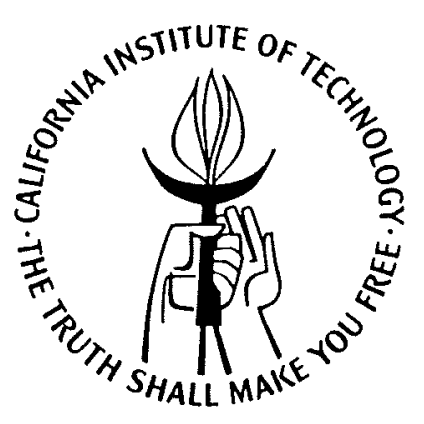


The existence of imperfect information is thought to provide firms with incentives to degrade contract quality by supplying terms that well-1nformed consumers would refuse. We show, in contrast, that these incentives are weaker than is commonly supposed; rather, when consumers gather relatively iittle information, the profit maximizing strategy for finms is 1ikely to involve offering the contract terms that consumers prefer, but at supracompetitive prices. In consequence, prefer, but at supracompetitive prices. In consequence,
standard state response to 1mperfect information problems regulating the substantive terms of transactions, is of te misplaced. When imperfect information exists, the state instead should reduce the costs to consumers of comparison shopping for contract terms, because such shopping reduces prices and also reduces further the incentive of firms to degrade contract quality. 
IMALIRYECT INFORUATION IN MAPRETS FOR CONTRACT TBRMS: THE EXNPLES OF WARRANTIBS AND SECURITY INTERESTS Alen Sohwertz* and Lonis L. Wildo**

Inperfect information is commonly assued to exiat whon consumers cannot choose contract terns that corroctly refloct their preferences because consumers are uninformed about the riaks that these terms allocate. Pirms aro said to exploit this lgnorance by degrediag contract quality. For example, if consuners bolieve products to be more reliable then they ere in faot, consunere will too readily accept discleimers, which shift the risk of prodnot defocts to them; and firms will respond by using discleinors frequently. This conventionel focus is misloediggly aerrow. Coneunors aleo ere disedvanteged whon they are uneware of the erray of prices and toras that the firms in arket cen offor. Conouers who lack this information aney accept poor deals because thoy do not know that botter ones exist: and fins will heve 1 ittle incentive to offer botter deale becauas theso will not be taken.

The notion thet imperfect information existe whon coneners cannot choose correctly and the nore novel notion that laperfoct information exists when consuners are ignorent of merkot opportunity sets both imply that firms wll rospond inadequately to consumer preferences. A focus on the latter fora of imperfect information, hovever, yields insights that differ strikingly froe those than can bo 
derived from the notion of Inperfoct informetion es incorroct cholce. Thle Flow Implice two fores of regulation: (1) Firms should be aedo to explein tranections to coneunors, so coneunors can choose corroctly. or (11) Plope choald be probiblted froe degreding contrect quelity by uedes exob teras a diseloleors. By fooneting on the notion of Inporfoot Infornation os lenorance of aerket opportanity sots we Identify an additlonal problon. Suppose, is an exeoplo, that the conoumers of a pertlonler product ere woll laformed about dofoct rleke and profor a werranty to a diecleleor, but these conewners laok Inforetion ebout the renge of prloes and worrenty teres thet the nerkot offore. Wo shor thet fine in thls olrounstence ere wuch noro likely to enpply werrantlos at enpreoonpetitive priese then rofuse to provide then eltogether. Hoxce, oven whon conswers are exficlontly Informod ebout rlake to oboose contract torme corroctly, en Infornation problea aey exlet: firee could be cherglng enpreconpotitive prioes for torne in roeponse to coneuner lenorence of merket poselbllitios. Couventlonal logel enelyale oopplotely overlooke thie probles.

We ersue boro, bowever, not thet suprecompotitive priolng ls en overlooked information problon in "aerkots for contract torns," but that often it la the only problen sufficlently sorlous to juatify rogulatory concorn. This lo because tho incorroct cholce problod exlsos only in e linitod aet of cssos. If consumer mistakes rospocting the rleke that contrect terne ellocsto fluctuste rendowly eround true values in en unblesed wey, fires will sct es lf consumers medo corroct cholcos. If oonsonors are "poselelstio," eystoneticelly oversteting the edverse consequences of parohese doolelone, firme in meny cssos egein will ect os if conemer cholose wore corroct. Also,

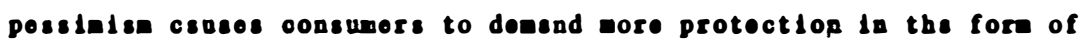
fevorable contract terwe then their botter laforeod eolves wonld choose, and auch overprotectlon hes not been thought to raleo serlous

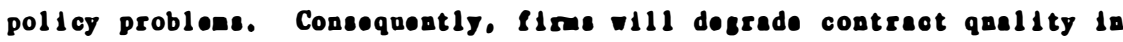
undealrable waye only if conewers eyetenotically anderotate the edverse consequences of parchese docledone. Conowners aey be "optlaletio" In thle way if thoy leok date ebont rleke or if they

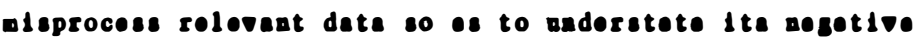
lapllostlons. In nost cosee, nolther poselbility le likely. Conemers bave Inoontives to becone Inforned abont laportent riske.

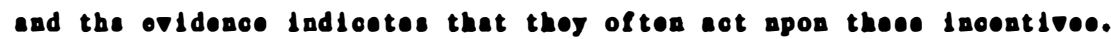
Also, en enelyels of the pejoholostoel literatere doeling itth cognitive orror susesets thet oonomors in tho eseresete soldos aleprocose prodnot rolated date ench that thoy eot optinlatioally. An excoption to these concluedors is conetituted by trouseotlone in

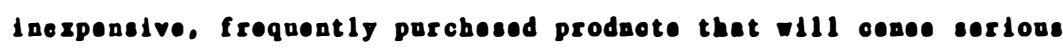
personel here a vory low percoutege of the tine, of whlob the paradige oxsople te the purchese of code in a bottle that later oxplodes. Wo show that the cosemers in these tronections aro velikely to ceerob for Inforation ebout the low rlak of harn, and any reepond optindetically to whetover inforetion about thle rlek como their wsy. 
The notion of imperfoct information as ignorance of market opportunity sets thus implios s regulatory scheme that differs sisnificantly fron the ones now in place. Decisionarers should "inprove" contract quality by banning contract terms much loss frequently then they now do. Instead, decisionnakers should attempt to identify and provont supracompetitivo pricing for those contract torns that are now in froquent use. Decause comparison shopping roduces prices, this lattor coal should bo implemented both by providing oonsuoers with oxplanations of transections and by lowering the costs to consuoves of eomperine the prices and terms that firms off or.

Part I briofly sumarizes curront regulatory responsos to the oxistence of Imperfoct information as it is thought to affoct contract torms. Part II aots out our model of arket for warranties: Part III thon sets out accurity interest model. Warranty and socurity interost clausos allocato significant risks between consumers and firas in very difforent ways. Henco, conclusions drawn from an snelysis of these clauses should genoralize prime fecie to other rist allocation toras in oonsumor contracts. Parts II and III for convenience Introduce the policy implications that the models generate only as they concern warranties and security intorests. Part IV next asks to what extent these implications aro impeached when cortain of the key assumptions underlying the formal models arc relaxed. As an example, our model of arranty warket supposos consumers to know product fallure probabilities perfectly. In Part IV, we drop this assumption to consider the consumer optinism question just described. Part $V$ then considers and rejects additional conceptions of tho possible offects of imperfoct information and sets out several recommendations for incrosing comparison shopping for contract terms. Before roaching the argument, two preliminery remerks should be made about it. First, wo assume that the state should be satisfied with the existence of competitive outcones in markets for contract terms. This premiso follows naturally from a concorn with imperfoct information. The existonce of Imporfoct Information 1s a species of market imperfoction that onablos firms to charso supracompetitive prices or imposo unwantod torns on consunors. The many rogulatory responses designed to provide consumers with information or amollorato the effocts of its absonce 1 thus must assuoe that oompetitive outcomes are desirable. This assunption also is justiflablo bocauso whon a warket 1 s in competitive equilibrion, firms are providing goods and contract toras at the lowest possible cost consistent with the continued existence of these firms. Thus, supposing a given distribution of wealth, consuners cannot do botter than purohase in competitive markets. ${ }^{2}$

Second, the economic and peycholosical theory relovant to contract performance under conditions of mecrtainty is rolativoly primitives ours, for example, are the only formal models of markets for contract teres that suppose it to bo costly for consuoers to acquire information about the offerings of different firms. Hence. our policy conclusions should be taken more es serious sugsestions 
then as hard recommendetions. Policy suggestions grounded in theory, however, seem an advance over the atheoretical intuitions that now influence regulation in this area.

\section{Regulation of Contract Torms}

States respond to information imperfections that are thought to affect contract terms by requiring disclosure or by baning disfavored clauses. Disclosure regulation typically is more concerned with explaining the individual transection to the consumer than with facilitating the consumer's ability to compare contract terms across firms. As examples, Regulation 226.b(a) to the Truth in Lending Law requires consumer credit disclosures to "be made clearly,

conspicuously, [and] in meaningful sequence": regulations $226.7(c)(1)-(3)$ require disclosure of the "conditions under which a finence charge may be imposed, including an explanation of the time period, if any, within which eny credit extended may be paid without incurring a finence cherge...", the "method of determining the balance upon which a finence charge may be imposed," and the "method of determining the amount of the finance charge..." ; and section 701.2 of the regulations implementing the Magnusson-Moss Warranty Act requires firms to provide a "step-by-step explanation of the procedure which the consumer should follow in order to obtain performance of any warranty obligation..." Such regulation inplicitly assumes that each consumer visits only one firm to make his first and last transaction of the type at issue.
Hegulation of the substantive terms of transactions is also common. Six states ban warranty disclaimers in all sales of consumer goods, ${ }^{3}$ and section 108 of the Magnusson-Moss Act bens such disclaimers whenever a firm makes a written express warranty respecting the product, "which is oftendone in sales of consumer durables. A1so, almost all states heve adopted the strict liability in tort doctrine, so that firas must warrant against defects that cause personal injury or property damage. In addition, when firws promise to repair or replace defective parts of consumer products, courts commonly require them to repair such products in relatively short order or to replace them; the promise to attenpt to repair parts is converted into a warranty to supply a well functioning whole. 5 States are beginning to adopt this rule by statute. 6 The presuned existence of imperfect information is often given as astification for all of this regulation. In addition, most findings of unconscionability depend crucially on the epparent presence of uninformed consumers. ${ }^{7}$ As a last example, the Uniform Consumer Credit Code prevents sellers from taking security interests in consumer goods, 8 other then purchase money security interests, and several states have adopted the Code or passed 1 ars similar to it. 9 Extensions of these laws or new ones in the same vein are frequently proposed. The regulation just summerized secningly assumes that comparison shopping will seldom improve consumer welfare for much of it makes little effort to increase the amount of comparison shopping that occurs; and this regulation also assumes that what a consumer 
learns in one transaction will not be applied in others like it. ${ }^{10}$ Statutes and legal doctrines that ban contract terms suppose that firms typically exploit the existence of imperfect information by of foring terms that consumers would reject were they properly informed. This paper argues that all of these assumptions are wrong or problematic.

\section{Warranty Markets}

\section{A. Convent lonal Viows}

The imperfoct information concept has tro aspects: (i) consumers may lack information about the risks that particular terms allocate: (ii) consumers may lack information about the prices and terms that different firms offer. Conventional explanations of the positive and normative foatures of warrantios suppose that imperfoct information in its socond aspect is absent; consumers are assumed to know the market opportunity set perfectly. These explanations differ in their troatment of the first aspect of imperfect information. "Signalling" explanations suppose consumers to be poorly informed about product quality though perfectly informed about prices and terms. "Comparative advantage" explanations suppose that neither aspect of imperfect information exists, but sometimes consider how their conclusions would be affected were consumers uninformed about the risk of product defects. The authors of these explanations, however, soldom specify in detail the relationship between the models' assumptions and the models' results; and this failing obscures the crucial contribution to these results that is made by assuning consumers to be perfoctly informed about prices and terms. We shall begin, then, by making explicit the role that is played in the conventional explanations by the assumptions the models make about firms and consumers, as a usoful prelude to our analysis of the effoct on warranty coverage of the fact that consumers never know all elements of the market opportunity set perfoctly.

\section{(1) Slgnalling Explanetions}

Signaling explanations assort that a waranty signals the quality of a firm's product. ${ }^{11}$ Such oxplanations suppose that: (i) Imperfect information in the first sense exists, in that consumers cannot distinguish among competing products on the basis of their likelihood of failure; (ii) Consumers believe that product quality corrolates positively with the extent and duration of warranty coverage: (iii) The cost to firms of making warranties varies inversely with procluct quality; the more likely a product is to fail, the more expensive it will be to comply with warrantios made respecting it: (iv) If firms do not communicate their quality levels to consumers, the consumers will suppose that oach firm sel1s a product of "average quality." Consumers also will assume that the average is relatively low: should consumers suppose average quality to be high, firms would oxploit this ignorance by offering low quality products at high quality prices. In consequence of these four assumptions, warranty coverage should correlate positively with product quality. Firms with products whose quality is above the low average that consumers perceive have an incentive to communicato this 
fact. According to assumption (ii), they can successfully communicate their quality by making "strong" warranties. Assumption (iii) then implies that firms with poor products will be unable to imitate these warranty "signals"; such firms incur relatively greater expense in making strong warranties than do firms with good products because the former sell products that fail more frequently. Hence, supposing product quality often to be heterogeneous, a variety of warranties should exist, each of thon signalling the quality of the product it accompanies.

Signalling explanations necessarily suppose consumers to have considerable knowledge about prices and contract terms, since firms have no incentive to send signals that will not be observed. Consequently, signalling models conmonly add an assunption (v), that consumers can costlossly observe the prices and terms of every firm in tho market. We sometimes refer to this as "the zero search cost assumption." This assumption is always false in fact, and its falsity seens at loast partly responsible for the major difficulty with signalling explanations, their inconsistency with the data. Three countereramples should suffice. Pirst, signalling theory predicts that firms with more durable products will make warranties that ertend over longer time periods. In contrast, actual warranties in given markets generally are made effective for identical time periods, which also are considerably shorter than the useful life of the products they accompany. ${ }^{12}$ Second, signalling theory implies that warranties will not be made in commercial markets or will take a different form there than in consumor markets. This is because firms are said to wake warranties to inform otherwise ignorant consumer buyers about product quality, while many commercial buyers supposedly are well informed about product quality. Warranties in commercial markets, however, seem as common as those in consumer markets, and take quite similar forms. ${ }^{13}$ Third, a strong positive correlation between warranty coverage and product reliability often seems difficult to detect. For example, frequency of repair data, such as that reported in Consumer Reports, sometimes show wide variations among firms, but the products themselves trade under similar or identical warranties.

Signalling explanations, in summary, fail to account for important phenomena, and for those and othor roasons ${ }^{14}$ are not useful for policy purposes. Part of the difficulty stems fron thoir use of the zero search cost assumption. Analysis of signalling explanations thus suggests that 1 ight may be shed on warranty issues by abandoning it.

(2) Compacative Advantago Explanations

This second set of explanations accounts for warranty coverago by reference to the comparative advantagos of firms and consumers in reducing the costs of or insuring against product defects. ${ }^{15}$ To see how such explanations work, suppose that (i) Pirns can reduce tho frequency of defects in refrigerator motors more cheaply than consumers can because firms have more expertise respecting motors, can take advantage of economies of scale in purchasing repair tools and so forth; (ii) Consumers can ensure the durability of refrigerator doors 
and shelves more cheaply than firms can because the most efficient way to achieve durability for these items is through careful use; (iii) Consumers are perfectly informed respecting the risk that defects will occur and are aware of the steps necessary to reduce this risk: (iv) Consumers minimize net purchase costs; (v) Firms maximize profits; (vi) Search costs are zero--consumers can costlessly observe every price and contract term that all firms in the market do or could offer.

Under these assumptions, firms will offer an optimal refrigerator warranty contract. Assumptions (i) and (ii) imply that a contract exists that minimizes consumer costs associated with defects in refrigerators. Under this contract, firms would assume the risk of defects in motors--1.e. warrant against them--but shift the risk of defects in doors and shelves to consumers--i.e. disclaim this risk. Assumption (iii) implies that consumers rould recognize the cost minimizing contract, and assumption (iv) ensures that consumers would purchase it were it available. Finally, assumptions (v) and (vi) imply that cost minimizing contracts will be offered. Since by assumption (vi) consumers can costlessly search for the cost minimizing contract, each firm knows that by offering it, the firm can take sales from rivals who offer different contracts. And by assumption (v), that firms are profit maximizers, firms would then offer this contract. Comparative advantage explanations thus predict that optinal warranties will emerge through the informed decisions of consumers and firms.
Comparative advantage explanations of warranty content seem plausible because consumers and firms do have differing abilities to reduce or insure against product related risks, and because consumers and firms often act as if they want to maximize profits or minimize costs. Also, these explanations account for some of what is actually observed. For example, Commercial Law does not require firms to repair or replace defective parts of consumer products; rather, it gives consumers a cause of action for the damages such defects could cause. ${ }^{16}$ Nevertheless, firms often warrant against defects in materials and workmanship. The comparative advantage theory predicts this result, for repairs of new products by firms often are less costly than repairs by consumers plus damage suits.

Comparative advantage explanations, however, have significant difficulties that also are traceable to the informational assumptions they make. These difficulties are perhaps best revealed by an analysis of the most recent serious comparative advantage explanation, that of Professor George Priest. ${ }^{17}$ Professor Priest's theory rests on the six assumptions just set out and one more, (vii), that consumers have heterogeneous preferences for warranty coverage: some consumers want broader coverage than others do. These soven assumptions imply that actual warranty coverage should be homogeneous in the ways in which consumers can be expected to be homogeneous. For example, all consumers would want coverage against defects in refrigerator motors, so all firms will offer basic coverage against such defects. The assumptions also imply that coverage should be heterogeneous in the 
ways consumers can be expected to be heterogeneous; some consumers, those with largo families for example, might want stronger than usual warranty coverage, so at least some firms should of er relatively extensive marranties. Priest then examined actual warranties and found that they "tended to confirm" his thesis, though "further research . . Is required before a confident conclusion can be reached." 18 In brief, he observed patterns of homo- and heterogeniety in warranty coverage that seened consistent with his theory, but in some cases the sample sizes were small and occasional counterexamples oxisted.

Professor Priest concluded that the coverage he observed probably was optimal. The consumers in his model were assumed to be perfectly informed about the risks of product defects and the best methods of avoiding them, and to want to minimize net purchase costs. Hence, they could recognize and would demand optimal warranty contracts. And because Priest also assumed search costs to be zero, be concluded that firms nopld offer optimal contracts. ${ }^{19}$ These contracts wero as described--homogeneous in some respects but heterogeneous in others. A focus on the contribution of the zero search cost assumption to these results suggests that they require qualification.

Initially. Professor Priest has not shown that the contracts he observed reflected correct consumer choices. Suppose that consumers are imperfectly informed respecting the risk of product defects. Such consumers nevertheless could have heterogeneous preferences for warranties; some may mistakenly think they need broad warranties while others mistakenly could think they need narrow ones. Ry assumptions (v) and (vi) above (firms maximize profits and search costs are zero), firms still will of fer the warranties that consumers want. These warranties, however, will be inefficient. Hence, Professor Priest's observation of hotorogenous warranty coverage cannot establish his claim that consumer warranties probably reflect "manufacturer and consumer investments to getimize product services." To sustain this claim, the assumption that consumers can accurately value risks must be independently justified or shown to be irrelevant to efficiency analysis.

Professor Priest also cannot sustain his claim that the warranties he observed correctly reflected the preferences that consumers actually held. To see why, suppose that assunptions (vi) and (vii) above are relared; consumers now no longer face zero search costs but have homogenoous preforonces-all want the same warranty coverage. Let assumptions $(1)-(v)$ be as above. In these circumstances, the search theoretic economic literature suggests that firms may still offer diverse warranty terms. Analysts working in this literature commonly suppose all firms to sell a homogeneous product under a sales contract that has only one term, the price. Consumers consequently must have homogeneous preferences respecting this term; they want it to be as low as possible, which occurs when firms charge competitive prices. Thus, all consumers want to purchase at the competitive price. A. standard result in this 1iterature, 
however, is that price diversity can exist when it is costly for consumers to inform themselves of the prices that different firms charge, even though all consumers prefer the same price. ${ }^{20}$ Inferring that consumers prefer different prices because different prices are observed rould plainly be a mistake; the heterogeniety in prices can only be the result of positive search costs.

Part II $B$, infre, next extends this standard result to the case of warranties, to show that when search costs are positive and all consumers prefer the same warranty, some firms nevertheless may not offer it; heterogeneous warranty coverage can exist in the face of homogeneous consumer preferences. Therefore, the diversity in warranty coverage that Professor Priest believed tended to confirm his theory could have been the result of heterogeneous consumer preferences, as he supposed, or the result of positive search costs-i.e. of imperfect information in its second aspect. If it was the latter, his conclusion that waranty coverage accurately reflected consumer preferences is incorrect. To exclude this possibility, one must analyze how warranty markets behave when the consumers in them face positive search costs. Neither Professor Priest nor any other comparative advantage theorist has made such an analysis.

To sumarize, comparative advantage explanations of warranties correctly identify important determinants of warranty coverage but are too partial. They suppose search costs to be zero, but this assumption at best implies that markets will satisfy consumer choices, whether based on correct or false assessinents of risl., Also, search costs are never zero, and much economic analysis suggests that in this event markets of ten can be relatively unresponsive to consumer preferences. It is essential, then, to explore the comparative advantage idea in a world of positive search costs.

\section{B. A Model of a Harranty Market}

(1) A Simple Search Equilibrium Model

To understand tho logic that underlies our analysis of warranty markets, it is helpful to begin with a relatively simple search equilibrium model. The word "search" refers to the process by which consumers become informed about the products, prices and terms that firms offer. The object of this class of models is to describe the outcomes--"equilibria"--that markets reach when consumers pursue specified "search strategies" (1.e. become informed in particular ways), and firms pursue specified profit maximizing strategies. ${ }^{21}$ An understanding of those models is essential to anyone concerned with the effect that imperfect information has on markot performance.

We initially developed a search equilibrium model 22 that supposed: (i) a large number of firms existed; (ii) these firms sold the same product--a "homogeneous" good-all of whose features were observable before purchase; consumers thus could not be uncertain about product quality; (iii) firms did not advertise, but instead communicated information to consumers when consumers visited them; (iv) a large number of consumers existed, each of whom would purchase no more than one unit of the product; (v) all consumers had a common "limit" price, which meant that every consumer would buy if he or she 
observed a price which equalled or was less than this common limit, while no one would buy at prices above the 1imit; (vi) consumers became informed about prices by using a "fixed sample size" strategy. Fach consumer, before entering the market, decided how many firms to visit, and would then visit all firms in the sample before purchasing: a purchase was then made at the lowest price observed, if that price was no greater than the 1 imit price; (vii) consumers fell into two categories respecting this fixed sample size strategy; some of them had sample sizes of one--they would visit only one firm--while others had sample sizes greater than one.

Such models raise three questions: First, what results does the model yield? Second, are the model's assumptions sufficiently plausible or its predictions sufficiently confirmed for these results to be taken seriously? Third, if the results do deserve serious consideration, what are their implications?

A principal result of this model is that the only possible equilibrium in which all firms charge the same price occurs when that price is competitive. To see why, first suppose that all firms in the market charge the same price, " $p_{0}$ ", which is less than the common 1 imit price, "p $\mathrm{p}$ ", but greater than the competitive price, "p" (i.e. $p^{*}\left(p_{0}<p_{L}\right)$. Then let one firm lower its price below $p_{0}$ by a very small amount. This firm would sell to all "nonshoppers"--consumers who only visit one firm--who visit it; the price cutter would also sel1 to all "shoppers"--consumers who visit it and other lifras-because its price would be the lowest one the shoppers observe. Thus, price cutting would be a profitable strategy for the firm, if all other firms continued to charge the old price, $p_{0}$. But these firms also have the same incentive to cut their prices. Consequently, an outcome in which all firms charged $p_{0}$ vould be unstable, since at least some firms rould undercut it; $p_{0}$ is not an equilibrium price. The competitive price, $p^{*}$, could be an equilibrium price because no firm would undercut it. This is because the competitive price by definition always equals each firm's minimum average cost, which means that the revenue from a sale just equals the lowest cost necessary to generate that sale. Since price cuts belor this point must produce losses, firms have no incentive to reduce prices below the competitive level.

Suppose next that a 11 firms are charging the competitive price, $p^{*}$. One firm then considers raising its price. If it does so, it would continue to sell to nonshoppers who visit it, provided that its new price does not exceed the 1 imit price, $p_{L}$. This firm would not sell to shoppers, however, because its new price would be higher than the other prices that the shoppers see. Since the firm would lose all of the shoppers' business at any price above p and retain a11 of the nonshoppers' business at any price equal to or below $P_{L^{\prime}}$ this firm would charge $p_{L}$. Whether the strategy of raising price to the 1 imit would be profitable necessarily depends on whether the gains made from charging $p_{L}$ to nonshoppers would exced the losses created by no longer being able to sell to the shoppers. If eoough shoppers cxisted, raising prices would be a losing strategy. Therefore, the 
competitive price would be the equilibrium price in a particular market if enough comparison shopping took place.

If too fer comparison shoppers existed to sustain a competitive equilibrium, many firms might still charge the competitive price. Other firms, however, would find it profitable to sell to a mix of shoppers and nonshoppers at supracompetitive prices. Thus, although the product is homogeneous and consumer preferences are homogeneous--all want to buy at the lowest price,--price dispersion would exist. Finally, if very fer consumers comparison shop, raising price above the competitive level could be profitable strategy for all firms: every price in equilibrium roulc exceed $p^{*}$, and for sufficiently fer shoppers prices would converge toward $p_{L}$. We sometimes refer to $P_{L}$ as the monopoly price because it is the pricc that monopolist would charge if it operated in the relevant market. given our assumptions about consumer demand.

We have discussed the assumptions that generate these results elsewhere. 23 and so will say only a fer words about them here. It is plausible to assume that consumers use a fired sample size shopping strategy for three reasons. First, fixed costs to search sometimes exist--the main shopping expense could be getting to the shopping district--and a fired sample size strategy vinimizes these fired costs by spreading them over visits to several stores. Second, search sometimes is a consumption activity; consumers who enjoy shopping thus may create and plan to exhaust a sample of several stores before they begin to search. Third, when consumers have little price information, their strategy choice is either to set samples or let the amount of search they engage in be a function of the prices they see. As examples of the latter sort of strategy, a consumer who visited tro stores and saw the same price at both might stop searching because he or she assumed that finding a significantly lower price rould be unlikely; this consumer could infer from observing identical prices that little price variability existed. In contrast, a consumer who saw two different prices might search great deal, believing significant price dispersion to exist. A strategy such as this makes the number of stores visited be partly a function of the prices one sees. Experimental evidence shows that this strategy is subject to misspecification, in the sense that consumers using it who are ignorant of the actual price distribution in the market may shop much less or much more than the variability in that distribution warrants. A. fixed sample size strategy, in contrast, is less subject to such nisspecification, and is thus a sensibly conservative strategy for consumers to adopt. Respecting other of the model's important assumptions, one of us has shown elserhere that the model's qualitative results are unchanged if consumers may purchase more than one uniti ${ }^{24}$ and these results will also obtain if each consumer is allowed to have an Individual 1 imit price. 25

This simple search model predicts that price diversity will sometimes be observed in actual markets, and it is. Also, tho model predicts that market prices may be lowered if consumers can be induced to engage in more comparison shopping. Evidence dramn from actual 
markets is consistent with this prediction. ${ }^{26}$ llence, the model's assumptions and predictions seem sufficiently plausible to warrant concern with its implications. What are they?

Initially, the model shows that information about market choices need not be perfect. A market can be in competitive equilibrium even though the ratio of comparison shoppers in it to total shoppers is considerably less than one. Such competitive equilibria are best achieved by increasing the amount of comparison shopping that takes place, for the model al so shows that greater comparison shopping correlates positively with lower prices. These implications are drawn from a model in which firms soll a homogeneous product, but we have elsewlere shown that they also hold when firms are allowed to vary product quality. ${ }^{27}$ The question we next take up. then, is the extent to which the lessons drawn from this relatively simple model must be modified when firms are allowed to vary contract qua1ity.

\section{(2) $\triangle$ Warranty Mode1 28}

This nodel retains the assumptions about firms and consuners made above and also supposes that a homogeneous good is sold. It necessarily adds several assumptions which it will be useful to discuss in detail. These are: (i) Consumers do not know, when they begin to shop, which firms sell with warranties and which do not. llence, the nonshoppers sample one firu at random from among all firms before purchasing, while the shoppers sample more than onc firm at randor from among all firms. This assumption is n:ade to capture the notion that consumers are imperfectly informed respecting the prices and terms that markets offer. We denote the ratio of nonshoppers to total consumers in the market by "a 1 " and the ratio of shoppers to total consumers by " $a_{2}$ "; $a_{1}+a_{2}=1 ;$ (ii) Consumers a1 so are differentiated according to their desire for warranties. A consumer prefers a warranty, in this model, if a consumer who sees the product of fered with a warranty at the competitive price and offered without a warranty at the competitive price would then purchase the product with the warranty. A consumer therefore is said not to prefer a warranty if he would be unwilling to pay the lowest possible premium that firms must charge to provide warranty protection. (iii) This model retains the assumption that consumers have common 1 imit prices, but modifies it because a consumer now has the additional choice of buying with or without a warranty. We let " $\mathrm{h}$ " be the 1 imit price, or "willingness to pay," for the product with a warranty and "h" be the 1 imit price for the product without a warranty. Here, hal al was is greater than $h_{N}$ because a warranty is a desirable product featuro; thus, it would be irrational of a consumer to be willing to pay more for the product Without a warranty than with one, even if the consumer prefors not to have warranties. This notation also allows us to capture more precisely the notion of a preference for warranties. The term $h_{W}-h_{N}$ can be regarded as a consumer's marginal willingness to pay for warranty protection. Then, a consumer prefers a warranty when $h_{W}-h_{W}>p_{W^{*}}^{*}-p_{N^{*}}^{*}$, where $p_{W}^{*}$ is the competitive price for the product with a warranty and $p_{M}^{*}$ is the competitive price for the product 
Without arranty. Assumptions (ii) and (iii) further imply that a consumer who prefers a warranty in the sense just defined would purchase without a warranty if (a) he or she only saw the product offered without warranties, and (b) the price equalled or was less than the limit price, $h_{N}$. Similarly, a consumer who prefers to buy without a waranty will buy the product with a warranty if $(0)$ he or she saw only warranties, and (d) the price equalled or was less than $b_{W}$. These 1 imit prices incorporate all relovant information respecting consumer proferences. For exaple, other things equal, the spread botween $h_{W}$ and $h_{N}$ will be greater if consumers strongly prefer warrantios. (iv) Consumers now purchase one unit of a product that has a positive probability, " $\pi$," of breaking and becoming useless; $\pi$ is independent of the care with which the product is used, and is known to firms and consumers. Thus, al though the relovant product can fail, once more no uncertainty about product quality exists. In the terminology used here, imperfect information in the first sense, dealing with the possible consequences of purchase, is absent.

Respecting the firms in the model, we add: (v) Firms produce the product with a fired cost, "F," and a constant marginal cost over some range, "c." This marginal cost is incurred whether a warranty is made or not. Firms can sell with a warranty or without, but cannot do both. (vi) A warranty in this model consists of a promise, that is alnays redeemed, to replace any defective product with a now one at no charge. ${ }^{29}$ (vii) offoring the product with a warranty does not directly affect each firm's vareinal cost, but nay require additional fixed costs, "F"." These additional fired costs may arise from administrative or other expenses that a replacement program could cause. (viii) Marginal cost nevertheless is increased when a waranty is made. A firm that sells with a waranty must plan for the replacement of defective products, and the replacements also could be defective. Hence, the firm must produce more than one unit to "support" a sale of one unit; the total amount that must be produced per sale is $1 /(1-\pi)$ where $\pi$ is the failure probability. Then, with a constant marginal cost, c, the firm's total variable cost if it makes a warranty and sells $x$ units is cx/(1-n). Its marginal cost, called "c cu", is this total variable cost divided by total of fective output, or $c /(1-\pi)$, which is greater than c since $\pi$ is positive but 108 s than one. Finally, let "s" be the firm"s output in competitive equilibrium when it sel1s without warrantios. Then, a firm that solls with warranties has a total output in competitive equilibrium of "s". where $s_{W}=(1-\pi) s$. The output $s_{W}$ is less than s because the firm nust provide for replacements.

ve next consider the model's results in tro paradigm cases. In the first, all consumers prefer warranties. This caso is considered because decisionmakers and commentators commonly suppose that consumers want more warranty protection than markets provide. Thus, it is useful to ask what is likely to happen when overy consumer in a murket wants a warranty but firms are permitted to disclaim. The second paradigm caso considered is when no consumer prefors a warranty. The rationale for analyzing this case is set out below. 


\section{(a) At1 Consumers Prefer Warranties}

Three mutually exclusive outcomes can occur in this case, of which the most desirable is that afl firms offer the product with a warranty at the competitive price. Whether this outcome obtains is once more a function of the amount of comparison shopping in which consumers engage. The logic that underlies this result is similar to that described above. Let all firms in the market sell with warranties at a price $p_{0}>p_{W^{*}}^{*}$, where $p_{W}^{*}$ is the competitive price. Then every firm has an incentive to cut its price by a small amount because it would continue to sell to nonshoppers and capture all of the shoppers who visit it. The price cutting strategy is not profitable at prices below the competitive price $p_{W}^{*}$; hence, a single price equilibrium can occur only if all firms charge this price. If all firms sell with warranties at $p_{W}^{*}$, a firm that wants to deviate in the price dimension will charge the limit price $h_{W}$ because it sells only to nonshoppers. This would be an unprofitable strategy--í. firm would have no incentive to deviate--if enough shoppers existed, for then the increased revenue gained from the nonshoppers would be more than of set by the losses resulting from the disappearance of the shoppers. A firm also could deviate from a competitive equilibrium, in which all firms sold with warranties at $\mathrm{p}_{W^{\prime}}^{*}$ by offering the product without a varranty. This firm too would sell only to ronshoppers, for every consumer in the market prefers a warranty by assumption and each shopper would see at least one other firm selling with a warranty at $\mathrm{P}_{\mathrm{W}}^{*}$. Hence, a deviant firm not only would disclaim but also would raise its price to $h N$, the most consumers would pay when not getting a warranty. Again, if enough shoppers existed, disclaiming warranties while charging monopoly prices would be an unprofitable strategy. In summary, then, when all consumers prefer warranties and enough consumers comparison shop, the market will provide warranties at competitive prices.

Suppose that too fen comparison shoppers exist to sustain a competitive equilibrium. The remaining possibilities are: Second, ell firms sell with warranties although some or all of them charge prices that are supracompetitive; the market porer that insuffioient consumer search creates is manifested in the prioe but not the oontract quality dimension. Third, some (possibly all) firms sell vithout warranties and charge supracompetitive prices. This outcome is plainly the least desirable. To see whether it or the second possibility will occur, we must introduce a particular concept of comparative advantage.

We define a comparative advantage with respect to firms by reference to the number of customers that a firm would need to break even when it charged the 1 imit price--the highest price consumers would be willing to pay. If a firm, as a result of its cost structure and consumer preferences, would need fewer customers to break even when selling at the 1 imit price with a warranty, we then say that the firm has a comparative advantage at selling with warranties. Similarly, if a firm would need fewer customers to break even when selling at the limit price without a warranty, the firm is said to have a comparative advantage at selling without warranties. 
To understand why this concept of comparative advantage is relevant, suppose that all firms in the market offered the product with warranty at $p_{w}^{*}$ and one firm considered deviating. In this illustration, too fer shoppers exist to make any deviation from the competitive case unprofitable. Because the deviant firm would sell only to nonahoppers, it mould charge the 1 imit price, but it now has the option of making a warranty and charging $h_{W}$ or disclaiming warranties and charging $h_{N}$. If the firm rould noed fever customers to break even when seling at hw, it would then offer a warranty. This strategy yields higher profits because the firm reaches its breakeven point with ferer sales. On the other hand, if the firm would need ferer customers to break even when selling at $h_{N}$, the firm would disclaim warrantica. When firms have a comparative advantage at selling without waranties--this third case--warranties could disappear altogether if very fer consumers shopped, though every consumer preferred one. Should there be a fair number of shoppers, horever, too fer nonshoppers would exist to support every firm that wished to disclaim warranties and charge monopoly prices. Thus, some warranties will be seen and some firms that disclaim will charge less than $h_{N}$.

To summarize, when firms have a comparative advuntage at seling with warranties, but not enough consumers shop to sustain a competitive equilibrium, disclaimers are not seen, but supracospetitive prices exist. When the comparative advantage runs the other way, some firms will degrade contract content but probably not all; again, supracompetitive pricing will occur for products with and without warranties.

When do firms have a comparative advantage at selling with warranties? This advantage obtains when (1) the making of a warranty adds little to a firm's fired cost ( $F^{\prime}=0$ or is smal1), and (2) consumers strongly prefer warranties. Respecting the rationale for these conditions, if consumers strongly prefer warranties, the highest price they would be willing to pay for the good with a warranty should significantly exceed the highest price they rould be willing to pay for the good without a waranty; hence, a firm offering the good at its highest price would need ferer cuatomers to break even when selling with warranties than when selling without them, unless fired costs are considerably higher with a waranty. Condition (1) rules this possibility out. This model therefore yields the seemingly sensible result that warranties will be more common when they cost relatively little to make and are strongly preferred, even in environents characterized by considerable imperfect information. The three possible outcomes just discussed can be characterized mathematically. In addition to the notation used above, let " $a$ " be the comparative advantage of selling with warranties, and "ap" be the comparative acivantage of selling without warranties. Then

$$
a_{W}=\left(F+F^{\prime}\right) /\left(h_{W}-c_{W}\right)
$$

and

$$
a_{N}=F /\left(h_{N}-c\right) .
$$


Given these definitions,

(1) The necessary and sufficient condition for all firms to sell with warranties at competitive prices is

$$
a_{1}{ }_{W} S \text { minimum }\left(a_{W} \cdot a_{N}\right) \text {. }
$$

(2) The necessary and afficient condition for all firms to sell with warranties, but with some or all firms charging supracompetitive prices, is

$a_{W} S$ minimum $\left(a_{1} s_{w} \cdot a_{N}\right)$.

(3) The necessary and afficient condition for some (possibly

11) firms to sel1 without warranties and at supracompetitive prices is

$a_{N} S$ minimum( $\left.a_{W} \cdot a_{1} s_{W}\right)$. Warranties will disappear

al together if

(a) $\left.a_{1} a_{w}\right)\left(a_{1}+2 a_{2}\right) a_{N}$, and

(b) $k_{W} S a_{1} F \cdot /\left(a_{1}+2 a_{2}\right) a_{N}$

whore $k_{w}=\left(h_{w}-o_{w}\right)-\left(h_{N}-c\right)$.

Respecting the last two conditions in case (3), the first implies that a complete deterioration of warranty content is unlikely if a fair number of consumers shop, for then $a_{1} s_{k}$ will be small relative to $\left(a_{1}+2 a_{2}\right) a_{N}$; the lnoquality is then less likely to be satisfied. The second condition implies that a complete deterioration of warranty content is unlikely if consumers strongly prefer varranties, for then $h_{W}-c_{W}$ should bo considerably larger than $h_{N}-c$. In this event, $k_{W}$ also will be large, and so the second inequality is less likely to be satisfied.

\section{(b) No Consumers Prefer Warranties}

$\Lambda$ warranty is an insurance policy that sellers offer against product related losses. In the case considered here, consuners prefer to spend on other things than insurance. Since consumers are perceived of ten to vant at least some protection against defects, especially when purchasing durable goods, another way to conceptualize this second case is to regard consumers as preferring "limited" warranties when firms have the technical capability to offer "full" warranties. ${ }^{30}$ We next show that in this event firms will never offer full warranties, but may charge supracompetitive prices for 1 imited ones. For convenience, we describe this case as involving consumers who prefer no warranties at all, but the essential result ahould be kept in mind: firms will never offer more warranty protection than consumers desire.

We make the same assumptions as above respecting consumers and firms, but change the notation slightly. Here " $\ell_{W}$ " is the consumer's willingness to pay or 1 imit price for the product with arranty while " $\ell_{N}$ " is the consumer's willingness to pay for the product without a waranty. Because consumers now do not prefer varranties, their preferences can be captured by the expression $l_{W}-l_{N}<p_{W}^{*}-p_{N}^{*}$; a consumer's marginal willingness to pay for warranty protection is less than the minimum cost firms must incur to sell with warranties. Also, the comparative advantage to firms of selling with warranties is then " $\beta_{W}$ " where $\beta_{W}=\left(F+F\right.$ ')/( $\left.\ell_{W}-c_{W}\right)$; the comparative advantage to firms of selling without warranties is then " $\beta_{N}$ ", where 
$\beta_{\mathrm{N}}=\mathrm{F} /\left(\boldsymbol{l}_{\mathrm{N}}-c\right)$.

Once more, if enough consumers comparison shop all firns will sell without warranties at the competitive price. The logic is similar to that used above. If all firms sell without warranties at the competitive price, a firm wishing to deviate will sell only to nonshoppers. Should it deviate in the price dimension only, it will charge $l_{N}$; should it deviate in both dimensions, it will make a warranty and charge $l_{W^{*}}$ Once more, if enough shoppers exist, the losses incurred by losing their business will outweigh the gains from either deviation strategy. Hence, a competitive equilibrium in which no firms offer warranties is sustainable. The necessary and sufficient conditions for this equilibrium to obtain are

$$
\text { (i) } a_{1} \leq \beta_{N} / s
$$

and

$$
\text { (ii) } a_{1} \leq \beta_{W} / s_{W} \text {, }
$$

If too fer shoppers exist to sustain a competitive

equilibrium, firms would deviate from the competitive outcome only in the price dimension; they would never offer unwanted warranties. To see vhy, we should look again at the concept of willingness to pay. $\Lambda$ consumer's "willingness to pay" for warranty protection may be conceptualized as the difference between the highest price that a consumer would pay for the product with a warranty and the highest price ho or she would pay for the product without one. If this difference is less than the marginal cost to firms of offering

warranties, no warranty would ever be offered. This is because a firw could induce a consumer to take a warranty only by offering it at less than marginal cost, and profit maximizing firms will not make such sales.

A consumer's willingness to pay for warranty protection may be written as $l_{W^{\prime}}-l_{N^{\prime}}$ and the additional marginal cost necessary to sell with a warranty is $c_{W}-0$. Hence, no warrantics are offered when $l_{\mathrm{W}}-l_{\mathrm{N}}<\mathrm{c}_{\mathrm{H}^{\prime}}-\mathrm{c}$. This condition does not necessarily hold under the relatively restrictive assumption wo make respecting firms' cost functions, that firms have constant marginal costs, and so sell up to a capacity constraint in competitive equilibrium. This assomption is made for analytical tractibility; were we to relar it, such that firms had more "normal" cost curves, it would turn out that $o_{W}=p_{W}^{*}$ and $c=\mathrm{p}_{\mathrm{N}}^{*}$ price equals marginal cost. Then, under this natural condition, that $l_{W}-l_{N}<p_{W}^{*}-p_{N}^{*}$ rould imply that $l_{W}-l_{N}<c_{W}-c$. Hence, we assume this latter inequality to hold. When it does, consumers who dislike warranties would never be willing to pay for warranty protection; thus, no warranties would ever be observed. If an insufficient number of shoppers exist to sustain a competitive equilibrium, firms will increase prices. This occurs then $a_{1}>B_{N} / s^{31}$

\section{Preliminary Normative Implications}

Firms commonly are said to respond to the existence of "imperfect information" by supplying less warranty coverage than consumers want. He have shown, in contrast, that consumers are likely in many cases to get just that warranty coverage that they desire. 
A1so, not every consumer must shop for warranties to make warranty markets responsive to consumer preferences. These results are significant for three reasons. First, because we have assumed that consumers can make correct choices--they know failure probabilities perfectly--the competitive equilibria that actually occur are efficient. Second, noncompetitive equilibria tale a different form than is commonly supposed. Firms are thought to degrade coverage in these equilibria, but they are more likely to offer the correct coverage at supracompetitive prices. This has obvious policy implications that we pursue below. ${ }^{32}$ Third, consumers in our model will purchase warranties only if they believe warranty protection to be worthwhile; that is, only if warranties are offered for sale at or belor the consumers' limit prices. Persons in general seembetter of if they can get what they want, though they sometimes may have to pay too much for it, than they would be if their desires were frustrated al together.

Finally, our model is suggestive respecting the question whether imperfect information causes a warranty market to behave noncompetitively. B.cononic rodels often are hard to apply directly to real world problems because it is difficult to gather the data on which their application depends. For example, explicit warranty prices seldon are observable because firms comatonly sell a joint product for a single price--the item with a werranty. Also, the necessary and sufficient conditions for the various equilibria we set out above include terms referring to firms marginal costs ( ${ }_{k}$ and $c$ ): marginal cost data is notoriously hard to get. Ilence, a model such as ours is useful for policy purposes only if it tells a story that is more plausible than competing but equally difficult to test explanations. The model also may ussist in the evaluation of actual market outcomes if, in addition, it suggests factors that correlate with normatively relevant states of the world and if decisionmakers can observe such factors relatively conveniently. Our model satisfies all of these criteria fairly well.

Initially, the model rests on two plausible intuitions about firms and consumers. The first is that firms will satisfy consumer preferences when doing so would increase profits. If enough consumers will withdraw business from firms that ignore their interests, satisfying those interests then becomes the profit maximizing strategy. Ilence, normatively desirable equilibria in our model correlate positively with the extent of comparion slopping in which consumers engage. The second intuition is that consumers will get what they want if they are willing to pay for it. In particular, if consumers strongly prefer warranties, firms are unlikely to have a comparative advantage at selling without warranties; consequently, the probable response of firms to imperfect information will be to raise prices rather than deteriorate warranty content. Thus, normatively desirable equilibria in our model al so correlate positively with consumers' Hillingness to pay. The factors of comparison shopping and willingness to pay fenerate a story about warranty markets that seems more plausible than the conpeting explanations criticized in Part II 
above. These two factors also will sometimes be of use to decisionmakers in ovaluating actual markets.

Refore showing how these factors can be used in this fashion we note a particular fact about consumer warranties, their homogeneity. Almost identical warranty coverage seemingly exists within and sometimes across product 1 ines. Jior many "hard" goods, as an example, there is a standard warranty, that (i) disclaims implied warrantios of merchantability and fitness: (ii) makes an express warranty against defocts in materials and workanship. (iii) 1 imits the consumers' recovery under this warranty to the repair or replacement of defective product parts; (iv) 1 imits the time within which claims can be brought under the express warranty; and (v) when personal injury or serious property damage is possible, excludes recovery for consequential damages. ${ }^{33}$ neviations from this pattern, broadly speaking, are of two major types. Somo firms will reduce coverage, as by 1 imiting coverage to the original purchaser or excluding it for specified uses, such as racing a passenger vehicle. A1so, some firms will expand coverage, primarily by lengthening the standard term within which claims can be brought. Because of the very small sample sizes in existing research of actual warranties and because researchers often compare warranties across industries rather than within particular product 1 ines, it is impossible to know how frequently these deviations from the standaro warranty actually occur. Consequently, we shall briefly consider three kypothetical but possible cases in $1 \mathrm{ight}$ of the unalysis above.
(1) Al1 firms selling a similar product 1 ine offer the same warranty, which provides less than full protection against product related larms. Our model shows that consumers will get no more coverage than they want but may get less; hence, complete homogeneity at less than the full protection level could reflect all firms offering the coverage that consumers prefer or all firms deteriorating warranty content in identical fashion. Tro factors that a decisionmaker could use to ascertain which possibility is most likely are the extent of comparison shopping and the consumers' willingness to pay for warranty protection. A numerical example will illustrate the relevance of these measures.

When consumers prefer a given level of warranty protection. all firms in a market will offer less protection than this if and only if all of three conditions are satisfied:

(1) $a_{N} \leq \min \left(a_{W Y_{0}} a_{1} s_{V i}\right)$;

(2) $a_{1} s_{K^{\prime}}>\left(a_{1}+2 a_{2}\right) a_{N}$ i

(3) $k_{W V} S a_{1} F^{\prime} /\left(a_{1}+2 a_{2}\right) a_{N}$

where $k_{\psi}=\left(b_{W}-c_{N}\right)-\left(h_{\psi}-c\right)$. Let

$\mathrm{l}=\$ 1,000$

$F^{\prime}=\$ 200$ (for a fuller warranty)

$s_{W}=100$ units

$\mathrm{c}=\$ 45$

$c_{\mathbb{W}}=\$ 46$ (for a fuller warranty) ${ }^{34}$

$h_{W}=\$ 62$ (for a fuller warranty)

$h_{N}=\$ 59$ 
$a_{1}=.80$ ( $80 \%$ of the consumers are nonshoppers).

Respecting the three conditions 1 isted above, the first is satisfied, for $a_{N}=71 ; a_{W}=75 ; a_{1} s_{W}=80$, and thus $a_{N} S \min \left(a_{W}, a_{1} s_{W}\right)$. Because firms have a comparative advantage at selling without warranties, some of them could deteriorate warranty coverage in response to a lack of comparison shopping. For all firms to act in this way, the last tro conditions uust also be satisfied. Condition two is not. While $a_{1} s_{W}=80,\left(a_{1}+2 a_{2}\right) a_{N}=85$; the left side of the inequality is less than the right side. Ilence, the observed homogeniety could not reflect a complete deterioration of warranty coverage. In addition, since at least some firms in this illustration would reduce warranty coverage in response to insufficient comparison shopping, that no firms have done so implies the occurrence of enough comparison shopping to sustain a competitive equilibrium. Also, we have defined a consumer's willingness to pay for a waranty as the difference between the highest prices the consumer would be willing to pay for the good with and without warranty protection. In the illustration, this difference is \$3. Let the willingness to pay for a warranty rise to $\$ 4.50$. Then the respective cotparative advantages are reversed; $a_{N}$ remains at 71 while $a_{y}$ declines to $6 \varepsilon$. In this cvent, firms would never respond to imperfect information by reducine coverage. Thus, al though the figures themselves are imaginary, they do suggest that if a moderate amount of comparison shopping occurs $(20$ percent in tho exariple) and if consunors strongly prefer varranties, an outcolue in which all firms offer the same coverage is unlikely to reflect the complete monopoly equilibrium. 35

(2) Host firms in a market offer the same warranty, but a very few offer extended coverage on important components. Since consumers will not get more warranty coverage than they want, this pattern could reflect (a) "Noise": The deviant firms are making promotional warranties, for example; (b) Unsuspected heterogeneity in products or consumer preferences. A decisionmaker evaluating coverage must wake an initial, largely impressionistic judgment as to what products are in the same market. ${ }^{36}$ Diverse warranty coverage could indicate previously unnoticed differences in product types or consumer wants: (c) All but a fer firms are deviating downard from the preferred coverage in response to a lack of comparison shopping.

These possibilities suggest the factors that a decisionmaker could explore. Promotional warranties are easy to identify since they commonly are associated with the introduction of new products.

Respecting a choice between the last tro outcomes, the question is whether consumers actually are shoppers for the products that have and lack the better warranty. Suppose that consumers who purchase the standard warranty would not purchase the better one, though they have the opportunity to do so, because they believe the additional protection not to be worth its cost to them. Then, tromarkets actually crist, one for a product with the standard warranty and the other for a product with the better warranty; coverage in each market is honogeneous and can be evaluated as above. But if consumers would 
pay tho premium roquisite for greater warranty protection, so that one market in fact exists, market performance is unsatisfactory. Hany firms are offering less preferred coverage at supracompetitive prices.

(3) Most firms in a market offer the same warranty, but a very few restrict coverage, as by 1 imiting it to the original purchaser. This pattern could reflect (a) Unsuspected heterogeneity. Consumers who purchase the restricted warranty would not pay the premium requisite to obtaining the standard varranty, or (b) One market exists and a fer firms in it are deteriorating warranty content. In this event, prices for the standard warranty also are likely to be too high, for insufficient comparison shopping occurs to sustain the competitive equilibrium. If inquiry rules out heterogeneity, a decisionmaker could know that while coverage is not a serious problem--only a few firms deviate--pricing could be. An analysis of actual pricing patterns would then illuminate the problem's seriousness.

Two general remarks should be made about this exercise. First, the factors that we suggest are relevant will seldom be susceptible of precise application. They rely heavily on survey data--how nuch shopping occurs? Vould consumers pay for broader warranties? Such data is expensive to gather, and sometimes will suffer from response bias. As an illustration, a consumer might say in an interview that he would be willing to pay a large sum for a warranty because he wants to portray hinself as a firudent person, while in fact he would buy without a varranty if given the choice.
Consumer surveys nevertheless may yield useful data, and are employed in other legal fields for similar purposes as those suggested hero. In antitrust, as an illustration, consumer attitudes toward possible price movements are used to determine whether different products actually are in the same market for the purpose of evaluating the competitive effect of mergers. Also, decisionnakers today evaluate the effect of imperfect information on contract quality innocent both of theory and data. Suggestive data whose relevance is implied by plausible theory should make possible more sensible policy.

Second, both the relatively happy normative outcomes that the model predicts--consumers often will get the warranties they want; all competitive equilibria are efficient--and the positive analysis itself depend heavily on the model's assumptions. For example, if consumers will make incorrect choices respecting warranty coverage because they are uninformed about risks, that markets by and large respond adequately to those choices may not be especially desirable. The model's assumptions thus nust be examined in more detail, but before doing so, we shall set out a model for a security interest market. This model is similar to the ones just discussed, and will complete the formal analysis of markets for contract terms.

\section{Security Interest Markets}

Security interests in consumer goods have been extensively regulated. Since the central concern is overbroad security, the relevant question is whether firms exploit the existence of either aspect of imperfect information by exacting more draconian security 
interests than well informed consumers would grant. $\Lambda$ s before, we initially suppose that consumers can make correct choices respecting security, and then set forth a model of a "security interest market" in which consumers aro imperfectly informed of market prices and terms. ${ }^{37}$ This model shows that firms will not respond to insufficient consumer search by exacting overbroad security interests, but may charge supracompetitive interest rates for those security terms that consumers prefer. Hence, regulation restricting security on imperfect information grounds is misconceived if consumer choices for and against security are correct, a question we take up in Part IV, infra. Ho initially suppose: (i) Creditors are banks, each of which makes loans for a fired amount, "L"; (ii) The probability that a consumer will default is " $\pi$ ", which is known to all; (iii) consumers who default may go bankrupt; the probability that a consumer will go bankrupt given that he or she has defaulted is " $\lambda$ "; (iv) Firros recover a fraction of the unpaid debt, "p", in bankruptcy proceedings; (v) A firm can lend with or without a security interest, but cannot do both. Security interests in this model are purchase money; the bank provides credit to enable the consumer to purchase the product. ${ }^{38}$ If a firm takes security, it can recover the value of the used good, "V," whether the consumer goes bankrupt or not. ${ }^{39}$ lie assunie that the collateral on reposscssion is worth less than the outstanding debt; $L, V_{i}(v i)$ " $r$ " is the interest rato. "S" is the total anount of funds available for loans, and $S / L=s$ is then the firm's capacity, the total number of loans that can be n:ade; (vii) "lin" is the firu's fixed cost in making loans, and "c" is its marginal cost. This cost is measured as an interest rate--the opportunity cost of not lending in nonconsumer narkets. Let " $c_{S}$ " be the marginal cost of lending with security und " $c_{N}$ " the marginal cost of lending unsecured. If a firm does take security, its fixed costs increase in an amount "F"", where $F^{\prime}$ includes the cost of drafting security agreements, administering a resale facility for repossessed collateral and so forth.

These assumptions imply that a firm's expected net marginal rate of loss due to bankruptcy is $\pi \lambda(1-p) \equiv k$. If a firm recovers a fraction of the unpaid debt, $p$, in bankruptcy proceedings, it loses the fraction (1-p) when the consumer becomes bankrupt. The probability of default is $\pi$, and of bankruptcy given defaplt is $\lambda_{\text {; }}$ hence, the total expected rate of loss from bankruptcy is the product of these factors, $\pi \lambda(1-p)$, which we denote by $k$. If the firm takes a security interest, it can recover the value of the used good, $v$. Since otherwise it might have to seel this value in bankruptcy, and its rate of loss on the sum would then be $k$, tho value of security to the firm is $V_{k}$; security saves the firm this sum. The additional cost of taking security per loan is $\mathrm{F}^{\prime} / \mathrm{s}$, where $\mathrm{F}^{\prime}$ is the increased cost of security and $s$ is the number of loans. Ve assume $F^{\prime} / s<V_{k}$, which is to say that the cost of security to a firm $(\mathrm{F} / \mathrm{s})$ is less than the gain $\left(V_{k}\right)$. If $r_{N}^{*}$ is the competitive interest rate on a loan without security and $r_{S}^{*}$ is the rate with security, it then follows that $r_{N}^{*}>r_{S}^{*}$; interest rates arc lower when firms take security because in competitive cquilibrium price equals cost and security lowers a firm's 
costs.

Respecting consumers, we assune that (i) each consumer wants to borrow L dollars or none; (ii) consumers shop exactly as they do for warranties. In particular, consumers set fized sample sizes before searching for loans, with some consumers' sample sizes equaling one (the nonshoppers) and some consumers' sample sizes exceeding one (the shoppers): ( $i i i) h_{N}$ is the 1 imit price (or interest rate) that a consumer will pay when no security interest is taken and $h_{S}$ is the 1 imit price when security exists. Here $h_{N} / h$ i consumers are willing to pay higher interest rates when no security is demanded; (iv) Consumers prefer not to give security. This is to say that a consumer offered the opportunity to borron at competitive interest rates with and $w$ ithout security will pay the premium necessary to compensate firms for lending unsecured. For convenience, consumers are said here not to prefer security at a11; the analysis also applies when consumers prefer less security than firms would like to obtain.

The only single price equilibrium in this model occurs when no firm demands security and all firms charge the competitive interest rate $r_{N}^{*}$. The logic underlyine this result is similar to that used above. First, let tie competitive outcomc obtuin. $\Lambda$ firm wishing to raise its price above $r_{1 /}^{*}$ but lend without security will lose the business of every shopper. This is because each shopper will see at least one price--r ${ }^{--t h a t}$ is less than the price of the deviant firm. lience, the deviant will lend only to nonshopers and vould charge them $h_{i y}$, the highest rate for a loan without security that consusers will pay. If too few nonshoppers exist, the firm would do better by staying at $r_{N}^{*}$ than by going to $h_{N}$. A firm vishing to deviate from the competitive outcome by demanding security also would lend only to nonshopers. The shoppers by assumption prefer to borrow unsecured at $r_{N}^{*}$ rather than borrow sccurec at the lowest price possible for security, $r^{*}$. IJence, this deviant firm also would lend only to nonshoppers, and thus would both exact security and raise its pricc to $\mathrm{h}_{S}$, the highest interest rate consumers are willing to pay for secured loans. Once more, if too few nonshoppers exist, this strategy would be 1 ess profitable than the strategy of continuing to lend unsecured at $\mathbf{r}_{N^{*}}^{*}$ Therefore, if enough comparison shopping occurs, the only single price equilibrium will be at the competitive price, without security.

If too fer shoppers exist to sustain a competitive equilibrium, firms will charge supracompetitive interest rates but would not demand security. To see why, recall that a firm's marginal cost for lending with security is $c_{s}$, and for lending unsecured is $c_{N}$. Firms rould not forego security unless consumers would be willing to pay them the cost of giving it up. This cost is $c_{N}-c_{s}$ and the consumers' willingness to pay to avoid security is $h_{N}-h_{S}$. Hence, security will not be seen if $h_{N}-h_{S}>c_{N}-c_{S}$. Again, though this inequality does not necessarily hold given the restrictive constart merginal cost assumption we make, we assume it to hold, for it would be the case that $c_{N}=r_{N}^{*}$ and $c_{S}=r_{S}^{*}$ were firms assumed to have more normal cost curves. Thereforo, if consumers do not want security but 
too few of them shop to senerate a competitive equilibrium, firms will charge supracompetitive prices but will not exact unwanted security interests.

Consumers may prefer security if $V k$, the savings that security makes possible to a firm, is large. In this event, security could reduce a firm's cost sufficiently so that $h_{N}-h_{S}<r_{N}^{*}-r_{S}^{*}$; consumers' willingness to pay $\left(h_{N}-h_{S}\right)$ is too slight to overcome the large premium that firms would charge to eschew security $\left(r_{N}^{*}-r_{S}^{*}\right)$. Supposing consumers now to want the interest rate reductions that security makes possible, the analysis is then similar to that made respecting warranties. In this event, (1) all firms will lend with security at $r_{S}^{*}$ if enough consumers comparison shop; (2) a 11 firals will lend with security but some or all will charge supracompetitive prices if (a) not enough shopping occurs to sustain a competitive equilibriud and (b) firms have a comparative advantage at selling with security, and (3) firms will both charge supracompetitive prices and esckew security if the comparative advantage is the other way and insufficient shopping occurs. Firms will have a comparative advantage at lending with security if the fixed cost of security (F') is low and the consumers' desire for the lower interest rates that accompany it- the willingness (not) to pay--is high. Ilence, consumers who prefer to borrow with security will be able to do so if their preference is sufficiently strone and security is not excessively costly for firms to take, even if little shopping for credit occurs.

This analysis inplies that current regulation of security interests in consumer goods is misconceived, to the extent that it is made to rest on the notion that consumers are imperfectly informed about the possibilities respecting security that the varket offers. legulation today is devoted almost exclusively to restricting the ability of firms to take security. But firms will not demand more security than consumers prefer to give, though they may exact less. A1so, those competitive equilibria that exist in markets for security interests are efficient, supposing consumers to be able to make correct choices respecting security. Thus, the principal problem in rarkets for security seemingly is that interest rates may be too high. This problem, however, has already been addressed by legislation suck as the Truth in Lending Law, apparently successfully. 40

Again, though, the positive and normative implications of this analysis are sensitive to its assumptions. For example, we suppose that consumers can make correct choices respecting security but have given no grounds in support of this assumption. We thus turn to an analysis of the important but seemingly controversial assumptions that underlie the models just described.

\section{Undorlying Assumntions}

Economic models con!monly make assumptions for heuristic purposes that may be false in fact. These assumptions often are innocuous. For exanple, our models assume that consumers have peculiar cemand functions--they always buy one unit or none--and that firms have peculiar cost structures--they have constant marginal costs so that average costs continuously decline until the level of output 
is reached at which they are minimized, after which costs become infinite. The mode $1 s^{\prime}$ results do not change vihen these strong assumptions are relaxed. ${ }^{41} \Lambda 1$ so, the models assume that consumers have common 1 imit prices and use fixed sample size search strategies. The former assumption is false and the latter is a plausible surmise, yet the predictions of our homogeneous goods model, which used the se assumptions, are consistent with actual market behavior. ${ }^{42}$ We shall discuss here two of the later models' assumptions that may seen particularly problematic: (1) consumers can value the risks that contract terms allocate--they know the "odds", and (2) consumers cannot affect the odds, an assumption which, among other things, allows us conveniently to suppose that consuwer preferences for warranty and security interest terms are homogeneous. The models' results must be qualified in light of a more realistic appraisal of these assumptions, but the qualifications seen less serious than may be thought.

\section{Inperfect Information in the First Sense: Knowing the odds}

The typical person's estimates of the odds of product failure or of his or her own default seldon vill equal the true values. Firns are believed to exploit those errors by imposing unwanted terns.

Firms, however, respond to consumers in the aggregate, vot as individuals; consequently, no firm lnows or could know the estimate of the odds that any particular consuier holds. ${ }^{43}$ ience, tho question is whether consuisers in the aggregate tible systemitic errors such that firns have incentives to degrace contract conterit. lic next argue that systematic error of this sort is uncommon.

(1) llarket Responsos to Consuner Errors

llarkets will correct for some forms of consumer error. To show how this occurs, we shall begin with products and make the more realistic assumption that a consumer's subjective probability of product failure is related to but is not exclusively determined by actual failure probabilities. Let "S" be the consumer's subjective belief of the likelihood of product failure; "A" be the actual odds and "e" be an error term reflecting the existence of imperfect information. Then $E(S)=E(\Lambda)+E(e)$, where "E" is used to denote the expected odds, and errors are assumed to be additive. If a consumer is "optimistic", believing the product to be more reliable than it is in fact, e is on average negative: $E(S)<E(A)$; if the consumer is "pessimistic," believing the product to be less reliable than it actually is, e is on average positive $E(S)>E(\Lambda)$. For the unbiased consumer, e is zero; $E(S)=E(A)$. This representation of consumer preferences seems plausible for two reasons. First, a consumer's subjective belief about product reliability probably is related to actual reliability. $\Lambda$ new car or stereo, for example, is unlikely to be radically nore or less reliable than prior models. A consumer of ten will have owned a prior model or talked with others who have owned it or who own the new hoclel. Blso, the characteristics of many new models are discussed in magazines and newspapers. Hence, the actual oclds are likely to influcnce the consumer's estimate of what thosc odds are. Second, becausc consumers lack the expertise and 
resources to test products, and because some product characteristics can only be revealed through use, a consumer's estimate of the actual odds will seldom be completely accurate. Thus it is realistic to represent this estimate as $E(S)=E(\Lambda)+E(e)$, where the error term o is generally positive or negative.

Three possibilities exist respecting the error term when it is viewed as an aggregate phenomenon. First, S fluctuates randomly around the true value $\Lambda$; $e$ is "unbiased." $\Lambda$ error term is unbiased when positive and negative estimates of the true value cancel out. Then, for consumers in the aggregate the mean estimate $\overline{E(S)}$ equals the true value $E(\Lambda)$. Since consumers in our models shop randomly across firms, each firm will probably see a representative sample of the narket. Therefore, each firm will respond as if the consumers visiting it knew the odds perfectly; that is to say, the firm will satisfy the correct consumer choices provided that the conditions derived above for satisfying any choices at all are met. Hence, if consumer estimates of the odds of product defects, or any other odds, fluctuate randomly around true values, that inperfect information in the first sense exists does not create a policy problea.

Markets a 1 so correct for most ranifestations of pessimism. To see how, consider two cases. In the first, consumers rould want a warranty if they knew the actual odds, and also are pessimistic. In this case, pessimisa is reflected in the 1 imit price, hy, which is higher than it would be were the truc odds known; pessimistic consuniers of this sort are willine to pay excessive prices for warranties. Such pessimism creates no policy problems independent of those that occur from insufficient comparison shopping itself. Initially, since the consumers at issue would prefer a warranty were they informed, one possible problem is that firms might respond to insufficient shopping with disclaimers. This outcome, though, is less likely to occur when consumers are pessimistic than when they are informed; for when $h_{1 y}$ increases relative to $h_{N}$, the limit price for the product without a warranty, firms aremore likely to have a comparative advantage at selling with warranties. Hence, when informed consumers would want warranties and actual consumers al so are pessimistic, firms are less likely to respond to insufficient shopping by degrading coverage than when consumers are perfectly informed respecting risks. Because $h_{W}$ is higher when pessimismexists, a second conceivable problem is that firms may charge pessimistic consumers hicher prices for warranties than well informed consumers would pay. Comparison shoppine prevents this outcome. Suppose that all firms offered a warranty at the 1 imit price, $h^{\prime}$ which pessimism causes to be artificially high. This price cannot constitute an equilibrium because firms have an incentive to undercut it. A firm can costlessly reduce its price below $h_{y}$ since its warranty expenses are a function of the actual odds, not tho odds that consumers believe to exist. If the firm did cut its price by a small amount, it would continue to sell to the nonshoppers and also sell to every shopper who visited it, for it would have the lowest price in the market. The firm could thereby increase profits over those earned by charging $h{ }^{\prime}$ 
even when a small amount of shopping occurs. Hence, $h_{W}$ could not be an equilibrium price. And by the logic of the warranty mociel set out above, no other price could constitute an equilbrium except the competitive price, which equals each firm's minimum average cost. This latter price reflects the actual odds of product failure. Thus comparison shopping can ensure that consumers pay correct prices for warranty coverage, despite pessimism.

To summarize, when consumers who know the odds would prefer a warranty and actual consumers also are pessimistic. no independent policy problem exists because (i) if insufficient comparison shopping occurs to sustain a competitive equilibrium, pessimistic consumers are more likely to get warranties than perfectly informed consumers are, and (ii) even modest anounts of comparison shopping will prevent firms from exploiting the greater willingness to pay of pessimistic consumers by charging artificially high prices for warranty protection. If pessimistic consumers do not shop sufficiently to sustain a competitive equilibrium, a probler, of course exists, to which the best state response is to facilitate comparison shopping. But ti:is also is the best response when well informod consumers engage in too little shopping. Hence, pessimism presents no independent policy problem in this first case.

$A$ concern may exist in the second case when well informed consumers would not prefer a warranty, but pessimisti respecting, the olds of failure causes actual consumers to want one. Comparison shoppinf would cause the resultant waranty prices to be well behaved, but consuriers would bc purchasing excessive coverage. This problem does not seen serious for two reasons. First, pessimism may be unstable becausc firms have an incentive to dissipate it. Pessimistic consumers not only prefer unnecessary warranties when they buy, but also will buy less than they would vere they well informed. Ilence. firms should make efforts to prevent or reduce systematic pessimism. Second, pessimism at worst causcs consumers to be overinsured.

Consumers are commonly thought to be much worse off if they are vithout protection against product related losses than if they sometimes have too much protection. ${ }^{44}$

$\Lambda$ similar analysis applies to consumer choices for and against security. If consumer estimates of the odds of default are unbiased, firms will respond as if consumers held correct estimates. Respecting pessimism, suppose first that consumers would reject security were they well informed and actual consumers also believe default to be more likely than it is in fact. These consumers will be willing to pay rore than they should to avoid security interests. Comparison shopping, however, will prevent firms from exploiting this greater willingness to pay by charging excessive interest rates. Suppose next that well informed consumers would prefer security but pessimism respecting the odds of default causes actual consumers to reject it. Then, whilc comparison shopping would cause interest rates for unsecured loans to be competitive, consumers are borrowing under the wrong contract. This probler: is not serious. Firms have an incentive to dissipate pessimisn because pessimistic consumers not only will 
reject security: some of them also will not borrow or will borrow less. Hence, systematic pessimism nany be unstable. Mlso, the perceived policy problea in this area is that security puts consumers too much at the mercy of firms; pessimism at worst causes consumers to be less at the mercy of firms than in the full information case. The third possibility respecting the odds is that consumers are optimistic. In this event, a policy problem exists because markets may correct poorly for optimism. As regards warranties, suppose first that consumers would want a waranty if they lnew the odds and actual consumers also are optimistic. In this case, optimism is reflected in the limit price, $h_{W}$, which is lower than it would be were the true odds knovn; optimistic consumers have an artifically low willingness to pay for warranties. If insufficient comparison shopping occurs to sustain a competitive equilibrium, firms are more likely to degrade contract quality than in the full information case. This is because when $h_{y}$ falls relative to $h_{N}$, firms are more like $l_{y}$ to have a comparative advantage at selling without warranties. Hence, when well informed consumers vould want warranties and actual consumers are optimistic, insufficient comparison shoping is likely to yield both supracompetitive prices and suboptimal coverage. This probleal can be cured, at least in theory, by lacilitating comparison shopping, but optimism causcs a second problent that is less easily treated.

If well informed consumers would want varranties but optimism causes actual consuncrs not to cenant then, werranties probably will not appear. Firms seemingly lack an incentive to offer broader warranties tran consutiers demand because such warranties are costly--a firm would have to redeem its warranty promise. Optimistic consumers might resist the price increases necessary to cover this cost. On the other hand, optimistic consugers who purchase too narrow warranties will often be disappointed; they will experience significant uninsured losses. Firms consequently will lose good will. Hence, firms seemingly are better of if consumers mould make correct choices, for then firms can preserve good will by vaking appropriate warranties, yet recover the full costs that these varranties create. Curing consumer optimism, however, could be difficult. Firms would bo reluctant to conduct advertising campaigns whose theme is "Our widget break a lot." A more promising response is to make correct warranties but bury the cost in the total price of the product. How of ten this is done is not lnovn. Also, at least some firms might maximize profits by exploiting consumer optimism in the stort run. Thus, systematic consumer opt imism respecting product failure rates creates a policy problem, but its seriousness is unknown.

If consumers believe default to be less likely than it is in fact, they will not resist demands for security interests strongly enough, for they may think that foreclosure will seldom occur. We showed above that firms will not demand security when consumers are villing to pay to avoid it. This occurs if $h_{N}-h_{h}>c_{N}-c_{S}$. Optimistic consumers may set $h_{N}$ too low or $h_{S}$ too high; in either cvont, the difference between $h_{H}$ and $t_{S}$ will be slapler than it 
should, which increases the 1 ikelihood that this dilference will not exceed the marginal cost to firms of doing without security. Hence, if consumers are optimistic regarding the odds of default, they seemingly will make too many secured loans. On the other hand, security gives firms advantages in compeling payment. Optimistic consumers who then default will come to believe that these alvantages are too great or too frequently employed--that firms act "unfairly." This also will cause good will losses, that it may be in the interest of firms to avoid. Firms could easily do this by demanding security only when the actual odds justify it. Again, how of ten they so act is unknown. Hence, consumer optimism respecting the odds of default also seems to be a policy problem of uncertain seriousness.

To summarize, aggregate consuner estimates of the odds will be unbiased, systematically pessimistic or systematically optinistic. The former two possibilities do not create serious policy problelus independent of those caused by insufficient consumer shopping for favorable terms itself, but the latter might. Thus, we next ask whether reasons exist to believe that consumers are systematically optimistic respecting the consequences of cornercial choice.

\section{(2) Consumer Optimism: The Nature of the proolem}

I'hether consumers are systematically optimistic respecting the odds that proclucts will fail or that they theciselves will defaul on loans is unknovn. N1so, rigorous tests of ar optimisa bypothesis seen difficult to contuct. Thus, it is necessary to nsk which assuantion in regard to optinism decisiontakers should hold, pencine the gathering of data. V/e shall initially consider this question for products, and then discuss default.

Imperfect information respecting product quality is primarily a problem for infrequently purchased items. Consumers buy toothpaste, milk and razor blades of ten enough to know how reliably they perform. Also, the law is concerned with expensive mistakes. Hence, the question is whether consumers believe that such items as cars, stereos and refrigerators perform better than they do in fact. There are two vays in which such optinism could exist. First, markets may provide insufficient data on which reliability can be gauged, and persons may respond to uncertainty with optimism. Second, the data exist but persons may erroneously make more optimistic predictions than the data permit. We shall discuss the first possibility hero and the second in Part IV A (3), infra.

Insufficient data is commonly thought to exist because when consuners purchase infrequently, they cannot rely on their own experience; new washers are different from ten year old washers. But consuners can search for information about new washers. Therefore, insufficient data might exist because consumers do not search for them or because no one has an incentive to provide them. Neither possibility seems plausible. Both economic and psychological analysis suggest that persons will attempt to acquire more information about expensive products than about cheap ones, largely because people want to avoid risk, and risk genorally increases with product price.

Pespecting an econonic analysis, suppose: (i) Persons dislike the risk 
associated with uncertainty and will incur costs to reduce it; (ii) Uncertainty concerning product reliability can be represented as a range of odds of a breakdown, as: "The probability that this product will fail is between .1 and . 3"; (iii) The "odds range" doesn't shrink as products become more expensive, which is only to say that expensive goods are at least as difficult to evaluate as cheap ones; (iv) There are economies of scale to search. (v) Consumers believe that they can reduce uncertainty by acquiring wore information about products. These assumptions imply that persons will search relatively more for reliability data when they buy expensive items. To see vhy, assune that a product costs $\$ 100$ and becomes useless when it breaks; a consumer believes the chance of a breakdown is between .1 and .3; and increased scarch could reduce this range to between .1 and .15 . Without search, the expected value of a loss ranges from $\$ 30$ to $\$ 10$. Search could reduce the range by $\$ 15$, to between $\$ 10$ and $\$ 15$. Now let the product cost $\$ 1,000$. By assumptions (i) and $(v)$, consumers will be motivated to search in both cases to reduce the range; by assurintion (iii), the expected value of a loss in the second case has a range of $\$ 200$, and can be reduced by $\$ 150$ by search, which creates a significant incentive for consumers to search; and by assumtion (iv), search itself is more fruitful in this second case since the more expensive is the product, the greater is the return per dollar invested in search in recucine uncertainty about possible losses. Herce, consumers should attenet to find out relatively noro about product relinbility when they buy expensive itcms. l'especting these assumptions, that expensive products by and large are as difficult to assess as cheap ones seems unexceptionable. The assumption that persons will incur costs to reduce uncertainty is consistent with the penchant of people to buy insurance, which substitutes certain for uncertain outcomes, and by behavior in financial markets, where investors frequently pay to reduce the variance in expected returns. Finally, economies of scale to search about reliability probably exist because a significant portion of these search costs are fixed. For example, a consumer who wants to discover reliability data for electric can openers and cars could in both cases. go to the public 1 ibrary and read ratings in consumer magazines. The cost of both searches is close to identical, but the dollar reduction in the range of possible losses is much greater for cars because they cost mucb more; dollars invested in searching for cars thus bring relatively greater returns than dollars spent in searching for can openers. Therefore, greater search should occur for just those products where the assumption that consumers know the odds seeris most questionable.

P'sychologists have developed the concept of "perceived risk." According to this concept, consumers experience subjective risk when they purchase. This $r$ isl: is a function of uncertainty--"will I be satisfied with the purchase?"--and consequences--"will a purchase crror cost me money, plysical harm, a loss of social status?" The size of the ferceived risk varies directly with the degree of incertainty and the Gravity of the possible bad consequences. A1so, 
people are supposed to dis 1 ike risk and be motivated to reduce it. ${ }^{45}$ This can be done by reducine uncertainty--by acquiring thore information about the purchase--or by reducing the possible bad consequences. The former alternative should be cliosen more frequently. For example, rich people may be worried about the risk of purchasine expensive cars, but not many will choose to recuce risk by buying subcompacts; rather, they will acquire information about the expensive cars in their choice sets. Hence, the psychological model a1so predicts more search as products become more expensive.

The little evidence that exists is consistent with the predictions of both mode1s; people attempt to acquire more infornation about expensive goods than about cheap ones. ${ }^{46}$ Thus, there vill be insufficient information on which people can assess the odds only if firms have insufficient incentives to respond to consuner requests. necause information about product reliability has public goods aspects, it is difficult to say that firms will produce the optinal amount of it. Nevertheless, impressionistic evidence suggests that there is much data about expensive, infrequently purchased consurer goods. There are several independent rating magazines, and many supposedly disinterested publications rate autorotive and electronic cquipment. A1so, consumers can learn tuch about products by using them, so word of mouth seems a useful informatior source. Studies suggest that consuncrs frequently use it. Data scts of course will sonctimes be incomplete, particularly as regards novel products, but theory and eviderce suggest that the case for systenatic consunor optimism respecting product reliability must rest more on some inability of consumers to process data than or the absence of data to process.

$\Lambda$ small but significant exception to this conclusion may exist. Suppose an inexpensive, frequently purchased product that in rare cases malfunctions in such a way that serious personal harm ensues. The soda pop bottle that explodes is an example. The property of exploding is not an "experience" quality in the sense that it is revealed by use; rather, explosions just happen. A1so, explosions occur so infrequently that consumers may act as if they never occur; that is, consumers act optimistically. Because the product is inexpensive, consumers will not search for much information about it, so the crroneous belief that causes this action would not be dissipated by information accidently revealed in the course of a general product evaluation. On the other hand, if consumers are aware that products such as soda bottles can malfunction in dangerous ways, it is a separate question whether they understate the risk of this harm. He take up this question in Part $\operatorname{IV} \Lambda(3)$, infira.

An argument that consumers are systematically optimistic respecting the odds of default also nust rest largely on consumers' inforantion processing capabilities. The three major causes of default on personal obligations are poor financial planning, ill lealth and job loss. Respecting the first, firms do better lending to fieople likely to repay than they do lending to people likely to Jefault and then repossessing their goods. Hence, firms have 
incentives to refuse credit to optimists. Two ways for consumers systematically to incur obligations that their financial circustances should preclude then exist. First, firns routinely lend to unjustified risks; that is, firms routinely make profit roducing 1oans. Occasional mistakes of this sort occur, but there is no reason to think that they are made systematicelly. Second, consumers have more information about their repaynent prospects than firms do; this information implies a higher likelihood of default than the information available to firms does; and cousumers systematically process this data in such fashion as actually to overstate the likelihood of repayount. In sum, if consumers do draw excessively' favorable inferences as to repaynent prospects from their own financial circumstances as these exist when loans are sought this seemingly is because consumers have rore data about these

circumstances than firms do but misprocess it.

Respecting the last two causes of default, consumers have morc inforantion respecting their own health prospcts than firms do.

Also, the case as to job loss is ambiquous. A bant nlay know vore about the prospects of the auto industry than a potential worker debtor does, but the worker nny knov more abolit lis ability to avoid layof $s$ than the bank does. Hence, consumers could mistakenly belicve that ill health or job loss is loss likely to cause default than these vill in fact largely becatise they hisprocess information, not because they have smaller data bascs on wisch to malec inferences than their creditors have.

\section{(3) Cognitive Errors and Optimist}

llo general theory of how people make inferential judgments cxists. In recent years, however, psychologists have developed a Ereat deal of evidence both from 1 aboratory experiments and from 1 ife as to how these judgnents are made. The central theme of this research is that people make serious, systematic and predictable cognitive errors. ${ }^{47}$ Will these errors cause people to misprocess inforration such that, in the aggregate, they will understate the ocids of defects or defaults? This section argues that the principal cognitive errors that semingly plague human inference in nost cases are either: (i) irrelevant to the question whether people generally are optimistic or pessimistic respecting the odds; or (ii) will cause pcople to make random errors; or (iii) in the case of products, may incline people toward pessimism.

\section{(a) The Odds of product Defocts}

Four sources of cognitive error could affect people's assessment of the odds of product defects, cognitive dissonance, nisuse of the "availability" and "representativeness" heuristics and a possible tendency to ignore very low probability events. The cognitive dissonance idea is derived from the theory of cognitive consistency. According to this theory, persons resist holding in awareness two conflicting ideas simultaneously. Thus, they tend to ignore or distort evidence relevant to the truth of one of these ideas. ${ }^{49}$ for example, people are said to believe that they are intelligent and prudent, and consequently will rake intelligent and 
prudent choices; hence, the theory predicts that people will devalue evidence that impeaches their choices after these choices have been made. A fair anount of evidence supports the theory. $\Lambda$ s

illustrations, workers taking jobs in unsate occupations apparently come to belicve that the industries are safe--suart, careful people would not work in dangerous places. Similarly, some buyers way have more affirutive attitudes towards products after purchase than be fore. ${ }^{49}$

Cognitive dissonance semingly could not cause persons to ignore unfavorable information in the case that concerns us, when they arc deciding whether to buy. Consurier purchases of riajor items are discrete events that have high saliencci people view them as beginnings--" nly new car." Dissonance is unlikely to occur when people consciously gather evidence in order to decide.

The "availability heuristic" can cause persons to malee mistakes about the frequency with which events occur. One making inferential judgments by use of this heuristic tends to ignore statistical data in favor of evidence that seens fermane and is in awareness--is available. For example, a person may understate the correlation between cigarette sinoking and lung cancer because his judgment of this correlation was excessively influencec by his knowledge of two neighbors, each of whon smoked for firty years anci died of stroke. The availability hecristic misleacls when the association betwcen cause and effect that is in awareness or is easily summoncl up correlates poorly with the frequency with which nossiblo causes and effects actually covary, as in the cigarette example. Psychologists believe tiat such nistakes occur frequently because the existence of eviderce in awareness is in considerable part a function of its "vividness"--its cmotional interest, ability to evoke imagery, corcreteness and spatial and temporal proximity. 50 Vivid evideuce is not necessarily the most probative evidence.

If people actually assess product reliability with the availability heuristic, their error term, when viewed in the aggregate, seemingly should be unbiased or yield pessimistic cstimates. Respecting the first possibility, let potential car buyers assess the reliability of new Saabs not by published frequency of repair data but by reference to what they know about cars in general and by what they can recall about Saabs. Hvidence of this sort will include the experience of acquaintances and rumor, and it is likely to suffer from the biases of small sample sizes; that is, any one person's sample will have too few data points to reveal the correct odds for a particular model. On the other hand, the method will generate estimates that are influenced by the true odds, for two reasons. First, everyone has some knowledge of hop cars in general perform, and the performance of Sabs is not excessively dissimilar from the norm. Second, the results of each person's sample will be affected by how reliable Saabs actually are. If Saabs always broke, no ore colild have a fricnci with a good word to say. Further, this method of acquiring information is unlikely to generate errors that alvays run in the same direction; sonc people may have had good 
experiences with cars or know people with goo saabs while other people may have had bad experiences or lnow people with bad Saabs. Henee, if consumer estimates of the odds are influenced by their use of the availability heuristic, those perceptions semingly should be unbiased in the aggregate.

Consumer errors may tond towarc pessimisat rather than randomess, however, because negative evidence is of en more vivid than positive evidence. This fact is used to explain why people tend to draw insufficiently strong inferences from events that fail to happen. 51 If a product performs well most of the time but fails noticeably, then, people may believe it to be less reliable than it is in fact because they give too little weight to the absonce of failure, and too wuch to its presence. In addition, psychologists refer to a familiar "script" for defective cars. Scripts are dranatic stories people tell themselves to organize thought and experience.

Once evoked, this [automobile] script in turn can elicit a weal th of additional images and stored episodes about other "lomons" one has known. The "lemon" script is particularly rich and potent.

Vith its cast of characters (impassive or evasive service

managers, bumbling mechanics, snickering neighbors who told you that you could have had a nice blatzmobile for half the price). and its stock scenes (waiting for buses in tite rain, begging rides, bringing the car home only to hear sone oninous new sounc as you pull into the driveway), the lenon script is capaile of stronely influencing one's infercnces and behavior. ilere statistics describing Urive-train dependability records or average per-year costs are less 1 ikely to call up the rich and evocative lemon script and its various instantiations ald ere conscquenty less likely to influence our inferences and behavior.

In consequence of the vividness of tuch infortation about roduct

failure anc the relotive palliducss of information about reliability, the orror component of people's estimates of the odds could be positive for consumers in the aggregate; they way overestimate the likelihood of defects.

The "reprosentativeness heuristic" also may cause people to make mistalien probability assessments. A considerable anount of evidence suggests that people's search for causal candidates is excessively influencod by superficial similarities between a subset of the possible causes of the phenomenon under study and the phenomenon itself. A crude illustration is the theory that a child's timidity is causcd by its mother being severely frightoned during pregnancy. $\Lambda$ more sophisticated version of the belief that outcomes actually are similar to or "represent" their underlying causes is the "gamblor's fallacy." Each turn of a fair roulette wheel or the toss of a fair coin is uncorrelated with prior turns or tosses; hence, the probability that a particular turn will be red is slightly less than .5 (a zero and double zero exist), and the probability of a heads is approximately one half. A victim of the gambler's fallacy will assign a much greater probability than .5 to the chance that the next turn will produce a red or the next toss a heads, if a 1 ong run of blacks or tails has occurred. This is believed to occur because people perceive the process that generates outcomes to be random, and randow sequences of reds and blacks or heads and tails seem more representative of such a process than a long run of blacks or tails. ${ }^{53}$ The apparent pervasiveness of the gambler's fallacy suggests that people will make pessimistic assessuents of product roliability. 
Most products, particularly appliances, work reliably. Consumers, however, know that appliances are made by people; that "human error" often exists; and that industrial workers nay lack the sense of craft their ancestors had. $\Lambda$ consumer whose existing appliances work well and who holds this view of the industrial process could believe that his next purchase will be less reliable than his last; consistent success is unrepresentative of a system in which human error and a lack of craft sense will cause a nontrivial number of failures. In the gambler's fallacy simpliciter, the consumer's error is to overstate the correlation between the present and the past--a run of heads implies a tails next time; in this version, the error would be similar--too many product successes imply a forthcoming failure. There is some evidence that consuners actually make this error. $\Lambda$ study by the Michigan Survey Research ('enter reported that people perceived a need for repairs in new horse appliances that was considerably greater than the repairs they had cxperienced in past periods. ${ }^{54}$ lence, use of the representativeness heuristic also may bias people torard pessimism.

Finally, people sometines tend not to insurc against very low probability events, even when these events have high negative payof For example, persons buy less flood and eartiluake insurance than the objective probabilities warrant. ${ }^{55}$ is applice to warranty issucs. personal injuries are a mucl: less frequent conseguerec of product defects than ordinary iulfunction. Therefore, persons way ignore--in cffect be optinistic about--the odds that products will harla ther., and
Jemand less warratity protection against personal injuries than they should. This possibility cannot be disinissed, but, apart from an exception to be discussed below, it nould be unwise to base policy on it. Initially, the theory uncierlying the refusal to insure phenomenon is poorly understood. One explanation is that it reflects cognitive dissonance. 56 A smart, prudent person would not buy a farm that has a nontrivial risk of being destroyed by a flood. Thus, people who own farns would ignore evidence of flood danger, and studies show that people in this circumstance are inadequately informed about the possibility of natural disasters. The warranty problem is set in the prepurchase context. Hence, the natural disaster case could support an inference that optimism exists in other areas, such as the case of personal injury from products, only if the price of land itself does not reflect the risk of flood or earthquake. Apparently, no one now knows whether it does or not.

The tendency to ignore low probability events may also reflect use of the availability heuristic. These sorts of events may seldom be in awareness because they occur rarely, so people respond inadequatcly to them. Some grounds exist for believine that the availability heuristic is partly responsible for the phenomenon. For example, whilc people may be insufficiently concerned with flood, fire and carthquake, there is great public concern about the risks of ruclear power and bil, though the probability that these phenomena vill cause harm is quitc low. This may be because these latter risks are casily heli in awareness, as they sre mucl: aiscussed and rould 
cause awful harms if they materialized; there may be "scripts" for nuclear meltdowns and genetic mutations.

If the availability heuristic is actually at work, it is premature to base policy on the penchant of people sometimes to iguore low probability cuents. What is needed but does not exist is a way to link the extent to which events may be in awareness with the objective probabilities that persons tend to ignore. For example, if a product carries a .01 risk of causing personal injury, will people act as if that risk is zero? Ilow can a decisionenaker know when a risk of a particular harm is below the threshold of attention? If people are concerned about nuclear power but unconcerned about floods, could they be similarly concerned about cars but not about skateboarcis? That is, if it is the availability heuristic that is misleading people, are generalizations about odds thresholds warrantod? ${ }^{57}$ Until cognitive theory develops enough to permit answers to questions of this sort. that people insure insufficicatly against ccrtain kinds of low probability events oannot support factunl inferences respecting other such events. And in the absence of such inferences, it seems unwise to recuire insurance by viandating waranties.

An exception to this conclusion may exist for frequently purchased, inexpensive iteus that cause serious personal harma very small percentage of the tinc. Ho case for optimisa iu the purchase of these products can be derived frol the representativeness or availability heuristics, but the connitive dissorance raracign ray imply optinism. This is because consur:crs olten will leara about the possibility of dangerous malfunction after they have made a comnitment to the product, for they freguently purchase it. Such negative information could be devalued. The risk that scrious personal harm may occur frou using sucl: products as soda in bottles, nonprescription drugs anci food thus could be in the class of risks against which insufficient insurance tends to be purchased.

\section{(b) The odds of Defau1t}

Are people optimistic respecting the odds of their own defaults, such that they will resist a creditor's demand for security less than their own bettor informed preferences would dictate? This question differs from the one just asked about products, for there the issue was whether consumors could correctly infer an objective frequency--the odds that a product vould fail. In this case, people nust predict the joint influence of their own abilities and objective circunstances. For example, a person about to make an auto loan niust consider whether he or sho is a sufficiently prudent manager to be able to make the paynents under stable personal financial circumstances, and must also assess the likelihood of unemployment. People generally have as much data about their own abilities as outsiders do: we also have argued above that they are likely to have as much data about their objective circumstances as others will have. The question we take up here is whether the cognitive errors peoplo ray roke in processing this data will bias them in particular dircctions. 
Recent psychological theory suggests that people make sclf assessments in the same way that they assess other persons. In particular, people seemingly search for causal candidates to assess their own traits and actions, use theorics to evaluate these, and makc inferential judgments about them from objective events, just as they do when assessing outsiders; self knowledge seemingly is a procuct of nuch the same processes as knowledge of others. As an illustration, a person may come to believe that he is prudent not by consulting some peculiarly private mental source revelatory of his traits but by inferring the existence of the trait of prudence fron facts relevant to how he has conducted his own financial affairs. If pcople actually make self assessments in this fashion, an outsider who observed thesc same facts rould draw the same conclusion respecting the existence of prudence that the person himself did. And evidence show that when actors and observers use the same theories and evidence to assess the actors' attitudes and judgments, both actors and observers reach similar conclusions. An actor, however, is belicved to bave an acvantage over an observer because the actor often has morc information. 58 Thus, if actors and observers have the saulc notion of prudence, a typical actor will be able to sumtion up more instauces of his or her own beliavior relevant to the existence of this trait than any observer can.

Jih a nalysis implies that a consumer--the actor--will lake at least as gooci a judgr:ent of how lise interactios beticen his or ner traits and circuristances will influence repayment prospects as a bank--the observer--vi11, unless the consuruer uses inferior theorics to assess this interaction or use the same theories as banks do but applies then hadly. Both possibilities are nontrivial but neither would bias consumers in particular directions.

Respecting the use of inferior theories, persons often commit the "fundamental attributior error." Attribution theory in psychology "is concerned with the attempts of ordinary people to understand the causes and implications of the events they witness." 59 The fundamental attribution error is to put too much weight on characterological factors and too little weight on situational ones when assessing or predicting behavior. For example, people tend to attribute an honest act to an honest disposition rather than to the existence of factors that encourage honesty, such as that one's behavior is carefully monitored or that one needs the approval of those with whom one deals. Attributions are said of ten to be mistaken in life largely because psychologists have been able in laboratories to induce actors to perform widely divergent behaviors by varying situationnl factors. Another way to put this is that environments apparently exert greater influence over behavior than is comnonly belicved.

As applied to default issues, actors may be thought, in predicting the odds, to place too much weight on their own traits, such as prudence, and too 1 ittle weight on situational factors, such as a shaky cconony; hence, if persons routinely think well of their abilitios tlicy will be Eore sanguine about their repaynent prospects 
than their circunstances actually warrant. The funcauental attribution error, however, partly derives from the availability heuristic: people comonly have nore salience for obscrvers than situations have; in consequence, observers evaluating behavior tend to focus more on the influence of actors than on their environnents. If this explanation is correct, people should comnit the fundanental attribution error less when assessing their own behavior than the behavior of others; the actor, being always present, has relatively less salience for himsolf than circumstances cio. The evidence is consistent with this prediction, showing that actors tenci to see their orn behavior as situationally determined while obscrvers sce the samo behavior as dispositionally determined. ${ }^{60}$ Hence, at this early stago in the understanding of thesc issues, thero seems an insufficient basis on which to predict that people will be systematically optimistic about tho odds because, thinking well of their abilitics, they arc led by the funciamental attribution crror to give those abilities unclue weight.

Lay persons also tenci to slight statistical data. Por example, a bank officer is likely to use statistical precictors suct: as past rates of default in sinilar consumer universes to guide lending practices, ${ }^{61}$ while individual ocbtors mat rely ow 1 ess probative factors, suct as their own and their fricnds' inistories. The errors that such nethocis coula cause scem ravidor. is an illustration, most pcople lnow that job loss is an inportant cause of default. If they evaluate this possibility by tise of tinc availability heuristic, tisey may overstate the likelihood of job loss if they personally know unemployed persons and understate it if they do not. !rence, if notential debtors use the availability heuristic, some of them could be pessinistic respecting the odds while others vay be optimistic. Also, peoplo using the representativeness houristic may ask tienselves whether their own traits and circumstances are 1 ike-arc "representative of"--high risk or low risk debtors, rather than usc statistical clata as to default rates. This inferential process will mislead unless the traits that consumers believe predict default corrclate strongly with the traits that actualy do predict it.

Infortunately, no one knows whether consumers routinely focus on the vrong traits, nor is it knopin in which direction their errors may run. Thus, if consuncrs do use the representativeness heuristic here, ratller than rely on base rate data, there is no way to predict the direction of their errors.

In sum, people sometimes may use inferior theories to evaluate the odds of their own defaul, but no reason exists to believe that these thoorics routinely will bias the users to be optimistic. Also, people to some extent will use the same theories that banks do; in assessing their ability to assume financial obligations, persons often look at their own incomes and job histories, just as lending officers do. Potential debtors probably make nore mistakes when using the right theories than do firns, because the debtors have less expertise. Hut again, there is no reason to think that these nistakes lead to a systenatically uptimistic bias, nor is there any way to know how 
serious they are.

\section{Surnmary}

The models set out in Parts II and III, supra, showed that firms are more likely to respond to the existerce of imperfect information in the second sense--consumer ignorance of prices and terms--by charging supracompetitive prices, not by clegrading contract quality. It seemingly followed from this that regulation to "improve" contract quality is of ten misconceived. This normative implication rested crucially on the assumption that imperfect information in the first sense did not exist--that consumers knov the odds sufficiently well to choose contract terms correctly. Part IIIA(1) next argued that while individual consumers may make mistaken assessuents of the odds that products are defective or that they will default on loans, it is wrone to focus on individuals. Rather, the question is whether consumer choices in the aggregate arc correct becausc lirms, in the circumstances discussed here, respond to consuncrs in the aguregate, not as individuals. It turns out that if consuner errors respecting the odds are unbiased or pessimistic, firms gencrally respond as if consumer choiccs are correct. liut firms nuy cxploit consuncrs in the sense of imposing unwanted cortract terus or acleting preferred terms if consurcer errors arc optinistic in the agireigate. Hence, the normatively relevant question is whether general oftimism respecting, the ocids exists. Part IIIA(2) then artued that consulars comandy have the illective to ackire, and sccuingly possess, enough wate to make reasonably approxinate predictions about tac ochs. litually, f'art
III (3) argued, using cognitive theory, that whilo consumers are likcly to misprocess this data, their errors in the aggregate respecting the odds of defects or defaults seemingly will be unbiased or pessimistic. Those two arguments are less likely to hold in one important circumstance, involving frequently purchased, inexpensive prociucts that on rare occasions cause serious personal harm. Consuncrs may be optimistic respecting the risk of harm from such products, either because the risk is so slight as not to be in any consumcr's consciousness or because cognitive dissonance causes consumers to understate the risk's magnitude. In the remaining cases, the preliminary normative implications of our models hold up under tiore realistic assumptions about what consumers actually know.

\section{R. The Assuription that Consumers Cannot Affect the Odds}

lie supposed that consumers could not affect the odds that products will fail or that they themselves will default. If this assumption is relayed, two possible difficulties may arise: first. coral hazard could exist; second, consumer preferences for contract tcrms could be heterogeneous. The former possibility has little effect on the conclusions roached above, but the latter possibility could soractimes make it difficult to use our models to evaluate actual markets.

espacting moral hazari in connction with products, a warranty is an insurance nolicy against product related harms. The r)arpinal cost to a consumer of using a protuct carefully always is positive (tine and effort are costs), while the harginal gain of 
further care seemingly is zero to a consumer who has alreacy purchased a warranty, for the consumer is fully insured frow the monent of sale. llence, consumers with warranties could be less careful in their use of products--could increase the odds of defects--, as contrasted with consuners who do not have warranties; the warranty hay create a "moral hazard."

lioral hazard is not important to the analysis rade above for tro reasons. First, it is unlikely to exist in this context. The standard market response to moral hazard is coinsurance; the insurcl bears part of the risk of accidents, as with deductibles in insurance policios. In this event, the insured has an incentive to takc precautions. Respecting varranties, a form of coinsurance actually exists. Consumer durables are bought for use, and the buyers scluon leep spares. Also, firms require many warranty repairs to be wade off the consumer's preaises. Consequently, defects inpose substantial costs on consumers in lost use, even when firnis achere fully to warranty obligations; the marginal gain of being careful is always positive and often large. Because of this, moral hazaro shotile seldom be a serious probleri.

Seconci, the existence of tioral bazard does not colitravene and nay reinforce our conclusions as to how varranty marlicts wort.

Initially, the existercc of toral hazarcilill increase the litulihoo that conpetitive equilibria are sustainable. Winen all consuncrs prefer warranties, a necessary anci sufficient conditior for an cquilibriun to occer in which only varrantios are offerec at corpetitive prices is $a_{1} s_{V} \leq \min \left(a_{W}, a_{W}\right)$. Here, $s_{W}$, the level of ol:tilut in conpetitive cquilibrium for a firm selling with warrantics, cquals $s(1-\pi)$. If consumers are nore careless when they have varrantics tian when they do not, $\pi$ rises and $s_{W}$ falls; intuitively, firsus will have to provide roore replacements at any volume of sales, ivlich causes output to fall. $\Lambda 1$ so, the comparative advantagos to firms of selling with and without warranties respectively are: $a_{W}=F^{*}+\Gamma^{\prime} / h_{W}-c_{W !}$ and $c_{W}=F / h_{W}-c$. If moral hazard exists, warranties are more important to consumers because warranties will save consumers greater frecaution costs; consequently, $h_{V}$ rises wore

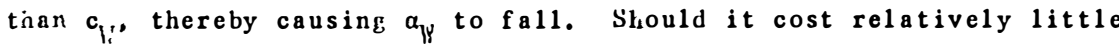
to make a warranty ( $F^{\prime}$ is smal1), however, $s_{W}$ will fall faster than $u_{11}$. Then, from the theorem a competitive equilibriun is more likely to obtain. This is not to say that moral hazard is desirable; because it increases defects, it increases costs and thus prices. But these priccs, arcmore likely to be competitive. In addition, when moral l:azard esists, firms are norc likely to respond to insufficient shopping by raising price not by reducing coverage. This is because boral hazard causcs consumers to have a greater desire for warranty protcction, and the likclihood that firms will have a comparative advantage at sclling with warranties is in corsiderable part a function of the strength of consumer preferences for then. In a nore teclinical vein, noral hazara causcs $h_{y !}$ to rise and thus causes $a_{V}$ to fall, but leaves $h_{N}$ and consequently $\psi_{: !}$unaffectec (moral hazard carnot cxist witen no varantios arc abde). Since $a_{y /}$ falls relative to 
$a_{3 N^{\prime}}$ firms are more likely to have a comparative actuantage at selline with warranties. In sum, our analysis accormodates the possible existence of moral hazard; should it occur, compctitive equilibria arc more likely and firms are more likely to provide warranties when consumers want them, though in either case prices will be higher than when consumcrs are appropriately careful.

The existence of a security interest will not increase the level of moral hazard that otherwisc exists in loan transactions. A consumer who has granted security is at a disadvantage after default relative to consumers who have not, since security gives a firm greater power to compel paynent. Thus, consumers who grant security will be at least as carcful respectine repayment prospects as those who do not.

lespocting the socond difficulty, if consumers can affect the odds of product defects, they may have heterogencous preferences for warranty coverage. For exanple, a consumer with ten children aay prefer a stroncer warranty on a washing machine than a consumer with no children. The existence of heterogeneous preferences will not affect our analysis if irms that offer warrantics do not compete with firms that sell without warranties. "Jarranty and nonivaranty warkets will "scer:ent" unless two conditions are met: ${ }^{6 \prime}$ lirst, consumers who rrefer warranties will buy procucts without warrantics if their shopning discloses only firms tliat refuse to verrant, anc consuriers who do not prefer warraties will buy with the if their search discloses only firns that offer waranties. If this coricition is not met, in effect two warkets will exist, in each of which firms sel1 homogeroous goods--products with and products without warranties. siccond, the Lurginal cost to firms of making warranties exceeds the willingness to pay for then of consumers who do not prefer warranties but is less tlan the willingness to pay for them of consumers who do. To understand this condition, suppose that the marginal cost of making warranties exceeds the willingness to pay for them of consumers who do and who clo not want warranties; then, no one would buy a product with a warranty. Suppose next that tie rarginal cost of warrantios was less than ti:e willingness to pay for then of all consumors; then, al1 consumers would buy vith warranties. If markets segment because this second condition is not mot, all consumers in a particular market viould prefer warranties or none would; this in fact is the situation Hodeled in Part II, supra. Since neither of these conditions for "nonsegmentation" is trivial and both must be satisfied, an analysis that supposes consumers to have honogeneous preficrences respecting warranty content seeming, ly applies in many cases.

When warranty and nonwarranty markets do interact, a competitive equilibrium will occur in both if enough consumers comparison shof. ${ }^{63}$ but merlict interaction poses two problems. First, competitive equilibria are tore difficult to sustain. Some firms in these marlets sell with varrantics and some without them. Such hetcrogenicty in market offerinls dillutes the effectiveness of scarch. To sec why, suppose that all shoppers visit no more than two stores. If a shoper who prefers warantics visits one store that 
offers them and another that does not, he or she is effectively a nonshopper for both products; it is as if all firms offered warrantics and the consumer went only to one of them. The effect is identical for consumers who do not prefer warranties. In short, il consuner shopping sample sizes are held constant, the effectiveness of search varies inversely with product and contract variety. Since competitive equilibria are a function of searcl effectiveness, they are less likely to occur when markets interact.

A second problem is that no one has yet characterized the cquilibria that can occur in markets in which both products and consumers are heterogeneous and insufficient snopping occurs to sustain competitive outcomes. The practical inportance of this failing is that neither the response of firms to insufficient scarch nor the features that characterize unclesirable equilibria, and by which they can be recognized, are now known precisely. On the other hand, no reason exists to believe that interactive markets behave much differently than the markets modeled above, and we also know that reducing the costs of comparison shopping is likely to improve matters in such tarkets aud usually will not lurt. ${ }^{64}$

Consumers also could have heterogencous preferences respecting sccurity, though the essential similarity of loan transactions inplies that this is less likely than heteroeercity respectine products. If it occurs, the analysis just made applics.

\section{Generalizations and Policy Implications}

Harranty terms allocate the risk of product defects between firms and consumers and security interest terms can make loans more or less risky for then. The analysis made above thus apparently applics prima racic to any contract term whose function is to allocate rist. With respect to any such term, the existence of comparison shopping together with a sufficient willingness on the part of consumers to pay for preferred terms semingly should cause firms to satisfy consumer preferences. And consumers are unlikely to assess the risks to which such terms relate in ways that differ widely from those described above.

This suggests that much regulation of terms in consumer contracts on imperfect information grounds is misconceived. The rogulation that we disapprove assumes individual consumers of ten to make mistaken risk asscssments, supposes firms to exploit these mistalios by offering unwanted terms, and responds to this supposed exploitation by enacting into lav those terms that consumors presumably do or should want. However, with respect to clauses that shift risks, consumer preferences seem entitled to controlling weight, and the most likely response of firms to the existence of imperfect information is to satisfy those preferences at excessive prices rather than frustrate then. Regulation should then be devoted, to a much Ereater cxtent tian previously, to ascertaining when pricing probleas actually exist and to romedying thom. ISefore making suggestions as to how these arc best cone, we shall first discuss an objection to our 
argument, which is that our notion of a correct choice is too restrictive. According to this objection, a choice cannot be correct unless: (i) it reflects a correct assessuent of the odds, (ii) it reflects a correct appreciation of the rarket opportunity set; and (iii) the person holding the preference that generated the choice correctly predicts that the preference will persist over time. Ve neglect this possible third aspect of a correct choice. Arewc justified in doing so?

\section{A. Imperfect Information in a Third Sense}

A central tenet of liberal theory is that persons' choices should control political and market outoomes. This tenet is easily derived from utilitarianism as it is comonly understood, from lantian sorality and from Judeo-Christian ethics. ${ }^{65}$ Liberal theory

accommodates the existence of imperfect inforantion by recognizing two exceptions to consurer sovereignty, those discussed above: persons talay be ignorant of the opportunity sets or of risls that they face. When either exception applies, state intervention of sone sort is justifiable within the theory. In recent years, a third form of inperfect information has been thought to exist. The effects of tiany lecisions that people make are felt years hence, anci people's preferences change over tinc. Consequently, a person deciding wlether to buy, borrow or vote nust consider whether fresent cloices will satisfy future preferences as well as present ones. peopleare saiu systematically to get this decisior vrong; they often io not knov: what they will cone to prefer. When private decisions involve an inportant temporal aspect and inperfect information in the sense of being ignorant of one's future self exists, the state also is thought to have a legitinate justification for intervening. Decisionnakers should anke laws that will satisfy people's future preferences when those are 1 ikcly to be inconsistent with people's present preferences. 66

This third aspect of the imperfect information concept cannot justify regulation of contract terms because it derives from a forn of utilitarianism that is unworkable in this contert. ${ }^{67}$ For this sort of utilitarianism to work decisionnlakers ("planners") must have a comparative advantage over persons in predicting future preferences. $\Lambda s$ regards personal consuaption decisions this advantage seens nonexistent. A person's future preferences are a function of: (i) how his or her present self will change as a result of internal growth and cxternal circunstances, and (ii) those external circumstances. Respecting the first factor, the best predictor of how the self will metamorphise seemingly is past changes. Persons have much more data about their pasts than planners will. For example, a person who today profers purchasing a house to renting an apartment has a 1 ifetime of cxperiences on which to draw when asking herself whether this preference will persist. She knovs how she has come to feel about previous dwelling places; how those dwelling places furthered or retarded her 1 if $c^{\prime} s$ plan or otherwise affected her happiness; how her bajor consumption decisions have turned out, and so forth. No planner could know as much. Herce, planners could have a comparative 
advantage over persons in predicting future preferences only wher the planners are better able to precict the occurrence of future events that may alter these preferences.

The future cvents that could alter preferences respecting, past consunption choices, however, are likely to be particular to individuals. For example, a person's present preference for an apartment over a house seems norc lilely to change as a result of his or her acquiring nore wealth, a fanily or a new hobby, than because of a public committment to nuclear powcr. People in general are better predicters of changes in their own circumstances than planners are.

Thus, planners seon bettor able to predict futurc preferences as regards consumption choices only in the unusual cases when those preferences may alter as a result of events of widespread consequence. that planners are better able to anticipate and compreherd.

Even this apparent advantage dissolves uncer analysis. The planner has no specific information about cach of the wany people whose preferences are at issue, and so $h$ is task is to decide how the typical person's preferences will alter as a result of major changes in public policy or social relations. To makc such predictions requires a theory, of a psychological or psychiatric sort, us to kow preferences alter over tinc in responsc to particular external stimuli or particular changes in the external environicint. Ho such theory exists. In conscquence, the likely outconc of attem,ts to predict future preferences will be the sutstitution of the planners' nreferences for those of their constituents. Fior exatple, a planner who thinks that sccurity interests should be banned because they will operate harshly against consuricrs in the coming hard tines is strongly predisposed to predict that if security interests are banned consumers will comc to prefer their absence. Regulation nade in this fashion nust be justified by reference to the planner's preferences, not those of the persons whose decisions may be overriduen.

To summarize, regulating consunption decisions on the basis of persons' future preferences is arbitrary, in the sense that no particular regulation could be justified by the utilitarianism that purports to justify the entire project of regulating on the basis of futurc preferences. This is initially the casc because persons have :aore data than planners do about their own selves and hor these are likely to alter in response to future circumstances, and commonly are better able to predict the occufrence of future preference affecting events. N1so, when planners are better able to predict or understand the occurrence of events of widespread consequence that could influence preforences, they are still unable to predict preference changes because they lack a theory relating events to changes. When planners are authorized to act but lack both data and a theory that could guide their actions, they nost probably vill plan by reference to tleir own conception of the common good. In consequence, regulation of consuntion decisions on the basis of supposed predictions of persons' future preferences cannot be justified by utilitarianism at all, for such regulation will be related to these preferences orly by happenstance. Nor is it easy to derive a 
justification from deontologioal schemes now in frecuent use, such as those premised on respect for persons. Under prevailine notions of political morality, then, persons' present preferences respecting contract terms should be regardec as controlline unless imperfect information in either of the senses discussed above exists.

\section{B. Policy Implications}

Imperfect information to which the state should respond nay exist in tro forms--consuners are ignorant of the opportunity sets they face or of the odds of misfortune implicit in particular choices. The state can respond to either form by banning a particular term or requiring disclosure respecting it. We shall discuss each possible response.

\section{(1) Banning Contract Terus}

$\Lambda$ decisionnaker may ban a particular term altogether. For exanple, some states have prohibited disclaimers in sales of consumer goods. We refer to this as a "general ban." The decisionwaker also can take a case by case approach; he or shc colid, as an illustration, ban disclaimers only when firms in a particular tarket have a comparative acvantage at selling without warranties and too 1 ittle comparison shopping occurs there to sustain a colaptitive equilibriun. Ve refer to this as a "particular ban".

ficneral bans seldon are an appropriate rosponse to the cxistence of imperfect information in its ifnorance of choice sets a spect. Firms arc more 1 ikely to respond to this form of inperfect information by raising prices for those terms that consumers do want, rather than by offering unwanted terms. Ilence, general bans are likely to te inconsistent with consumer preferences. Also, it apparently takes a relatively snall awount of conparison shopping to prevent firms from altogether neglocting consumer preferences respecting contract terms. ${ }^{68}$ Therefore, if a widespread degradation of contract quality response by firms to insufficient consuner shopping is suspected, a disclosure solution probably will yield a satisfactory outconc.

Ceneral bans of terms that allocate risks because consumers cannot accurately value these risks will be inappropriate in most cases. The relevant questions are whether consumers systematically underestimate the true ocids, and whether their ignorance will persist. Answers to these questions are context dependent and difficult. Using products as an example, wc suggested that people may be pessimistic largely because they tend to attach excessive weight to vivid data; negative iuformation, such as a spectacular accident, is more vivid than the simple absence of failure. On the other hand, vivid positive data about a particular iten could come to dominate for a time. A new product could have obvious attractions but subtle drabacks.

Consequently, a decisionalace should presune pessimism or unbiased cstinates as regards warranties, but be open to the possibility of consumer optimism in particular cases. In suck cases, hovever, the situational factors tlat affect consumer risk assessments could change. To recur to the exanple above, if the new product begins to 
fail in dramatic fashion, optimism could becone pessinism. Such changes in situational factors are difficult ior decisionalecrs to predict. This analysis suggests that general bans of teras becausc consumers will make incorrect choices respecting then are justifiablc only when systematic optimism is likely both to cxist and persist. Ve have identificd one such case, involving frequently purchased,

inexpensive items that malfunction so as to cause personal injury a very low percentage of the time. Strict liability is appropriate for transactions involving such products. Othervise, general bans of terms on information grounds are without justification. 69

Case by case determinations, such as those that courts walie under the unconscionability doctrine, seem more justifiable but should seldom cause terms to be banned on information erounds, for threc related reasons. First, inperfect information in cither aspect will cause firms to deteriorate contract content only in a uninority of cases. Firms respond to the ignorance of opportunity scts aspect nore by raising prices than by offerinc unwanted terms, and respone undesirably to the ignorance of the odds aspect only when systeratic optimism exists, which apparently occurs infrequently. Ihus, when a clausc is challenged on information grouncis, courts should assurat, in the absence of eviderce to the contrary, that the term accurately' reflected consumer preferences. Sccond, courts will have difticulty acquiring t'ie data requirce to overcome this prosurition. 'The existence of solic consumers who did not sion or of miny consusacrs wio miglit have nistalen the odds are an insufficicut basis on which to tan a tera. Rather, courts must ascertain whether the factors that correlate with poor marict performance, such as 1 ittlo comparison shopping, a weak pillingness to pay for preferred terms, and a pervasive underestimation of the odds, existed when the term was used. Law suits involving consumers will seldom be about stakes that will incluce the litigants to incur the considerable expense of providing evidence relevant to these factors. Third, a sensible judicial response to the fact that firms generally will satisfy consumer preferences respecting terms, but that it is difficult to l:now when firms have not done so, is to allow decision to be influenced by the gravity of the risk at issue. For example, the presumption against bans way be relaxed or abandoned when the contract has shifted to a consuner a risk of large magnitude, such as buying a car that is a lemon. It is in just these cases, however, that consumers are likely to searcli for information about the prociuct, and to pay attention to the information they get. The presumption that firms are satisfying consurser sreferences thus should be strengthened rather than weakened when the stales increase. ${ }^{70}$ This suggests that a court should ban a term on information trounds when the risk that the term shifted has a rclatively low valuc but the term is widely used, so that the possible total ctficiency loss it causes could be large, and the evidence surgests that it is the wrong term. Ilow nany such clauses there are seers unlinown, nor will such cases be litigated frequently. And these three reasons, taken tocether, ilaply that though particular bans can be justifiable, decisionuakers should be less inclined to enact theu 
than they have been.

\section{(2) Requiring Disclosure}

The apparent solution to the ignorance of the odds problera is to reguire the odds to be disclosed. Decisionmakers, however, would face significant practical difficulties in obtaining odds information, developing concise and comprehensible disclosure formats, and causing information to be presented in such fashion that consumers will pay attention to it. For example, a car could fail in several ways and in varying degrees. Aggregating different failure probabilitics into a composite failure probability seens very difficult, while presenting consnriers with a series of discrete estinates ray be morc confusing than useful. N1so, if product reliability is viewed as an output, both the firm and the consurer provide inputs to it; that is, failure in a function both of manufacturc and of usc. because firms cannot observe use patterns excent at great cost, they may be unable to disclose "true" failure probabilities. ${ }^{71}$ Further aralysis nay stow such difficulties to be less serious than tiney now appar but in its absence we suspect that strict liability is a Lore efficient solution to any ignorance of the odds probless that now cxist.

Respecting i gnorance of rarket choicc sets, the extent of comparison shoping varics inversely with the costs to consuricrs of comparing narket alterratives. Hence, the question is hov to reciuce the se costs, I'e suggest three wethous. First, contract terts that lay be of concern should ve disclosed in starciarci fasinial. 111 security interest clauses, for exame, shoula be roquired to radin the same way, except in so far as individual iterus dominate, such as descriptions of the collateral. Standardization is preferable to plain language laws, which conmonly require disclosures to be made in clear and sirple fashion. ${ }^{72}$ The goal here is to facilitate comilarisons across firms; this is best done by requiring firts to use the same language. This language may be more abstract or complex, and thus rorc difficult to read, than the contracts that a particular plain language statute nay require. The relevant comparison, hovever, is not betweer the costs to a consumer of reading one contract written in relatively difficult or in relatively simple language. The stanclard contract would be used by all firms, and onco mastered is mastered forcver. Hence, the comparison is between the costs entailed in reading many different simple contracts or in reading one standard conplex contract. The latter task seculs cheaper than the former and is thus more likely to be done.

A second method of reducing shopping costs is to require firms to give price and important contract term quotes over the phone. The quotes need be effective only for short periods--"our price is $\$ 100$ until Friday"; also, firms could charge less but not more than the quoted prices. Hany firms nov quote prices by phone, so the proposal is not farfetched. The obvious difficulty is the consumer who calls a department storc and requests information about thirty itens, but problers of this sort coula be aneliorated by permitting firms to 1 imit tic number of guotes per caller or by requiring thea to provide quetes only for expensive iteas. The cost recucing potential of 
telephone shopping seems great enough for this reform to be tried.

A third reform is to subsidize the production and distribution of 1 ists of the prices and important contract terms that firms offer. If consumers have this information before they begin to shop. firms will face considerable pressure to offer competitive prices and preferred terms; and the evidence shows that providing comparative prico data yields lower prices. We have discussed elsewhere the practical difficultios involved in providing this information ${ }^{73}$ and want to call attention here to two vehicles for the transuission of comparative data whose use has been insufficiently explored.

"teletert" and "vldeoter." 74

Teletert is a one way communication system that broadcasts information or sends it on cable to homes where it appears on TV soreens; videoter is a two way communication system, whereby a person requests information by phone, which is then transmitted to appear on a TV screen. Comparative price and term data could be sent in either mediom, and rould plainly facilitate interfirm comparisons. Cable television companies do sonetimes transmit price data, so this proposal also has a real world analogue. Thero are a large number of cable channe1s, and trenty eight percent of American homes now have cable, a percentage which is expected to increase considerably. When shopping problems are perceived to exist, the state should therefore seriously consider transmitting compative price and term data over selected cable channels, or over teletext should it become more widely used.

\section{Conclusion}

Consuacr contracts are frequently regulated on imperfect inforation frouncls, but this regulation is itself uninformed. Imperfect information exists when consumers choose contract terms incorrectly because they are uninformed about risk, or when consumers are ignorant of the full array of choices that firms can offer. We show that firms are likely to respond to the existence of imperfect information in this latter sense by charging supracompetitive prices for those contract terms that consumers prefer; firms will less often offer unwanted terms. The best renedy for this second aspect of the imperfect information problem is to reduce the costs to consumers of comparing the offers of different firms; comparison shopping drives prices down and reduces further the likelihood that firms will frustrate consumer preferences respecting terms.

Imperfect information in the sense of incorrect choice is thought to be pervasive, but this is because decisionmakers and cormentators focus on representative individual consumers, each of whom riay lack the data and skill to calculate risks perfectly. Firms, however, commonly respond to consumcrs in the aggregate, not as individuals; hence, the question is whether consumer vistakes respecting purchase risks in the aggregate are systenatically biased such that ir irs will act as if each consumer will make incorrect choices. If consuners as a group make errors respecting the odds that are citiner systenatically pessinistic or unbiased, firms generally vill respond as if their choices verc correct. Also, pessimistic 
choices seldom seriously disadvantage consumers. Firris have an incentive to exploit consumers only if consursers routinely understate the adverse consequences of purchase choices, and an analysis of the psychological literature dealing with cognitive error suggests that such systematic consumer optimism respecting the odds exists only in a small set of cases.

Much regulation of contract terms on information frounds is devoted to "improving" contract quality by banning contract terms that are thought to be the product of incorrect consumer choices. The analysis above shows that the presumed existence of inferfcct information can seldom support such bans; consurior contracts by and large correctly reflect consumer wants. Courts, however, should be free to ban terms in use in particular markets when iaperfect information exists there, though we bclicve that appropriate casos for such action arise less frequently than is commonly supposed. The principal inperfect infornation problem, instead, is that its existence is likely to cause contract terns to bc offered at supracompetitive prices. Disclosure regulation scouingly responds to this problom, but a good part of such legislation that is now in place is devoted to explaining particular trarsactions to consumers rather than facilitating the ability of consumers to shop conjaratively for prices and terms. Such regulation is at best a partial response to the imperfect information probler. Therefore, attention should now turn to the enresolvect theoretical difficulties involved in recognizing vhen taarkets are behaving badly for inforational reasons, and to the practical difficulties involved in implenenting the nost promising roluedy, a reduction in the costs of comparison shopping. 
iootnotes

*!aurice Jones, Jr. J'rofessor of Lav, University of Southern California law Center; Professor of Law und Social Science, California Institute of Technolosy.

* Professor of Economics, California Institute of Technology.

lesearch for this paper was supported by NSF Grant No. SES 81-17708. This paper vas inproved by comments made at a U.S.C. Law Centcr Faculty Workshop, a seminar in Contract Theory held at the Berkeley Law School and a faculty workshop at the University of Virginia. llolvin $\Lambda$. Kisenberg, Will T. Jones, Margaret Jane Radin, lobert B. Scott and Hatthew Spitzer also made very helpful suggestions. Technical versions of the warranties model discussed in Part II !b, infra, benefitted considerably from comments received at workshops held at the California Institute of Technology, the "niversity of Chicago, Northwestern University and Stanford University.

1. Wany of thesc regulatory initiatives are discussed in Schwartz and Vilde, Intervening in larkets on the Basis of Iraperfoct Information: $\Lambda$ Legal and Economic Analysis, $127 \mathrm{U}$. Pa. L. Rev. 630(1979) (herein cited as "Intervening in Markets") and Beals, ('raswell anc ialop. The Efficient Regulation of Consumer Infornation, $24 \mathrm{~J}$. Law and Econ. 491(1981).

2. A fuller justification of the view that the statc should intervene in warlicts on infornation grounds only when noricompetitive cquilibria occur is given in Intervening in 
Narkets 635-39,666-71. Wo do not discuss two possible objections to this promise. The first, using products as an example, is that poor consumers may profer to give up warranties so that they may buy decent shelter; to describe a market outcome that reflects this preference as desirable is morally wrong. This objection is irrelevant to our analysis. The poor consumers in tho 111ustration are assumed to make lnformed cholces, and we are concerned hero only with tho question when the existence of uninformed cholces should ground regulatory interventions. Requiring firms to mako warranties also would not help consumers pot to tho cholce betmeen shelter and marranties; these consumers would be made worse of by the requirement for thoy profer tho former but aro conpelled to take the latter. Potentially better solutions to the wealth distribution concern that generates this objection are to make transfer paydents to poor consumers or to subsidize the production of warranties. The latter possibility is discussed in Schwartz, $\Delta$ Re-oremingtion of Nonsubstentive Unconselonabllity, 63 Va. L. Rev. 1053,1063-64(1977). A second sot of objections to our premise that competitive equilibria are prima faole desirable follows from the vier that it is morally problematic for the state to give controlling weight to presentiy held preferences. Initially, such preferences may be "adaptive." An adaptive preference reflects a more or less unconscious adjustment on the part of the preference holder to evil social conditions. For example, persons may come to prefer discipline as a vay to make tyranny psychologically tolerable. Such preferences have 1 ittle normative value. See, e.g., Elster, Sour Grapes - Utilitarianism and the lienesis of Vants in Iltilitarianism and Beyond 219 (eds. A. Sen and B. Williams 1982) Sinilarly, people sometimes may consume in a manner inconsistent $v$ ith their actual best interests; they nay, that is, consume excessively or without regard to the effect of their consumption decisions on others whose interests they profess to hold

important. This occurs because the ideology of market cconomy regards self interested consumption as desirable behavior, and thereby prevents persons from recognizing that their present preferences are inconsistent with their real wants and needs. See R. Guess, The Idea of a Critical Theory (1981). We make the perhaps strong assumption that the se varieties of false consciousness do not cxist. We do not know how to distinguish "ordinary" preferences for contract terms from adaptive or otherwise false preferences. Given this inability, the question is whether to regard particular preferences as provisionally true or false. We regard them as true because this is more consistent with a respect for the autonomy of persons. Part $V \Lambda$, infra. docs discuss a final difficulty with allowing present preferences to control, that they may be unstable over time.

3. These states are Íansas, Maine, Maryland, Massachusetts, Vermont ard liest Virfinia.

4. 89 Stat. 2103 , section 103 
5. See A. Schwartz and R. Scott, Commercial Law: Principles and Policies 200--6 (1982).

6. Cal. Civil Code section $\mathbf{1 7 9 3 . 2}$ as arended by Assembly Bill no. 1787 ("Warranties-Hotor Vehicles-liepairs") (1982).

7. See, e.g., Schwartz, supra note 2 .

8. Uniform Consumer Credit Code section 3.301.

9. These 1 aws are summarized and discussed in Schwartz The Enforcement of Security Interests in Consumer Goods, 26 J. Law and Econ.117(1983). Restrictions on the taking of security interests often are justified on noninformational grounds, such as that creditors allegedly fail to maximize the proceds fron repossessed collateral. The Schwartz paper argues that such justifications are unpersuasive; hence, the security interest legislation referred to in the text is evaluated here in informational terms.

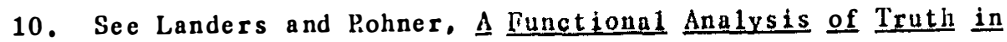
Lending, 26 U.C.L. A. L. Rov. 711 (1979); Intervening in liarkets 677. This paper discusses two aspects of the imperfect information concept, that consumers are ignorant of risks or narket opportunity sets. Lavyers sometimes claim that a third a spect exists: consumers do not understanci the legal relationship that obtains betwcen them and firras because they cannot read the 1 anguage in consuner contracts. See, e. $\not$. llavis Revamping Consumer Credit Law, 6\& Va. I. licv. 1333(1982). We believe that this clain is overstated, at loast as regards warranties and security interests. See note 35 , infra, and text at note 72 , infra. The typical response to this imperfect information problem is to make contracts more comprehensible. Sec statutes cited in Davis, supra, at 4.48, p.1345 and n.54, p.1347.

11. For representative explanations, see Grossman, The Informational Role of Harranties and Private Disclosure About Product Quality, 24 J. Law and Econ. 401(1981): Spence, Consumer llisperceptions, Product Failure and Producer Liability. $44 \mathrm{Kev}$. of Econ. Studies $561(1977)$.

12. See Priest, A Theory of the Consumer Product Harranty, 90 Yale L. J. $1297(1981)$.

13. See Schwartz and Scott, supra note 9 at 189-94, 196-206.

14. The welfare effects of signalling equilibria are very hard to cvaluate. Such equilibria, when they exist, reflect only the sustained confirmation of a party's beliefs. Thus, if consumers believe warranty coverage to correlate positively with product durability and if sellers with more durable products incur lower costs in makine warranties than do sellers with less durable products, the former sellers have an incentive to make more extensive warranties. If they actually do so, a signalling equilibrium night arise in which warranty coverage varies directly with durability; in this event, the informational contert that consuriers attribute to the varranty signal is confirmed by the signals they see. This equilibrium would be 
efficient, however, only if the increased costs to firrs of sending such warranty signals are loss than the welfare gains to consumers of being able to distinguish more accurately among products on the basis of durability. 'this conparison is very difficult to make.

15. Farly but still interesting comparative advantage explanations are found in G. Calabresi, The Cost of Accidents, 16173(1970);0i. The Economics of Iroduct Safety, 4 Be11 J. 3(1973); UcKean, products Liability: Trends and Inplications, $38 \mathrm{U}$. Chi. L. Rev. $25(1970)$.

16. U.C.C. sections 2-712-2-715.

17. See Priest, supra note 12.

18. Id. at 1347 .

19. Id.

20. The search theoretic literature is recently roviowod in Schwartz and Wilde, Inperfect Information, Monopolistic Comptition, and Public Poliey, 72 Amer. Econ. Liev. 18(l'apers and Proceedings 1982).

21. Iliesc models use the Nash equilibriun concept. Lach actor in an environtent such as a carlet is assumed to pursue a specified strategy, designed to achieve a partictiar objective, such as to rininize purchase costs or maxinize frotits. A set of stratogies is in a Masb cauilibrium when ro actor has an incentive to alter his or her strategy, given that the other actors continue to pursue their strategies; because no onc has an incentive to change, a market outcome described by such a Mash equilibrium set of stratceics is stable. Conversely, when at least one actor has an incentive to alter his or her strategy, given that other actors continue to pursue their strategies, a market outcone described by such a strategy sot is not in equilibrium; the outcome is unstable. Frod a normative viewpoint, the equilibria in a model reflect the model's predictions of what the world is like. They are thus useful to decisionmakers in understanding and evaluating market outcomes. For a fuller explanation, see Intervening in Markets $640-41$.

22. This model is set out in Wilde and Schwartz, Equilibrium Comparison Shopping, 46 liev. Ècon. Studios 543(1979).

23. See Intervening in llarkets 646-49.

24. Sadanand and Vilde, A Generalized Mlodol of Pricing for Ilonogeneous Goods Under Imperfeot Information, $49 \mathrm{Rev}$. Econ. Studies 229(1982).

25. If each consumer is assumed to have an individual 1 imit price, one could derive a demand function for every firm from the distribution of individual 1 imit prices; the nodel would then behave similarly to that found in Sadanand and Wilde, supra note 24. Search models typically do not do this because their results are qualitatively unclanged under the simplifying assumption.

26. For example, two researchers provided consumers with some comparative price information and with a weighted index of prices on 65 common looc items for supormarkets in a Canadian city for a 
five-week period. Prices in the sample market declined substantially and price dispersion decreased during the experimental period, wlile prices and dispersion were largely unaffected in the control market. See Devine and liarior:, The Influence of Consumer price Information on ketail pricing and Consumer Behavior, 61 AOJ. J, of $\Lambda_{g r i c}$. Bcon. 228(1979). This study was replicated in McCraclien, Boynton and lialie. The Iapact of Comparative Food Price Information on Consumors and Grocery Letailers: Some Preliminary Findings of a Field Experinent, $16 \mathrm{~J}$ Cons. Affairs $224(1982)$. Other studies report similar fincings.

See MicNeil, Nevin, Trubeck and lliller, llarlet Disgrimination Against the Poor and the Impact of Consuner Disclosure Laws: The Used Car Industry, 13 Lay, and Soc. Hev. 699(1979); l'usso, Rrciser and lliyasuita, $\underline{\text { n }}$ lefective Display of Unit Price Information. Journal of liarketing (April 1975), at 11. Several studies also report lower prices where price advertisine is permitted than where it is not. Sec Crasivc11, rieg-ins: The Consur.ier Protection Aspects, 62 liost. U. L. liev. 661,676 n.63(1982) (sumarizing stucies).

27. Schwartz and Hilde, Competitive bquilibria in larkets for lleterogeneous Search Goods Under Inpertect Information: A Theoretical Analysis witir policy Inplications, 13 Bell J. Lcon. $181(1982)$.

28. Technical vorsions of tiis tociel appear in Schivartz and Vilde, Consuncr !aricets for liarrantics. Cal. Inst. of 'Tecl:. Social
Licicnce l'orking Paper no. 445(1982): Schwartz and Wilde, Waraanty :iarlots and Public Policx, $1 \mathrm{~J}$. of Information licon, and Pub. Policy _(1983)(forthcoming). The present discussion is meant to nake the teclinical analysis accessible to lawyers, and to stress its normative implications.

29. Ve make this assumption because it is analytically tractable. Its essential feature is that the raking of a warranty raises a firm's marginal cost and reduces its effective output (because it must provide for replacements). Any warranty that has these features, such as a promise to repair or replace, is captured by our node 1 .

30. Under the Magnusson-Hoss $\Lambda c t$, a firm makes a full warranty if it agrees to remedy defective products at no charge "within a reasonable time", not linit the duration of implied warranties, and replace any defective products it cannot fix. Lesser varranties must be denominated "limited." See Magnusson-lioss $\Lambda$ ct sections $103 ; 104$.

31. The text describes models of warranty markets in two special cases, when all consumers prefer warranties and when none do. We have not modeled the intermediate case, when some consumcrs prefer waranties but others do not. This case is less inportant normatively than the models set out above, is quite tedious to analyze and is unlikely to yield different results. The two polar cases inply outcones that run in the same direction--firas in both cases comonly respond to insufficient shoping with 
higher prioes rather than lowered contract quality: an intermediate case is unlikely to inply outcomes that run in a different direction. In a rolated model, wo characterized necessary and sufficient conditions for competitive equilibria to obtain in markets for goods of different qualitios when consumers have heterogeneous quality preferences. Seo Schwartz and Wilde, smpes note 27. This nodel yielded results that are consistent With those described above. The relevance of heterogeneity to our conclusions is further pursued in Part IVB, infsa.

32. Soe text at notes $68-70$, infere.

33. This pattern usod to desoribe consumer and commercial warranties, but the former have been modified by the Magnusson-Mloss Act. Which prohibits disclaimers of implied warrantios if firms make express warranties, and by the strict liability in tort doctrine, Which requires firms to bear the risk of consumers' personal Injuries. Seo also UCC 2-719(3). Warranty patterns are described in Schwartz and Scott, supro note 5, at 189-94 and Priest, supre note 12 .

34. This illustration supposes $\pi$ to be .01 . Then, if $c=\$ 45, \mathrm{o}_{\mathrm{H}}=$ $\$ 46$ because $c_{W}=\frac{c}{1-\pi}$.

35. Soarching for warrantios may be more costly than searching for prices, and thus $108 s$ term search may occur, because it of ten will take more time to absorb and compare information about terms than about prices. See Intervening in Markets 660. The illustration suggests that when this cost difference is significant, the likely result is supracompetitive pricing for terms rather than provision of the wrong terms. If consumers care almost not at all about terms, however, their 1 imit prices for contracts with a particular term will be quite close to their linit prices for those contracts without the term. In this case, firms are likely to have a comparative advantage at selling vithout the term. Studies of consumer awareness of warranty terms suggest that consuncrs care enough about warranties to make this possibility negligible. See Darden and Rao, A Linear Covariate Hode 1 of Warranty Attitudes and Hohaviors, $16 \mathrm{~J}$. Hark. les. 466(1979); Whitford, Strict products Linbility and the Automobile Industry: Much Ado About Notuing, 1968 Wis. L. Rev. 83,146-51. A1so, no one claims that consumers are unaware of their creditors' right to repossess on default whon security interests exist. Slost comentators believe that consumers have preferences respecting the security torm.

36. The lenault $\Lambda$ lliance, for example, is unlikely to compete with the fiercedes 300sD. The existence and relevance of product and consuner heterogeneity are discussed in more detail in Part IVE. infrn.

37. A technical version of this model is given in Schwartz and Hilde, Sonc lesults on Consuncr Pinancial Markets and Security Interests Under Inperfoct Information, (1982) which is attached as an appencix. Several explanations of why security is given exist, suck as that security reduces net lending costs or signals the 
creditworthiness of debtors. None of thesc explanations is persuasive. See Schwartz, Security Intorests and Bankruptcy Priorities: A Review of Current Theories, $10 \mathrm{~J}$. Leg. Stud. 1(1981). We are concerned here, however, not with why security is used but only with whether imperfect information will cause it to be used in ways that frustrate consumer preferences.

38. This assumption is made for convenience. The model's qualitative results are unchanged if other comion forms of sccurity are a s sumed.

39. Firms have more difficulty recoverinc consumer goods in bankruptcy than this assumption suggests, partly because bankruptcy courts can stay the enforcement of security interests, and also because consumers in some cases can keep the collateral if they nake specified paynents on it. Sec Lankruptcy Code sections $362,522(F), 1322$ and 1325. This dificulty in foreclosing can be captured by substituting for $V$ an expected value for the collateral, $E(V)$, where $E(V)<V$. The analysis then goes through unaffected.

10. Sec Intervening in llarkets 656-58.

41. See Sadanand and Vilde, supra note 23.

42. See authorities cited in note 26 , suprif.

13. The text assumes that firns cannot learn cnough about consumers in typical consumer transactions to of fer cach consuwer a different contract, based on that consurer's sophistication. The pervasiveness of standard form contracts is consistent with this supposition. Sec Left, Contract $\Delta$ s Thing, 19 Amer. Univ. L. liev. 131(1970). To be clear about the argument that follows, this paper acopts the standard assumption that consumers hold belicfs about the oids, and that the se beliefs influence purckase choices: consumers who think products are reliable will care less about warranties than consuners who think products are likely to fail, other things equal.

14. We assume that all consumers in a market hold similar views respecting the odds, but the shoppers may hold different views. Firms respond to the shoppers, so a question arises whether the analysis is affected if the shoppers and nonshoppers differ. The answer is no because the shoppers rill probably be more pessimistic than the nonshoppers when the two groups differ. To understand the effect of this relative pessimism, consider three cascs. First, all consumers would prefer warranties were they properly informed, the nonshoppers hold unbiased or pessimistic vicws respecting the odds, and the shoppers arc pessinistic. Since firms respond to such pessinists who shop as if they wake correct choices, when the nonshoppers hold unbiased or pessimistic vicws the relatively greater pessimism of the shoppers is irrelevant; in both cases, firms will act as if all consumers make correct choices. Second, all consumers would prefer warranties were they properly inforucl, the nonshoppers are optinists, and the suoppers are pessimistic. $\Lambda$ se next show, if a 11 consumers are optimists a policy problem exists, but 
the effect of optimism by the nonshoppers may be tioderated by the relatively greater pessimism of the shoppers. For example, firms day offer warranties in response to the shoppers' pessimism.

Third, no consumers would prefer warranties were they properly informed, the nonshoppers hold correct or optinistic estimates in the aggregate and the shoppers aro pessimistic. Firms may respond to the shoppers by offering unwanted warranties, but the text argues that this is not a serious problen. Hence, if shoppers and nonshoppers hold different vievs respecting the odds, but the shoppers are relatively more pessirsistic than the nonshoppers, the analysis above is unaffected. The shoppers probably will be more pessimistic than the nonsoppcrs when the two groups differ because, as we later show, an imprortant motivator of search behavior is the perception by consumers that purchases are risky. Consumers search for information about products in part to recluce the psychological discomfort that would otherwise be experienced by bearing risks. See text at notes 45-46, infra. Since pessinists are likely to experience this discomfort while optinists are likcly not to, shoppers as a class will if anything be nore pessinistic than novshoppers.

45. The perceived risl: 1 iterature is surveyed in koss, porceived Risk and Consumer Behavior: 1 Critical Review, in Volunc 2 hdvances in Consumer l:esearcl: $2.52(1975)$.

46. See ross, supra note 45; Intervening, in larke ts 648 . A recent study also reportec considerable search for consumer dirables ard for the credit with which to finance their purchase. The average number of store visits by consumers in the researchers' sample was 3.49 , and these consumers averaged one additional visit to a "cash loan source," such as a bank. Because the stores also offered credit, the consumers in fact made several visits to creditors as well as to stores. See Shay and Brandt, Consuner Credit Protection Legislation and Consumer Credit Shopping: Truth-in-Lending and Equal Credit Opportunity Acts in The Costs and lenefits of Public Regulation of Consumer Financial Services 163, 242-43 (Report for National Science Founclation under MSF/RANN Grant NSF-C76-18548 1980). See also, Westbrook and Forne 11, Patterns of Information Source Usage Among Durable Goods Buyers, $16 \mathrm{~J}$. Mark. lies. $303(1979)\left(68.6^{\circ}\right.$ ) of consumers in sample visited two or more stores when shopping for durable goods; $46.2 \%$ also used "neutral" information sources such as books and magaz ines).

47. This psychological literature is thoroughly reviewed in R. Nisbett and L. looss, lluman Inference: Strategies and Shortcomings of Social Judgment (1980) (herein cited as "lluman Inference"). Another valuable source is Judgment Under Uncertainty: llueristics and biases (eds. D. Kahneman; P. Slovic: A. Tversky 1982) (herein cited as "Judgment Under Uncertainty"). Whether a person is raking a cognitive error must be decided by reference to the task the person is attempting to solve. Thought processes that routincly generate crrors when persons are performing discrete, 
relatively simple tasks ma be functional in enrivonnents in which the actors make continuous decisious and receive feeduack, or in environments "of great complexity." Sec linhoru and llogarth. Dehavioral Decision Theory: Processes of Iydguent and Choice, 31 Ann. Psychol. Hev. 53,73(19\&1); liogarth, Beyond Discrete Biases; Functional and Wysfunctional Aspects of Judgmental lleuristics, 90 l'sychol. Bul1. 197(1981): Lopes, Some Thoughts on the Psychological Concept of Risk. $9 \mathrm{~J}$. Exper. Psychology: IItuan Percertion and Perfornance 137(1983). In the discussion that follows, we assume that the task of choosing contract terms is discrete and relatively simple, so that the thought processes that have been shown to produce errors in other contexts will produce the same crrors in this context. $\Lambda 1$ so, the concept of rationality has at least tiro aspects: a person is behaving irrationally if he chooses means that are unlikely to achieve his ends or if he pursues crazy ands. The literature on cognitive error presupposes the rationality of persons' ends in the environments in which these persons arc studied, but claims that people pursue these ends irrationally because they systematicelly make wistalies. Ve acopt this approach here, for ne suppose consumers to hold rational preferences for contract terms and then ask whether corsuners will halic correct-rationa1--choices when acting on these prefercnces. The entirc linc of psycloological reseurch uset licre is strongly, though in our view not porsuisively, criticized in Colen, Are people
Programied to Corunit Fallacies? Further Thoughts About the Interpretation of Lixperimental pata on Probability Jucigment, 12 J. for the Theory of Social Eelavior 251(1982).

48. An analysis of cognitive dissonance as it may upply to economic tssues is found in Akerloff and lickens. The Economic Conseguences of Cognitive Dissouance, $72 \mathrm{imer}$. Econ. Rev. $307(1982)$.

49. Iㅁ.

50. Iluman Inference, 45-59.

51. Id. at 45-49.

52. Id. at 54. It a 1 so is apparently the case that consumers attach disproportionate weight to negative information about products.

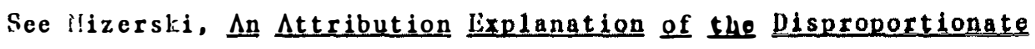
Influence of Unfavorable Information, $9 \mathrm{~J}$. Cons. Res. 301(1982).

53. Sce, e.g., Kahneman and Tversky, Subjective Probabifity: A Judgaent of Represontativeness, in Judgment Under Uncertainty at 32: Zukicr. The Dilution Effect: The Role of the corcelation and the Dispersion of Predictor Variables in the Use of Nondiagnostic Information, $43 \mathrm{~J}$. of P'ersonality and Social Psych. 1163(1982).

54. The study is cited in Courville and Ilausman. Warranty Scope and Reliability Under Imerfect Information ond Mlternative llarket Structures, 92 J. Bus. 361(1979). The authors do not interpret the results

55. tluch of this research is described in slovic, Bischoff and lichtenstein, legulation of lisk: $\Lambda$ psychological perspective, in 
Regulatory l'olicy and the Social Sciences__(L. Holl, ed.. forthcoming 1983). Sec also Slovic, Fischoff, Lichtenstein, Corrigan and Combs, Preferences for Insuring Arainst Probable Stal1 Losses: Insurance Implications, $44 \mathrm{~J}$. Risk and Ins. $237(1977)$.

56. This is suggested in Mkerloff and Dicleens, supra note 48.

57. Surveys show that people overestimate the frequency of deaths from sone causes, such as accidcnts, homicides and tornadoes, and underestimate the frequency of deaths from otser causes, such as saallpor vaccination, diabetes and asthma. These inistakes are attributed to the availability houristic. See Slovic, Fischofit and Lichtenstein. Facts versus Fears; Understanding percoived Risk in Judgment Under Uncertainty 463, 465-67.

Psychologists have been atteapting to develop general theories that explain the use of the hueristics ciescribed above. Tro observers recently stated:

[A]11 these theorios clain that in an inference situation tine subject's decision is a function of the suuset of the most salient dimensions which are processed sequentially in order of salicrec.

lial1sten and Barton. I'rocessing Probabilistio Uultidimensional Infortation for Decisions, $8 \mathrm{~J}$. Uxper. Psych.: Learning, Henory, and Cognition $361,362(1982)$. Experinental tests or this hypotlesis yicld results that are consistent with it but nlso are far from conclusive. Sec id. The lypothesis does suggest. tiough, that the failure to iusure against some low probability events is a function of the low salience that these events have for the persons tiney may affect. In the toras used above, the cvailability hueristic may partially account for the failure to insure phenoricnon.

58. The researct on which this paragraph is largely based is reported in Iluman Inference 196-225. See also, Kassarjian, Consumer Psychology, 33 Ann. liev. Psychol. 619,633-34(1982); K. G. Shaver, An Introduction to the Attribution Process 73-92(1975).

59. lioss and Ancierson. Shortconings in the Attribution Procoss: 0n the Origins and llaintenance of Erroneous Social Assessments in Judgrent Under Uncertainty 129.

60. Sec liuman Inference 123-24: Kiesler and Munson, Attitudes and Opirions, 26 Ann. Rev. Psychol. 415,429-30(1975). A review of the recent data concludes that both actors and observers tend to attribute more inportance to traits than to situations when naking attributions, but persons have a greater tendency to attribute causality to the environment when assessing their own actions than when assessing the actions of others. That is, actors colimit the funcamental attribution error less than observers do. Sec latson. The Actor and the observer: llow Are Their Porcentions of Causality Divergent? 92 Psych. Bull. $682(1982)$. The evidence riost strongly supports the relative salicnce explanation that the text gives for this phenomenon-environtients have less salience for observers than for actors. 
Id. at 698. A second explanation that also has support in the evidence is that of "preciction and cortrol." Accordine to it, actors know their own traits and response patterus; for actors these to sone extent are imutable. Thus, actors can maximize "their ability to prodict aud control future events by locusing on the response requirewents of specific situations and on the effects that these situations have on their behavior." $\underline{I d}$. at 692. In contrast, observers need to understand the persons with whom they deal; thus they can enhance their ability to predict and control events "by categorizing people according to important trait dimensions." Id. This explanation also is consistent with our view that persons will give appropriate veight to situational factors when assessing their own creditworthiness.

61. The factors that credit managers do and should look at when naking consumer loans are sunsarized in R. Brealey and $S$. Hycrs, Principles of Corporate Finance 573-76(1931).

62. These conditions are formally derivec! and explained in Schwartz and Hilde, supra note 27. The following analysis of segmentation is theoretical backgrounc to the discussion at $\mathrm{pp} .33-40$ of when firms that offer different warrantics actually sell in the sanc narket.

63. Id.

64. See note 31, supra; Sclwartz and lilde, sunra rote 27 . An additional assumption made in our wodels, that is stanciard in the economic literature, is that cach lira sclls a sincte procuct; for example, eack firm sells with warranties or without them, but cannot offer different coverages. In actual markets, firms somctises sell with a standard warranty but of fer consumers an optional warranty at extra cost that is either more extensive or of longer duration than the regular warranty. Our analysis does not pernit a formal evaluation of this practice, but re suspect that its welfare effects aro ambiguous. The gain to consumers is an increased likelihood of getting warranties thoy want at reduced scarch costs. If consumers search for desired warranty coverage as well as for low prices, however, the presence of "multicoverage firms" may in fact reduce search, which could cause prices to rise. A similar ambiguous welfare effect could attend regulation that requires firms generally to expand varranty coverage. If consumers would search less because they knew that every firm offers a good warranty, prices could rise. (n) the other hand, if firms are required to warrant only in the particular cases when they have a comparative advantage at selling without warranties and present search in the market at issue is insufficient to generate a competitive equilibrium, the requirement way produce net welfare gains, administrative costs a side.

65. See $\Lambda$. Nonegan. The Theory of Horality (1979).

66. This position is strongly argued in R. Goodin, Political Theory and Public Policy 39-56(19S2), who also cites earlier papers in the same vein. See also lennedy, Distributional and 
Paternalistic Motives in Contract and Tort Lav witin Speciul Ieforence to Coapulsory Terms and Unequal bargaining Power, 41 lII). L. Rev. 563,624-49(1982) (arguing for paternalistic intervention in consumer protection contexts). The phenomenon of changing preferences is discussed in detail in J. Elster, Ulysses and the Sirens: Studies in Rationality and Irrationality 36111(1979). In particular, see 65-89. lister, however, believes that the welfare state should not be justified on the ground that preferences may change but rather on the apparently distributionally motivated ground that risk taking should be a partially cushi oned activity. Id, at $85-86$. Such distributional concerns are irrelovant to the analysis here. Sec note 2 , supra.

67. See R. Goodin, supra note 66 , at 12-18. (justifyine the project of regulating on the basis of future preferences on utilitarian grounds).

68. See text at note 35 , supra.

69. This analysis implies that statutes such as those bannine all disclaimers in consumer sales or prohibiting creditors froll taling nonpurchase money security interests in consutier goocis cannot be justified on ti:e crounc that inperfect inforation exists in either of its aspects. Such statutes falscly assurca pervasive inconfruence betweer. consurec freferences anci consubier contracts. Also, the strict liability in tort coctrine bans all terins that allocate to consuisers risis o $i$ personal injury or property cianage causcl by procect defects. This doctrine is justifiable only in the limited circunstances discussed above.

As regaris warranty content, the informational assumptions that comparative advantage explanations make thus are less fatal to their conclusions than the critics of these assumptions claim. Iiee text at notes $15-20$, supra. Conparative advantage theorists, however, oiss the problem that correct coverage nay be offered at incorrect prices as well as the problem that coverage may be incorrect in the case of inexpensive, frequently purchased, occasionally dangerous goods.

70. An exception to this argument is the case of the low probability, inexpensive, high risk product, such as the soda bottle that explocies. This case, however, should be covered by a general ban of the sort that the strict liability in tort doctrine enacts.

71. See Gerner and Bryant, The Demand for Bopair Service unrias Warranty, 53 J. Bus. 397,413(1980) ("The impact consumers have on. -repairs. .may have particular importance in any attompt to 1 abcl appliances with their expected failure rates, since in part that failure rate will be the result of consumers themselves").

72. E..g., H.Y. Gen. Ob1 iñ. Lavi section 5-702 (Nlckinney Supp. 1981(2)): Conn. Gen. Stat. Ann. sectiors 42-151-158 (liest 1981).

73. See Interveniug in inrkets 673-77. The authorities cited in note 26. supra, suggest that substantial price reductions and other f:ains may flow from production of this kind of data.

74. These ticthods are thoroughly explored in J. Tydeman, M. Lipinsí. 
R. Adler, M. Nyhan and L. Zwimpfor, Teletext and Videotext in the United States: Narket Potential, Technology, Public Policy Issues (1982).
APPENDIX

SORE RESULTS ON CONSUMER FINANCIAL MARKETS AND SECURITY INTERESTS UNDER IMIPERFECT INFORMATION

We are concerned here with consumer financial markets in which lenders may or may not take a security interest in goods for whose purchase they make loans to consumers. Consider a consumer who wishes to finance the purchase of some good, say a car. He or she goes to a lending institution to obtain a loan. The lending institution, a bank, say, charges some interest rate and may or may not wish to take a security interest in the good. The loan is made. Afterwards there is some chance the consumer defaults on the loan payments. This may be because the consumer goes bankrupt or it may be for other reasons. If the consumer defaults, the bank sues for breach of contract. If the consumer is not bankrupt, the bank recovers in full any unpaid principle. Otherwise, how much it recovers depends on whether it has taken a security interest. If the bank has taken a security interest it recovers the good, and if the value of the used good exceds the unpad principle it returns the difference to the consumer. However, if the value of the used good is less than the unpaid principle, the bank must sue to recover the difference. Since the consumer is bankrupt, it generally will only recover a portion of this remaining 
debt.

If the bank does not take a security interest and the consumer defaults due to bankruptcy, then the entire unpaid principle must be recovered through the courts. Again, only a portion will generally be obtained since the consumer's debts exceed his or her credits. Of interest here is whether banks will request security interests, and how the answer to this question is related to loan rates, and consumer information.

To begin a formal analysis of these issues, we assume all loans are for a fixed amount, L. The probability of default is $\pi$ and the probability of bankruptcy given default is $\gamma$. The rate of recovery in a bankruptcy proceding is $\rho$. The value of the used good is $V$.

We need also to specify the "technology" facing the lending

institutions. We assume firms offer loans with or without a security interest but not both. Let $r$ be the interest rate they charge consumers. Let $S$ be the total amount of funds available for consumer loans and $S / L \equiv s$ be the total number of loans that can be made. Let $F$ be the fixed costs associated with lending in this market and c the marginal (or "opportunity") cost, measured as an interest rate, of making loans; i.e. the marginal cost of loaning L dollars is cL. Finally, let $F^{\prime}$ be any additional fired costs associated with taking a security interest (essentially the costs of selling used goods on a Wholesale market).

On the demand side we assume each consumer desires a loan of L dollars or none. The total number of consumers is fired at A. Of these $A_{1}$ are nonshoppers and $A_{2}$ are shoppers, the latter of whom sample precisely two firms. Initially we assume consumers prefer not to have security interests taken. We let $h_{N}$ be the limit price (or interest rate) when no security interest is taken and $\mathrm{h}$ be the limit price (or interest rate) when a security interest is taken.

A summary of notation to be used follows:

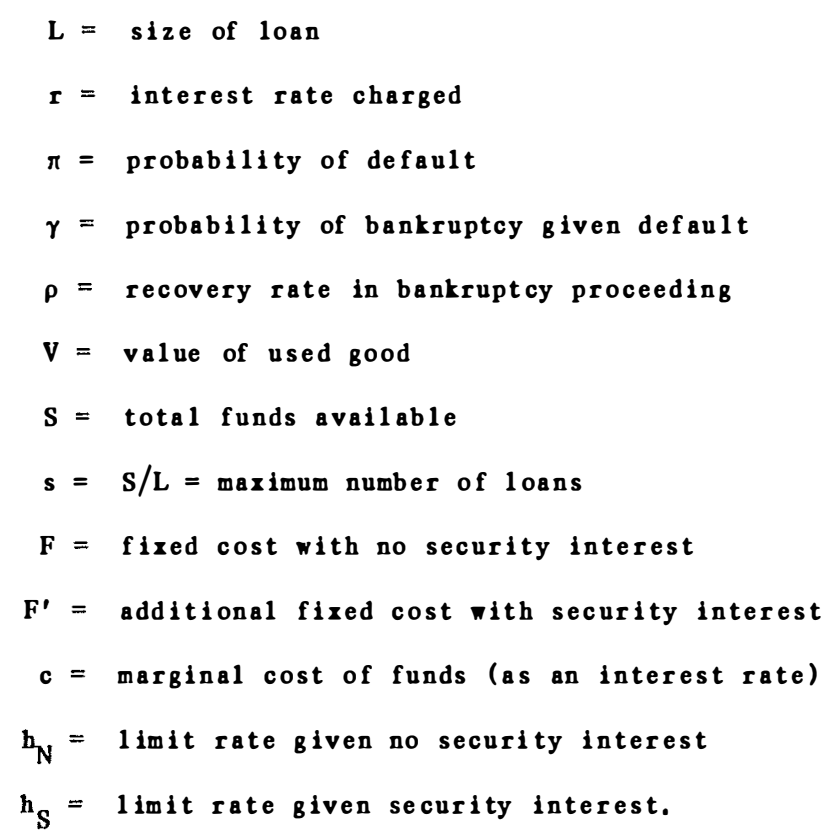

kE $\pi \gamma(1-\rho)=$ expected net marginal loss due to bankruptcy $\mathbf{r}_{N}^{*}=$ competitive interest rate given no security interest $\mathbf{r}_{S}^{*}=$ competitive interest rate given security interest 
$a_{N}=$ breakeven demand for a monopolist taking no security interest $a_{S}=$ breakeven demand for a monopolist taking a security interest.

\section{Several assumptions will be used in the analysis which}

follows. These are given next.

Assumption 1: L > V.

This assumption will be used in the following way. To keep things simple, dynamic elements of the problem will be ignored. This Will have no qualitative effect but helps the analytics. In particular, all interest rates $\mathbf{w}$ ill be treated as simple interest in a one-period framerork. No "down-payments" will be made, and any defauls will occur before any of the principle has been paid. Thus if $L>V$, the used good is worth less than the new good the instant it is purchased. Since many defaults occur after some time has passed and some payments on the loan have been made, this assumption captures the most common case -- that in which a security interest is not adequate to cover the remaining principle given a default.

As sumption 2: $\mathrm{h}_{\mathrm{N}}>\mathrm{h}_{\mathrm{S}}$.

This assumption is obvious -- consumers are willing to pay more if no security interest is taken than if one is taken. Somenhat stronger is the following.

Assumption 3: $h_{N}-r_{N}^{*}>h_{S}-r_{S}^{*}>0$.

Assumption 3 states that consumers prefer no security interest to a security interest given the opportunity to take loans with or without a security interest, but always at the relevant competitive price. The terms $h_{N}-r_{N}^{*}$ and $h_{S}-r_{S}^{*}$ represent consumer surplus and are assumed to be strictly positive.

Two more assumptions, of a more specialized, technical nature, will turn out to be useful.

Assumption 4: $F^{\prime} / s^{2}<$ Vk.

As sumption 5: $\left.\mathrm{h}_{\mathrm{N}}\right) \mathrm{Vk} / \mathrm{L}(1-\pi)$.

The first tro of these assumptions guarantees that $\mathrm{r}_{\mathrm{N}}^{*}>\mathrm{r}_{\mathrm{S}^{*}}^{*}$ i.e., the competitive interest rate on a loan with a security interest is less than that on a loan whout a security interest. It implies this because $F^{\prime} / s$ is the additional average cost of taking security interests when the maximum number of loans are made, and $V k$ is the additional gain per loan from taking a security interest -- with a security interest the value of the used good $V$ is gained before the bankruptcy process is initiated and $k$ is the rate of $10 s$ due to being forced into that process. The second assumption is more obscure. It is equivalent to Assumption 3 except that instead of using $\mathrm{r}_{\mathrm{N}}^{*}$ and $\mathrm{r}_{\mathrm{S}}^{*}$, one uses $(c+k) /(1-\pi)$ and $[c+k+(V k / L) /(1-\pi)]$ respectively. This is the "differentiable" average cost function analogue to our "fired cost, constant marginal cost, fired capacity" formulation and is generated by letting $F^{\prime}=0=F$. Its role in the analysis which follows will be made clear below.

To begin this analysis we need to characterize profits as a function of the level of demand, $x$, and the interest rate charged 
consumers, $r$, for firms who make loans with and without a security interest; denoted $\pi_{S}(x ; r)$ and $\pi_{N}(x ; r)$, respectively. To $w i t$ :

Lemma 1:

$$
\begin{aligned}
& \pi_{N}(x: r)=\operatorname{Lx}[r(1-\pi)-c-k]-F, \\
& \pi_{S}(x: r)=\operatorname{Lx}[r(1-\pi)-c-k]+\mathbf{r} \mathbf{k}-\left(F+F^{\prime}\right) .
\end{aligned}
$$

Proof: Consider first no security interest.

$$
\begin{aligned}
\pi_{N}(x ; r) & =[(1+r) L x-F-(1+c) L x]+\pi x[-(1+r) L+(1-\gamma) L+\gamma L \rho] \\
& =L x[r-c+\pi[\gamma(\rho-1)-r]]-F \\
& =\operatorname{Lx}[r(1-\pi)-c-k]-F
\end{aligned}
$$

The first bracketed term in (1) is direct profits if there were no defauls. With $x$ loans, $\pi x$ is the expected number of defauts.

Initially $(1+r) L$ is lost on each default. But $1-\gamma$ percent of the defaulors are not bankupt, and for these the entire principle $L$ is recovered. For bankruptcies, $\gamma$ percent of the defaults, the recovery rate is $\rho$. Hence the second bracketed term is net recoveries given default. Similarly,

$$
\begin{aligned}
\pi_{S}(x ; r)= & {\left[(1+r) L x-\left(F+F^{\prime}\right)-(1+c) L x\right] } \\
& +\pi x[-(1+r) L+(1-\gamma) L+\gamma[V+(L-V) \rho]] \\
= & L x[r-c+\pi[-r-\gamma(1-\rho)]]+x V k-\left(F+F^{\prime}\right) \\
= & \operatorname{Lx}[r(1-\pi)-c-\mathbf{L}]+\mathbf{r V k}-\left(F+F^{\prime}\right) .
\end{aligned}
$$

The difference between (2) and (1) is the additional fired cost $F^{\prime}$ and the additional expected recoveries given default. If the consumer is bankrupt, $V$ is recovered with certainty and the balance L-V is recovered at rate $\rho$ because only it is forced into the bankruptcy process.

Lemma 2:

$$
\begin{aligned}
& \mathbf{r}_{N}^{*}=[(F / L s)+c+k] /(1-\pi) \\
& r_{S}^{*}=\left[\left[\left(F+F^{\prime}\right) / L s\right]+c+k-(V k / L)\right] /(1-\pi) .
\end{aligned}
$$

Proof: Competitive interest rates are defined by zero profits at capacity s. Hence for no security interest,

$$
0=\pi_{N}\left(s ; r_{N}^{*}\right)=L s\left[r_{N}^{*}(1-\pi)-c-k\right]-F,
$$

$$
\mathbf{r}_{N}^{*}=[(F / L s)+c+k] /(1-\pi) .
$$

Similarly,

$0=\pi_{S}\left(s ; r^{*}\right)=L s\left[r_{S}^{*}(1-\pi)-c-k\right]+s V k-\left(F+F^{\prime}\right)$

Which yields r

Q.E.D.

Lemma 1 also allows us to express $a_{\mathrm{N}}$ and $a_{\mathrm{S}}$ formally.

Lemma 3:

$$
\begin{aligned}
& a_{N}=F / L\left[h_{N}(1-\pi)-c-k\right] \\
& a_{S}=\left(F+F^{\prime}\right) /\left[L\left[h_{S}(1-\pi)-c-k\right]+V k\right] .
\end{aligned}
$$


Proof: By definition $a_{N}$ and a $a$ are breakeven demands for monopolists offering loans without and with security interests, respectively.

Hence

$$
0=\pi_{N}\left(a_{N} ; h_{N}\right)=L a_{N}\left[h_{N}(1-\pi)-c-k\right]-F,
$$

and

$$
0=\pi_{S}\left(a_{S} ; h_{S}\right)=L \alpha_{S}\left[h_{S}(1-\pi)-c-k\right]+a_{S} V k-\left(F+F^{\prime}\right) .
$$

Solving for $a_{N}$ and $a_{S}$ gives the lemma.

Q.E.D.

A final lemma relating $a_{N}$ to a will turn out to be of use 1 ater.

Lemma 4: $a_{N}<a_{S}$

Proof: From Lemma 3 we have $a_{N}<a_{S}$ if and only if

$$
F / L\left[h_{N}(1-\pi)-c-k\right]<\left(F+F^{\prime}\right) /\left[L\left[h_{S}(1-\pi)-c-k\right]+V k\right] .
$$

Simplifying (3), we have $a_{N}<a_{S}$ if and only if

$$
\left(h_{N}-h_{S}\right)(1-\pi)>(V k / L)-\left(F^{\prime} / F\right)\left[h_{N}(1-\pi)-c-k\right] .
$$

But Assumption 3 states $h_{N}-r_{N}^{*}>h_{S}-r_{S}^{*}$ which, using Lemma 2, implies

$$
\begin{aligned}
& h_{N}-[(F / L s)+c+k] /(1-\pi)> \\
& \left.\left.\quad h_{s}-\left[\left(F+F^{\prime}\right) / L s\right)+c+k\right]-(V k / L)\right] /(1-\pi) .
\end{aligned}
$$

Rearranging (5) gives

$$
\left(h_{N}-h_{S}\right)(1-\pi)>(V k / L)-\left(F^{\prime} / S L\right) .
$$

Inequality (6) implies inequality (4), and hence the lemma, if

$$
\left(V_{k} / L\right)-\left(F^{\prime} / s L\right)>(V k / L)-\left(F^{\prime} / F\right)\left[h_{N}(1-\pi)-c-k\right]
$$

Inequality (7), however, reduces to

$$
\operatorname{sL}\left[h_{N}(1-\pi)-c-k\right]-F>0
$$

But $\operatorname{sL}\left[h_{N}(1-\pi)-c-k\right]-F=\pi_{N}\left(s ; h_{N}\right)>0$ since $h_{N}>r_{N}^{*}$ by Assumption 3. Thus (7) must hold, implying (4) holds, implying $a_{N}<a_{S}$. Q.E.D.

This completes our preliminary analysis. We are now ready to consider the possible equilibrium configurations in more detail. Equilibriom here is a consumer-firm ratio, $\sigma \equiv A / N$, a distribution of firms between those offering loans with security interest, n' and those offering $10 a n s$ without security interest, $\mathrm{n}_{N}$; and a distribution of interest rates in each market, $G_{S}\left({ }^{\circ}\right)$ and $G_{N}\left({ }^{\circ}\right)$, such that all firms earn zero profits and no firm can earn positive profits by changing its interest rate. Here

$$
\begin{aligned}
N & =\text { total number of firms } \\
N_{N} & =\text { number of firms without security interest } \\
N_{S} & =\text { number of firms with security interest } \\
n_{N} & =N_{N} / N \\
n_{S} & =N_{S} / N .
\end{aligned}
$$


Theorems 1 through 8 all presume Assumptions 1 through 5 hold.

Theorem 1: A necessary and sufficient condition for ${ }^{n_{S}}=0$ and the market for loans without security interests to be competitive is ${ }_{1} s \leq a_{N}$

Proof: With $n_{s}=0$ and the security interest market competitive, expected demand at $r_{N}^{*}$ must equal s. Hence $\sigma=A / N=s$. A firm entering this market above $r_{N}^{*}$ should charge $h_{N}$ since it gets nonshoppers only. Nonpositive profits thus requires $a_{1} \sigma L\left[h_{N}(1-\pi)-c-k\right]-F S 0$, or using Lemma $3, a_{1} \sigma \leq a_{N}$. A firm entering the security interest market should analogously charge h Nonpositive profits then requires $a_{1} \sigma L\left[h_{S}(1-\pi)-c-k\right]+$ $a_{1} \sigma V k-\left(F+F^{\prime}\right) \leq 0$, or $a_{1} \sigma \leq a_{S}$. But Lemma 4 shows $a_{N}<a_{S}$. Thus $a_{1} \sigma \leq a_{N}$ implies $a_{1} \sigma \leq a_{s}$.

Q.E.D.

Theorem 2: $\mathrm{n}_{\mathrm{N}}=0$ and the market for loans ith security interests to be competitive is impossible.

Proof: In this case $\sigma=A / N=s$ again, since capacity is insensitive to whether a security interest is taken or not. Now $h_{N}-r_{N}^{*}>h_{S}-r_{S}^{*}$ (Assumption 3) implies there exists an interest rate $\bar{r}_{N}>r_{N}^{*}$ such that $h_{N}-\bar{r}_{N}=h_{S}-r_{S}$. At this interest rate consumers are indifferent to a loan with no security interest and one ${ }^{2}$ ith a security interest at rate $r_{s}$. Hence a firm entering the market for loans without security interests at $\bar{r}_{N}$ iill get expected demand equal to $s$. Profits are then $\operatorname{Ls}\left[\bar{r}_{N}(1-\pi)-c-k\right]-F$ which is strictly positive since $\bar{r}_{N}>r_{N}^{*}$ and
$\operatorname{Ls}\left[r_{N}^{*}(1-\pi)-c-k\right]-F=0$ by definition of $r_{N}^{*}$ (see proof of Lemma 2).

Theorem 3: Both markets competitive is impossible.

Proof: The proof of this result is analogous to that of Theorem 2-a firm charging $\bar{r}_{N}$ and not taking a security interest must necessarily earn strictly positive profits.

Theorem 4: A necessary and sufficient condition for ${ }^{n}=0$ and the market for $10 a n s$ ithout security interests to be noncompetitive is $\mathrm{a}<\mathrm{a}_{1} s$.

Proof: When $n_{S}=0$, the highest interest rate in the market for loans without security interests is $h_{N}$. Zeroprofits thus implies $\sigma a_{1} L\left[h_{N}(1-\pi)-c-k\right]-F=0$, or $\sigma=a_{N} / a_{1}$.

Now consider the distribution of interest rates in the no security interest market, $G_{N}\left({ }^{\circ}\right)$. Suppose it has a mass point at ${ }_{N_{N}^{*}}^{*}$ Expected demand at $r_{N}^{*}$ is

$$
\sigma\left[a_{1}+2 a_{2}\left[1-\left(G_{N}^{*} / 2\right)\right]\right]
$$

Zero profits then implies

$$
\sigma\left(a_{1}+2 a_{2}\left[1-\left(G_{N}^{*} / 2\right)\right]\right] L\left[r_{N}^{*}(1-\pi)-c-k\right]-F=0,
$$

or

$$
G_{N}^{*}=\left[\left(a_{1}+2 a_{2}\right)-(s / \sigma)\right] / a_{2} .
$$

A noncompetitive distribution of interest rates in the no security 
interest market requires $G_{N}^{*}<1$, or $\left(a_{1}+2 a_{2}\right)-(s / \sigma)<a_{2}$. Since $\sigma=a_{N} / a_{1}$, this reduces to $a_{N}<a_{1} s$.

What about entry into the market for loans with security interests? To calculate expected profits at various interest rates in this market we need to know the exact form of $G_{N}\left({ }^{*}\right)$. Expected demand at interest rate $r$ is $\sigma\left(a_{1}+2 a_{2}\left[1-G_{N}(r)\right]\right\}$. Hence if we 1 et $\pi_{N}(x, r)$ when $x$ equals expected demand at $r$ be denoted $\pi_{N}^{e}(r)$,

$$
\pi_{N}^{e}(r)=\sigma\left[a_{1}+2 a_{2}\left[1-G_{N}(r)\right]\right\} L[r(1-\pi)-c-k]-F .
$$

Zero profits requires $\pi_{N}^{e}(r)=0$ (for those $r$ actually offered). Hence (8) yie1ds

$$
G_{N}(r)=1-\frac{F-a_{1} \sigma L[r(1-\pi)-c-k]}{2 a_{2} \sigma L[r(1-\pi)-c-k]} .
$$

If a firm enters the market for loans with security interests at rate ${ }^{9}$ it loses some shoppers to firms offering loans without security interests. In fact, at rate $q_{N^{\prime}}$, where $h_{N}-a_{N}=b_{S}-q_{S^{\prime}}$ consumers are indifferent, and for any $r<q_{N}$, they prefer to take a loan without a security interest at rate $r$ rather than take one with a security interest at rate ${ } S^{\cdot}$ Thus, defining $\pi_{S}^{e}\left({ }^{*}\right)$ analogously to $\pi_{N}^{e}\left({ }^{*}\right)$,

$$
\pi_{S}^{e}\left(q_{S}\right)=\frac{\sigma\left[a_{1}+2 a_{2}\left[1-G_{N}\left(h_{N}-h_{S}+q_{S}\right)\right]\right]}{\left(L\left[q_{S}(1-\pi)-c-k\right]+V k\right]}-\left(F+F^{\prime}\right) .
$$

Using (9) in (10) we get

$$
\pi_{S}^{e}\left(q_{s}\right)=\frac{F\left(L\left[q_{S}(1-\pi)-c-k\right]+V k\right)}{L\left[\left(h_{N}-b_{S}+q_{S}\right)(1-\pi)-c-k\right]}-\left(F+F^{\prime}\right) .
$$

Differentiating (11) with respect to ${ }^{9}$ gives

$d \pi_{S}^{e}\left(q_{S}\right) / d q_{S}=\frac{F L(1-\pi)\left[L\left(h_{N}-h_{S}\right)(1-\pi)-V k\right]}{L^{2}\left[\left(h_{N}-h_{S}+q_{S}\right)(1-\pi)-c k\right]^{2}}$.

The sign of $d \pi_{S}^{e}\left(q_{s}\right) / d q_{S}$ equals the sign of $L\left(h_{N}-h_{S}\right)(1-\pi)-V k$. But by Assumption 5, this is positive. Hence $d \pi_{S}^{e}\left(q_{S}\right) / d q_{S}>0$ and $\pi_{S}^{e}\left(q_{S}\right) \leq 0$ for al1 $q_{S} \varepsilon\left[r_{S}^{*} h_{S}\right]$ if and only if $\pi_{S}^{e}\left(h_{S}\right) \leq 0$. But from (11) this reduces to $a_{N} S a_{S}$, which necessarily holds given Lemma 4 .

Q.E.D.

Theorem 5: $\mathrm{n}_{\mathrm{N}}=0$ and the market for $10 a n$ with security interests to be noncompetitive is impossible.

Proof:

If $\mathrm{n}_{\mathrm{N}}=0$ then the highest interest rate in the market for loans with security interests is $h_{S}$. Zero profits then implies $\sigma=a_{S} / a_{1}$. A firm entering the no security interest market at $\mathrm{h}_{\mathrm{N}}$ will attract $a_{1} \sigma$ customers. Profits are then $a_{1} \sigma L\left[h_{N}(1-\pi)-c-k\right]-F$ which are nonpositive if and only if $a_{S}<a_{N}$ a condition which contradicts Lemma 4. Q.E.D.

Theorem 6

The market for loans with security interests to be competitive and that for loans without security interests to be noncompetitive is impossible.

Proof: The 10 ogic here is the same as in the proofs of Theorems 2 and 
3-expected demand at $r_{S}^{*}$ is $s$. A firm offering $\bar{r}_{N} \equiv h_{N}-h_{S}+r_{S}^{*}$ wi11 also attract s consumers and must therefore earn strictly

positive profits.

Q.E.D.

\section{Theorem 7: The market for loans without security interests to be} competitive and the market for $10 a n$ mith security interest to be noncompetitive is impossible.

Proof:

This proof follows as that of Theorem 5--zeroprofits at h implies $\sigma=a_{S} / a_{1}$ and $t h i s$ consumer/firm ratio necessarily allors strictly positive profits at $h_{N}$ unless $a_{N}>a_{S}$, a condition which

violates Lemma 4.

Q.E.D.

\section{Theorem 8:}

\section{Both markets noncompetitive is impossible.}

Proof: To prove this theorem we need first to shor there cannot exist tro interest rates in the market for security interests, say $p_{S}$ and $q_{S}$, such that $q_{N} \equiv h_{N}-h_{S}+q_{S}$ and $p_{N}=h_{N}-h_{S}+q_{N}$ are both offered in the no security interest market. For suppose there were tro such interest rates. Expected demand at $p_{S}$. rill equal expected demand at $p_{N}$ and expected demand at $q_{S}$ will equal expected demand at $q_{N}$. Define these values by $D_{S}\left(p_{S}\right), D_{N}\left(p_{N}\right), D_{S}\left(q_{S}\right)$ and $D_{N}\left(q_{N}\right)$, respectively. Then zero profits gives

$$
\begin{aligned}
& { }^{L D_{S}}\left(\mathrm{p}_{S}\right)\left[\mathrm{p}_{S}(1-\pi)-c-k\right]+D_{S}\left(p_{S}\right) \mathrm{Vk}-\left(F+F^{\prime}\right) \\
& =L D_{N}\left(p_{N}\right)\left[p_{N}(1-\pi)-c-k\right]-F
\end{aligned}
$$

and

$$
\begin{array}{r}
\operatorname{LD}_{S}\left(q_{S}\right)\left[p_{S}(1-\pi)-c-k\right]+D_{S}\left(q_{S}\right) V k-\left(F+F^{\prime}\right) \\
=L_{N}\left(q_{N}\right)\left[q_{N}(1-\pi)-c-k\right]-F .
\end{array}
$$

But $p_{N}=h_{N}-h_{S}+p_{S}$ and $D_{S}\left(p_{S}\right)=D_{N}\left(p_{N}\right)$. Bence (12) is equivalent to

$$
\begin{aligned}
\mathrm{LD}_{S}\left(\mathrm{p}_{S}\right)\left[\mathrm{p}_{S}(1-\pi)-c-k\right]+D_{S}\left(\mathrm{p}_{S}\right) V \mathbf{r}-\left(F+F^{\prime}\right) \\
\quad=\operatorname{LD}_{S}\left(\mathrm{p}_{S}\right)\left[\left(\mathrm{h}_{N}-\mathrm{h}_{S}+\mathrm{p}_{S}\right)(1-\pi)-c-k\right]-F,
\end{aligned}
$$

or,

$$
D_{S}\left(p_{S}\right) V k-F^{\prime}=L D_{S}\left(p_{S}\right)\left(h_{N}-h_{S}\right)
$$

Solving (14) for $D_{S}\left(p_{S}\right)$ gives

$$
D_{S}\left(p_{S}\right)=F^{\prime} /\left[V k-L\left(h_{N}-h_{S}\right)(1-\pi)\right],
$$

Which is independent of $\mathrm{p}_{S}$ and thus must hold for $q_{S}$ as well. Bence $\mathrm{p}_{S}$ equals $\mathrm{q}$, and only one such point can exist. But such a point must exist if both markets are noncompetitive. Furthermore,

$D_{S}\left(p_{S}\right)>0$ if and only if $V k>\left(h_{N}-h_{S}\right)(1-\pi)$, which contradicts Assumption 5. Thus no such point can exist since expected demand there will be negative.

Q.E.D.

This completes our analysis of the case in which consumers prefer loans without security interests, given competitive pricing. It can be summarized nicely in the following corollary.

Corollary 1: Under Assumptions 1 through 5, the market for loans $w$ ith 
a security interest can never exist. The market for loans without a security interest is competitive if and only if $a_{1} s a_{N}$. It is noncompetitive if and only if $a_{1} s>a_{N}$.

It should be pointed out that if Assumption 5 does not hold the necessary and sufficient conditions for ${ }^{n}=0$ and the no security interest market to be noncompetitive are more restrictive (Theorem 4), and the possibility of both markets being noncompetitive arises

(Theorem 8).

Ne now want to consider a situation in which consumers prefer to have loans made $w$ ith security interests if they are priced competitively; i.e.. the reduction in price from $r_{N}^{*}$ to $r_{S}^{*}$ is more than enough to compensate consumers $f$ or the presence of the security interest. Some new notation will be needed. In this case we let $\mathbf{1}_{\mathrm{N}}$ be the limit rate for loans without a security interest and $1 \mathrm{~s}$ be the 1 imit rate for loans with a security interest. We also let $\beta_{N}$ and $\beta_{S}$ be the breakeven demands for monopolists charging $1_{N}$ for loans without a security interest and ${ }^{1} \mathrm{~S}$ for $10 a n s$ with a security interest,

respectively. The relevant assumptions for this case are:

Assumption 2:: $1_{\mathrm{N}}>1_{\mathrm{S}}$

Assumption 3': $0<1_{N}-r_{N}^{*}<1_{S}-r_{S^{*}}^{*}$

Assumptions 1 and 4 remain unchanged and the analogue to Assumption 5 can be stated as a 1 emma.

$\underline{\text { Lemma } 5}: 1_{N}-1_{S}<V k /(1-\pi) L$.
Proof: We know from Assumption $3^{\prime}$ that $1_{N}-1_{S}<r_{N}^{*}-r_{S}^{*}$. But $r_{N}^{*}-r_{S}^{*}=[V k / L(1-\pi)]-\left[F^{\prime} / \operatorname{sL}(1-\pi)\right]$. Bence $1_{N}-1_{S}<V_{k} /(1-\pi)$ if

$$
\left.[\operatorname{Vk} / L(1-\pi)]-\left[F^{\prime} / \operatorname{sL}(1-\pi)\right]<V_{k} /(1-\pi)\right] L,
$$

which obviously holds since

$0<\pi<1$.

Q.E.D.

Lemma 6:

$$
\begin{aligned}
& \beta_{N}=F / L\left[1_{N}(1-\pi)-c-k\right] \\
& \beta_{S}=\left(F+F^{\prime}\right) /\left(L\left[1_{S}(1-\pi)-c-k\right]+V k\right) .
\end{aligned}
$$

Proof:

This result follows as Lemma

3 .

Q.E.D.

Lemma 1 and 2 are still valid. However, the analogue to Lemma 4 now fails; that is, $\beta_{N}$ and $\beta_{S}$ bear no particular relation to each other. Theorems 9 through 16 are analogous to Theorems 1 through 8. All presume Assumption 1, 2', 3' and 4 hold.

Theorem 9:

$n_{S}=0$ and the market for loans without security interests to be competitive is impossible.

Proof:

With $n_{S}=0$ and all loans with no security interest priced at $r_{N^{\prime}}^{*}$ 
$\sigma=A / N=s$. A firm offering loans with security interests at $\vec{r}_{S}$, where $\bar{r}_{S}$ is defined by $1_{S}-\bar{r}_{S}=1_{N}-r_{N}$, will also attract $s$ consumers. Profits are then:

$$
\pi_{S}\left(s ; \bar{r}_{S}\right)=\operatorname{Ls}\left[\bar{r}_{S}(1-\pi)-c-k\right]+s V K-\left(F+F^{\prime}\right),
$$

which are strictly positive since $\pi_{S}\left(s, r_{S}^{*}\right)=0$ by definition and $\overline{\mathbf{r}}_{\mathbf{S}}>\mathbf{r}_{\mathbf{S}}^{*}$

\section{Theorem 10:}

A necessary and sufficient condition for $\mathrm{n}_{N}=0$ and the market for loans with security interests to be competitive is $a_{1} s \leq \min \left(\beta_{N^{\prime}}, \beta_{S}\right)$.

Proof:

The proof of this result is similar to that of Theorem 1. With $\mathrm{n}_{\mathrm{N}}=0$ and all loans with security interests priced at $\mathrm{r}_{\mathrm{S}}$, $\sigma=A / N=s$. Nonpositive profits at 1 s reduces to $a_{1} s \leq \beta_{S}$ and nonpositive profits at $1_{N}$ reduces to $a_{1} s \beta_{N}$. Since $\beta_{N}$ and $\beta_{S}$ bear no special relation to each other, both constraints are

\section{relevant.}

Q.E.D.

\section{Theorem 11:}

Both markets competitive is impossible.

Proof: This proof is analogous to that of Theorem 9--a firm charging $\vec{r}_{S}$ and taking a security interest must necessarily earn strictly positive profits.

Q.E.D.

Theorem 12: A necessary and sufficient condition for $\mathrm{n}_{S}=0$ and the market for loans without security interests to be noncompetitive is:

$$
V k-L\left(1_{N}-1_{S}\right)(1-\pi) S a_{1} F^{\prime} / \beta_{N}\left(a_{1}+2 a_{2}\right)
$$

Proof: With $n_{S}=0$ and the no security interest market noncompetitive, the highest price in the latter must be $1_{N}$. Hence $\sigma=A / N=\beta_{N} / a_{1}$ by zero profits. Furthermore, $G_{N}\left(x_{N}^{*}\right)=0$; there can be no mass at $r_{N^{\prime}}^{*}$ for if there were firms could enter at $\bar{r}_{s}$ and earn strictly positive profits (see the proof of Theorem 9). Let $t_{N}$ be the lowest price in the no security interest market actually offered, and define $\pi_{N}^{e}(r)$ be equal to $\pi_{N}(x, r)$ when $x$ is expected demand at $r$. Then

$$
\pi_{N}^{e}\left(t_{N}\right)=\sigma\left(a_{1}+2 a_{2}\right) L\left[t_{N}(1-\pi)-c-k\right]-F .
$$

Zero profits then gives

$$
t_{N}=\left\{\left[F / \sigma L\left(a_{1}+2 a_{2}\right)\right]+c+k\right\} /(1-\pi) .
$$

It must be that $t_{N}>r_{N}^{*}$ Using (16) and Lemma 2 , this reduces to $a_{1} s>\beta_{N}\left(a_{1}+2 a_{2}\right)$. But this is implied by Assumption 3'.

What about entry into the market for loans with security interests. As in the proof of Theorem 4, we have for any $r \varepsilon\left[t_{N}, 1_{N}\right]$,

$$
\pi_{N}^{e}(r)=\sigma\left(a_{1}+2 a_{2}\left[1-G_{N}(r)\right]\right) L[r(1-\pi)-c-k]-F .
$$

Using $\pi_{N}^{e}(r)=0$ this gives

$$
G_{N}(r)=1-\frac{\left[F-a_{1} \sigma L[r(1-\pi)-c-k]\right]}{2 a_{2} \sigma L[r(1-\pi)-c-k]} \text {. }
$$

Let $t_{S}$ be defined by $1_{S}-t_{S}=1_{N}-t_{N}$. Then for any $q_{S} \varepsilon\left[t_{S}, 1_{S}\right]$, 


$$
\pi_{S}^{e}\left(q_{S}\right)=\frac{\sigma\left[a_{1}+2 a_{2}\left[1-G_{N}\left(1_{N}-1_{S}+q_{S}\right)\right]\right]}{\left[L\left[q_{S}(1-\pi)-c-k\right]+V k\right]}-\left(F+F^{\prime}\right),
$$

where $\pi_{S}^{e}\left({ }^{\cdot}\right)$ is defined analogous1y to $\pi_{N}^{e}\left({ }^{\circ}\right)$. Using (17) in (18), we get

$$
\pi_{S}^{e}\left(q_{S}\right) \frac{F\left[L\left[q_{S}(1-\pi)-c-k\right]+V k\right]}{\left.L\left[t_{N}-1_{S}+q_{S}\right)(1-\pi)-c-k\right]}-\left(F+F^{\prime}\right),
$$

and differentiating,

$$
\partial \pi_{S}^{e}\left(q_{S}\right) / d q_{S}=\frac{F L(1-\pi)\left[L\left(1_{N}-1{ }_{S}\right)(1-\pi)-V k\right]}{L^{2}\left[\left(1_{N}-1_{S}+q_{S}\right)(1-\pi)-c-k\right]^{2}} .
$$

Now Lemma 5 implies the bracketed term in the numerator is negative. Hence we need only guarantee $\pi_{S}^{e}\left(t_{s}\right) S 0$ to prevent entry in the no security interest market. But $t_{S}=1_{S}-1_{N}+t_{N}$. Hence

$$
\pi_{S}^{e}\left(t_{S}\right)=\frac{F\left[L\left[\left(1_{S}-1_{N}+t_{N}\right)(1-\pi) c-k\right]+V k\right]}{L\left[t_{N}(1-\pi)-c-k\right]}-\left(F+F^{\prime}\right) \text {. }
$$

Using (16) this reduces to

$$
\pi_{S}^{e}\left(t_{S}\right)=\sigma\left(a_{1}+2 a_{2}\right)\left[V k-L\left(1_{N}-1_{S}\right)(1-\pi)\right]-F^{\prime} .
$$

Since $\sigma=\beta_{N} / a_{1}, \pi_{S}^{e}\left(t_{S}\right) \leq 0$ can be stated in the form given in the Theorem. Note that Lemma 5 implies $V k-L\left(1_{N}-1_{S}\right)(1-\pi)>0$ so this constraint is nontrival when

$F^{\prime}>0$.

Q.E.D.

Theorem 13: Necessary and sufficient conditions for $n_{N}=0$ and the market for loans with security interests to be noncompetitive are:

$$
\begin{aligned}
& \text { (i) } \beta_{S}<a_{1} s, \\
& \text { (ii) } \beta_{S} \leq \beta_{N} .
\end{aligned}
$$

Proof: With $a_{N}=0$, the highest rate in the securities market must be $1_{S}$. Zero profits then implies $\sigma=\beta_{S} / a_{1}$. To guarantee that $G_{S}\left({ }^{*}\right)$ is nondegenerate we follow the usual procedure (see the proof of Theorem 4 for example): assume a mass point exists at $r$, use zeroprofits to calculate its size, and then require it to be strictly less than 1. This yields $\beta_{S}<a_{1} s$, condition (i).

Condition (ii) is also given by standard arguments regarding nonentry in the no security interest market. Using zero profits we show for $r$ > $\mathbf{S}^{*}$,

$$
1-G_{S}(r)=\left\{\left[\left(F+F^{\prime}\right) / \sigma[L(r(1-\pi)-c-k)]\right\}-a_{1}\right\} / 2 a_{2} .
$$

Hence for $q_{N} \in\left[r_{N}^{*}, 1_{N}\right]$,

$$
\pi_{N}^{e}\left(q_{N}\right)=\frac{\left(F+F^{\prime}\right) L\left[q_{N}(1-\pi)-c-k\right]}{\left.\left.L\left(1_{S}-1_{N}+q_{N}\right)(1-\pi)-c-k\right)+V k\right]}-F,
$$

and

$$
d \pi_{N}^{e}\left(q_{N}\right) / d q_{N}=\frac{\left(F+F^{\prime}\right) L(1-\pi)\left[L\left(1_{S}-1_{N}\right)(1-\pi)+V k\right]}{\left.L\left[\left(1_{S}-1_{N}+q_{N}\right)(1-\pi)-c-k\right]+V k\right]^{2}} .
$$

Thus Lemma 5 implies $d \pi_{N}^{e}\left(q_{N}\right) / d q_{N}>0$ and we need only guarantee that $\pi_{N}^{e}\left(1_{N}\right) \triangleleft 0$. Thus, however, reduces to $\beta_{N} \geq \beta_{S}$, condition (ii).

Q.E.D.

Theorem 14: Necessary and sufficient conditions for the market for 
loans mith security interests to be competitive and that for loans rithout security interests to be noncompetitive are:

$$
\begin{aligned}
& \text { (i) } \beta_{N}<a_{1} s \\
& \text { (ii) } V k-L\left(1_{N}-1_{S}\right)(1-\pi)<a_{1} F^{\prime} /\left[2 a_{1} s-\left(a_{1}+2 a_{2}\right) \beta N\right] .
\end{aligned}
$$

\section{Proof:}

With the no security interest market noncompetitive and the security interest market competitive, the highest rate charged in the former

must be $1_{N}$. Zero profits then gives $\sigma=\beta_{N} / a_{1}$.

As usua $1, G_{N}\left({ }^{\circ}\right)$ cannot have a mass point at $r_{N}^{*}$ (see Theorems 9, 11 and 12). Furthermore, expected demand at $r_{S}^{*}$ must equal s.

Hence

$$
\sigma\left[a_{1}+2 a_{2}\left[n_{N}+\left(n_{S} / 2\right)\right]\right\}=s,
$$

or $\operatorname{nsing} n_{N}+n_{S}=1$ and $\sigma=\beta_{N} / a_{1}$,

$$
n_{N}=\left[\left(a_{1} s / \beta_{N}\right)-1\right] / a_{2}
$$

Hence $a_{N}>0$ yields $a_{1} s>\beta_{N}$ and $n_{N}<1$ yields $a_{1} s<\beta_{N}\left(a_{1}+2 a_{2}\right)$.

However, the 1atter is implied by Assumption $3^{\prime}$. Hence we have (i). Let $t_{N}$ be the minimum rate charged in the no security interest market. Then zero profits implies

$$
\sigma\left(a_{1}+2 a_{2} n_{N}\right) L\left[t_{N}(1-\pi)-c-k\right]-F=0,
$$

or

$$
t_{N}=\left[\left[F /\left(2 s-\left(a_{1}+2 a_{2}\right) \sigma\right) L\right]+c+k\right) /(1-\pi) .
$$

Hence $t_{N}>r_{N}^{*}$ if and only if $\beta_{N}\left(a_{1}+2 a_{2}\right)>a_{1} s$, the same constraint associated with $n_{N}<1$.

Consider, finally, entry into the security interest market above $r^{*}$. Following the standard procedure re have

$$
1-G_{N}(r)=\left\{[F / \sigma L(r(1-\pi)-c-k)]-a_{1}\right\} / 2 a_{2} n_{N}
$$

and

$$
\pi_{S}^{e}\left(q_{S}\right)=\frac{\left\{F\left[L\left(q_{S}(1-\pi)-c-k\right)-V k\right]\right.}{\left.\left.L\left(1_{N}-1_{S}+q_{S}\right)(1-\pi)-c-k\right]\right\}}-\left(F+F^{\prime}\right)
$$

Thus

$$
d \pi_{S}^{e}\left(q_{S}\right) / d q_{S}=\frac{\left.F L\left(1-1_{N}-1_{S}\right)(1-\pi)-V k\right]}{\left\{L\left[\left(1_{N}-1_{S}+q_{S}(1-\pi)-c-k\right]\right]^{2}\right.}
$$

Lemma 5 then implies $d \pi_{S}^{e}\left(q_{S}\right) / d q_{S} \leq 0$, so we need $\pi_{S}^{e}\left(t_{S}\right) \leq 0$, or after some algebra,

$$
V k-L\left(1_{N}-1_{S}\right)(1-\pi)<a_{1} F^{\prime} /\left[2 a_{1} s-\left(a_{1}+2 a_{2}\right) \beta_{N}\right],
$$

condition(ii).

Q.E.D.

Theorem 15: The market for loans without security interests to be competitive and the market for $10 a n$ mith security interests to be noncompetitive is impossible.

Proof:

Firms could always enter the securities market at $\overrightarrow{\mathbf{r}}_{\mathrm{S}}$ and earn strictly positive profits (see Theorems 9 and 11).

Q.E.D. 
Theorem 16: Necessary and sufficient conditions for both markets noncompetitive are

$$
\begin{aligned}
& \text { (i) }\left(a_{1}+2 a_{2}\right) \beta_{N}\left[V k-\left(1_{N}-1_{S}\right)(1-\pi) L\right]>a_{1} F^{\prime} \\
& \text { (ii) } F^{\prime}>\beta_{N}\left[V k-\left(1_{N}-1_{S}\right)(1-\pi) L\right] \\
& \text { (iii) } a_{1} F^{\prime}<\left[V k-\left(1_{N}-1_{S}\right)(1-\pi) L\right]\left[2 a_{1} s-\left(a_{1}+2 a_{2}\right) \beta_{N}\right]
\end{aligned}
$$

Proof: The first step in this proof is to show that the maximum price in the no security interest market is $1_{N}$ and the maximum price in the security interest market is strictly less than $1_{S}$. For suppose the opposite is the case (both $1_{N}$ and $1_{S}$ cannot be offered). As in Theorem 8, there can exist on $1 y$ one rate, say $p_{N}$, such that both $p_{N}$ and $p_{S}$ are offered, where $p_{S}$ is defined by $1_{N}-p_{N}=1_{S}-p_{S}$. At $p_{N}$, expected demand is $\sigma\left(a_{1}+2 a_{2} n_{S}\right)$ since $p_{N}$ is the highest rate in the no security interest market (and by assumption $p_{N}\left(1_{N}\right.$ ). But expected demand at $p_{S}$ is a 1 so $\sigma\left(a_{1}+2 a_{2} n_{S}\right)$. Wence zero profits yie1ds

$$
\begin{aligned}
& \sigma\left(a_{1}+2 a_{2} n_{S}\right) L\left[p_{N}(1-\pi)-c-k\right]-F \\
& \left.\quad \sigma\left(a_{1}+2 a_{2} n_{S}\right)\left(L\left[p_{S}(1-\pi)-c-1\right]-V k\right]\right)-\left(F+F^{\prime}\right) .
\end{aligned}
$$

or

$$
\sigma\left(a_{1}+2 a_{2} n_{S}\right)=F^{\prime} /\left[V k-L\left(1_{N}-1_{S}\right)(1-\pi)\right] .
$$

Solving for $\mathrm{n}$ '

$$
n_{S}=\left[\left(F^{\prime} / Z o s\right)-a_{1}\right] / 2 a_{2}
$$

where $Z=\left[V k-L\left(1_{N}-1_{S}\right)(1-\pi)\right]$. We need $0<n_{S}<1$, or

$$
\left(a_{1}+2 a_{2}\right) \sigma Z>F^{\prime}>a_{1} \sigma Z
$$

Next, let $q_{N}$ be the minimum rate in the no security interest market. It must be that $q_{N}>\vec{r}_{N}^{*}$ or entry at $\bar{r}_{S}$ would yield strictly positive profits. But consider entry in the security interest market at $\mathrm{q}_{S}$ ' where $q_{S}$ is defined by $1_{N}-q_{N}=1_{S}-q_{S}$. Zero profits at $q_{N}$ implies

$$
\sigma\left(a_{1}+2 a_{2}\right) L\left[q_{N}(1-\pi)-c-k\right]-F=0,
$$

or

$$
\mathrm{q}_{N}=\left[\left[F / \sigma\left(a_{1}+2 a_{2}\right) L\right]+c+k\right] /(1-\pi)
$$

Thus

$$
\begin{aligned}
\pi_{S}^{e}\left(a_{S}\right) & =\sigma\left(a_{1}+2 a_{2}\right)\left(L\left[a_{S}(1-\pi)-c-k\right]+V k\right]-\left(F+F^{\prime}\right) \\
& \left.=\sigma\left(a_{1}+2 a_{2}\right)\left[L\left[1_{S}-1_{N}+a_{N}\right)(1-\pi)-c-k\right]+V k\right]-\left(F+F^{\prime}\right) .
\end{aligned}
$$

Substituting for $q_{N}$ and requiring $\pi_{S}^{e}\left(q_{S}\right) \leq 0$ gives

$$
L\left(1_{S}-1_{N}\right)(1-\pi)+V k S F^{\prime} / \sigma\left(a_{1}+2 a_{2}\right)
$$

or

$$
\sigma\left(a_{1}+2 a_{2}\right) Z \leq F^{\prime}
$$

which contradicts the left-hand inequality in (19) - $n_{s}<1$.

Thus it must be that the maximum rate in the no security

interest market is $1_{N}$ and in the security interest market it is $p_{S}$ ' 
Where $p_{S}$ is defined as above. The minimum price in the no security interest market is $p_{N^{\prime}}$ where $p_{N}$ and $p_{S}$ satisfy $1_{S}-p_{S}=1_{N}-p_{N}$. As before, we can solve for expected demand at $p_{N}$ and $p_{S}$. Mere we have that it equals $\sigma\left(a_{1}+2 a_{2} n_{N}\right)$ and thus

$$
\sigma\left(a_{1}+2 a_{1}+n_{N}\right)=F \cdot / Z \text {. }
$$

Thus $0<n_{N}<1$ imp 1 ies

$$
\left(a_{1}+2 a_{2}\right) \sigma Z>F^{\prime}>a_{1} \sigma Z
$$

as in (19). It must also be that $p_{N}>r_{N}^{*}$. But $p_{N}$ is given by

$$
L \sigma\left(a_{1}+2 a_{2} n_{N}\right)\left[p_{N}(1-\pi)-c-k\right]-F=0,
$$

or

$$
p_{N}=\left[\left(F Z / F^{\prime} L\right)+c+k\right] /(1-\pi) .
$$

Thus $1_{N}>p_{N}>r_{N}^{*}$ if and only if

$$
\beta_{N} Z<F^{\prime}<s Z \text {, }
$$

the first of these being equivalent to $n_{N}>0$ and the second to

As sumption $3^{\prime}$.

Two considerations remain: nondegeneracy of $\mathrm{G}_{\mathrm{S}}\left({ }^{\circ}\right)$ and entry above $p_{S}$ or below $p_{N^{*}}$. Concerning the former, suppose $G_{S}\left({ }^{\cdot}\right)$ has a mass point at $r_{S}^{*}$. Then zero profits implies

$$
\sigma\left[a_{1}+2 a_{2}\left[n_{N}+n_{S}\left(1-G_{S}\left(r_{S}^{*}\right)\right) / 2\right]\right\}=s
$$

or

$$
G_{S}\left(r_{S}^{*}\right)=\left[2\left(a_{1}+2 a_{2}\right)-(s / \sigma)\right] /\left[\left(a_{1}+2 a_{2}\right)-\left(F^{\prime} / \sigma Z\right)\right]
$$

Thus $G_{S}\left(r_{S}^{*}\right)<1$ if and only if

$$
a_{1} F^{\prime}<Z\left[2 a_{1} s-\left(a_{1}+2 a_{2}\right) \beta_{N}\right]
$$

Concerning entry above $p_{S}, d \pi_{S}^{e}(r) / d r<0$ for $r$ e $\left[p_{S}, 1_{S}\right]$ (as in Theorem 12). For entry belor $p_{N^{\prime}} d \pi_{N}^{e}(r) / d r>0$ for $r \varepsilon\left[r_{N^{*}}^{*} p_{N}\right]$ (as in Theorem 13). Mence zero profits at $p_{S}$ and $p_{N}$ covers these tro cases. Substituting $\sigma=\beta_{N} / a_{1}$ into (20), (21) and (22) and using $Z=V t-\left(1_{N}-1_{S}\right) /(1-\pi) L$ gives the theorem.

These results can be summarized in the following Corollary.

\section{Corol1ary 2:}

(i) A competitive equilibrium in the market for loans with security interests with $n_{N}=0$ exists if and only if $a_{1} s \min \left[\beta_{N}, \beta_{S}\right\}$.

(ii) A noncompetitive equilibrium in the market for loans without security interests ith $n_{N}=0$ exists if and only if (a) $\beta_{S} \leq \beta_{N}$ and (b) $\beta_{S}<a_{1} s$.

(iii) $n_{N}>0$ if and only if $\beta_{N}<\min \left(a_{1} s, \beta_{S}\right)$. Furthermore $n_{S}=0$ if and only if [V $\left.-L\left(1_{N}-1 S\right)(1-\pi)\right] \beta_{N}\left(a_{1}+2 a_{2}\right) \leq a_{1} F^{\prime}$.

These conditions are exhaustive and mutually exclusive.

Proof: Parts (i) and (ii) follow from Theorems 10 and 13. The negative of these cases is equivalent to $\beta_{N}\left(\min \left(a_{1} S, \beta_{S}\right)\right.$. The 
necessary and sufficient conditions for each of these cases reduce to:

$$
\begin{array}{ll}
12: & Z \beta_{N}\left(a_{1}+2 a_{2}\right) \leq a_{1} F^{\prime} \\
14: & Z\left[2 a_{1} s-\left(a_{1}+2 a_{2} \beta_{N}\right]<a_{1} F^{\prime}\right. \\
16: & Z \beta_{N}\left(a_{1}+2 a_{2}\right)>a_{1} F^{\prime} \\
& F^{\prime}>\beta_{N} Z \\
& a_{1} F^{\prime} \leq Z\left[2 a_{1} s-\left(a_{1}+2 a_{2} \beta_{N}\right],\right.
\end{array}
$$

where $Z=V k-L\left(1_{N}-1_{S}\right)(1-\pi)$. But $F^{\prime}>\beta_{N} Z$ is equivalent to $\beta_{N}<\beta_{S}$ and this is implied by $\beta_{N}<\min \left(a_{1} s, \beta_{S}\right)$. Furthermore, the necessary and sufficient conditions for Theorem 16 which remain are the negation of those for Theorems 12 and 14 . Thus when

$\beta_{N}<\min \left(a_{1} S, \beta_{S}\right)$ one of the three cases must hold. 